Linköping Studies in Science and Technology

Dissertations No. 1743

\title{
Fucoidan-Mimetic Glycopolymers Synthesis and Biomedical Applications
}

\author{
Mattias Tengdelius
}

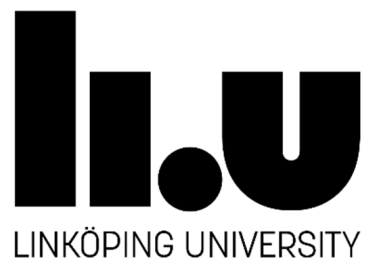

Department of Physics, Chemistry and Biology

Linköping University, Sweden

Linköping 2016 
During the course of the research underlying this thesis, Mattias Tengdelius was enrolled in Forum Scientium, a multidisciplinary doctoral program at Linköping University, Sweden.

(C) Copyright Mattias Tengdelius, 2016, unless otherwise noted.

Published articles has been reprinted with the permission of the copyright holder.

Paper I @ 2014 American Chemical Society

Paper II @ 2015 The Royal Society of Chemistry

Paper III @ 2016 WILEY-VCH Verlag

Cover: 3D models of three different fucoidan-mimetic glycopolymers

Mattias Tengdelius

Fucoidan-Mimetic Glycopolymers - Synthesis and Biomedical Applications ISBN: 978-91-7685-834-9

ISSN: 0345-7524

Linköping Studies in Science and Technology Dissertations No. 1743

Printed by LiU-Tryck, Linköping, Sweden, 2016 
Till morfar som inspirerade mig att börja och Lina och Theo som inspirerar mig att fortsätta. 

The marine polysaccharide fucoidan has demonstrated several interesting biological properties, for instance being antiviral, anticoagulant, anti-inflammatory, anticancer, and platelet activating. Many of these properties are desirable for various biomedical applications. Yet, there are few reports on fucoidan being used in such applications. The reasons for this are primarily the heterogeneity and low structural reproducibility of fucoidan.

This thesis describes the synthesis of polymers with pendant saccharides bearing the key structural features of fucoidan. These glycopolymers were synthesized via different radical polymerization techniques yielding polymers of different chain lengths and dispersity. These glycopolymers showed antiviral and platelet activating properties similar to those of natural fucoidan, thus making them fucoidan-mimetic glycopolymers. However, compared to fucoidan from natural sources, the fucoidan-mimetic glycopolymers had homogeneous and reproducible structures making them suitable for biomedical applications.

Further studies demonstrated that platelet activation, caused by these glycopolymers, showed dose-response curves almost identical to fucoidan. The platelet activation was induced via intracellular signaling and caused platelet surface changes similar to those of fucoidan. Fucoidan-mimetic glycopolymers can therefore be used as unique biomolecular tools for studying the molecular and cellular responses of human platelets.

Fucoidan-mimetic glycopolymers generally assert their antiviral activity by blocking viral entry to host cells, thus inhibiting spreading of the viral infection but not acting virucidal, i.e. not killing the viruses. Introduction of hydrophobic groups to the polymer's chain ends improved the antiviral properties significantly and is an important step towards yielding glycopolymers with virucidal properties.

The fucoidan-mimetic glycopolymers were also applied as capping agents when synthesizing gold nanoparticles. These fucoidan-mimetic glycopolymer coated gold nanoparticles showed improved colloidal stability compared to uncapped gold nanoparticles. Furthermore, the nanoparticles also demonstrated selective cytotoxicity against a human colon cancer cell line over fibroblast cells. 



\section{Populärvetenskaplig Sammanfattning}

Sedan urminnes tider har människan vänt sig till naturen för att bota sjukdomar och andra krämpor. Genom extrakt från framförallt växter har bland annat feber, inflammationer och olika infektioner behandlats långt innan läkemedelskonsten utvecklades till vad den är idag. Även när den moderna läkemedelsvetenskapen, farmakologin, började utvecklas var det naturen som var den främsta resursen och inspirationskällan. Då sökte forskare jorden runt efter växter och andra källor i naturen med läkande egenskaper. Med tiden växte kunskapen om exakt vilka kemiska substanser som har de medicinska egenskaper som observerats hos vissa arter sedan lång tid tillbaka. I och med denna kunskap började kemister modifiera de aktiva, läkande, substanserna för att ytterligare förbättra deras verksamma egenskaper.

Idag ligger fokus vid utvecklingen av nya läkemedel på att framställa syntetiska substanser, som inte har sitt ursprung i naturen, ämnade för att bota specifika sjukdomar. Denna utveckling har skett dels genom den ökade förståelsen för hur våra kroppar fungerar, samt hur specifika substanser påverkar dessa, och dels genom att allt färre nya aktiva substanser påträffas i naturen. Även om de moderna syntetiska läkemedlen många gånger är både säkrare och mer effektiva än läkemedel med ursprung i naturen så finns det dock ändå aktiva substanser i naturen som än så länge är outnyttjade resurser. En sådan typ av substans är fukoidan.

Fukoidan är en av många typer av kolhydrater, det vill säga socker. Denna återfinns främst i brunalger som till exempel blåstång. Fukoidan har i både cell- och djurstudier visat sig ha en mängd intressanta medicinska egenskaper. Den dämpar inflammationer, är blodförtunnande, motverkar cancer och förhindrar infektioner av olika virus som HIV och Herpes Simplex. Fukoidan interagerar även med blodplättarna i våra kroppar, vars uppgift är att stoppa blödningar, och aktiverar dessa så att detta förlopp går fortare.

Kolhydrater är mest kända som födoämnen men spelar långt fler viktiga roller $\mathrm{i}$ våra kroppar än bara det. I kommunikationen mellan våra celler är kolhydrater ofta inblandade och så även i olika sjukdomsförlopp samt immunförsvarets respons på dessa. Kolhydrater används också till viss del som läkemedel. Det mest kända exemplet är det blodförtunnande läkemedlet heparin. Därmed borde även fukoidan kunna ha sin användning som läkemedel. Tack vare sina många medicinska egenskaper skulle fukoidan även kunna tjäna som byggstenar i moderna biomedicinska material, till exempel olika implantat för att förhindra avstötning av dessa. Dock har fukoidan än så 
länge använts mycket sparsamt inom dessa områden. Det har sin förklaring i fukoidans kemiska sammansättning.

Liksom andra kolhydrater består fukoidan av långa kedjor uppbyggda av enkla sockerarter, monosackarider. Men där till exempel heparin är uppbyggt av relativt få typer av monosackarider i regelbundna mönster, är fukoidan betydligt mer komplex och byggs upp av många olika typer av monosackarider i till stor del oregelbundna mönster. Extraheras fukoidan från brunalger kommer dessutom dessa mönster variera beroende på årstiden. Detta kan göra det svårt att reproducera exakt de verksamma egenskaper som tidigare observerats när fukoidan uppbyggd av något annorlunda sackaridmönster studerats.

Arbetet som ligger till grund för denna avhandling har syftat till att framställa substanser med de verksamma egenskaperna hos fukoidan, men med förbättrad reproducerbarhet och kontroll över den kemiska strukturen. Att på labb syntetisera långa kedjor bestående av monosackarider är tidskrävande och därför valdes en snabbare metod, nämligen att syntetisera polymerer. Polymerer är liksom kolhydrater uppbyggda av långa repetitiva kedjor, dock bestående av så kallade monomerer. I detta arbete framställdes en speciell typ av monomerer, där den vanligast förekommande monosackariden i fukoidan var en av beståndsdelarna. Genom olika tekniker kopplades sedan dessa monomerer ihop till olika polymerer, så kallade glykopolymerer (vilket betecknar att sackarider är en beståndsdel i polymererna).

Analyser av dessa glykopolymerer visade att deras förmåga att förhindra infektioner från herpesvirus samt aktivera blodplättar i hög grad liknade de motsvarande egenskaperna hos fukoidan. Därmed hade det bevisats att de syntetiska glykopolymererna har samma verksamma egenskaper som fukoidan, de är fukoidan-mimetiska. Jämfört med fukoidan från brunalger har dock glykopolymerernas kemiska struktur avsevärt bättre reproducerbarhet.

Senare studier av glykopolymerernas aktivering av blodplättar avslöjade att de kan tjäna som värdefulla verktyg för att på labb studera vad som sker i celler vid aktivering av blodplättar. Fukoidan-mimetiska glykopolymerer användes även för att belägga ytan hos små guldnanopartiklar. Dessa kan i sin tur användas som en ny metod för att behandla tjocktarmscancer då förmågan hos såväl fukoidan som guldnanopartiklar att bekämpa cancer kombinerats. Fördelen med att glykopolymererna framställs syntetiskt i labb visades också genom att polymerkedjornas ändar kunde modifieras med kemiska 
grupper som liknar olika fetter, till exempel kolesterol. Dessa modifieringar visade sig avsevärt förbättra glykopolymerernas förmåga att förhindra infektion av herpesvirus.

Arbetet i denna avhandling har visat att de medicinska egenskaperna hos en av naturens outnyttjade resurser, fukoidan, kan göras mer tillgängliga genom bildandet av syntetiska fukoidan-mimetiska glykopolymerer. Dessa har redan funnit användning som verktyg för studier av aktiveringen av blodplättar, som potentiella verksamma substanser för att bekämpa herpesvirus och som ytbeläggning av guldnanopartiklar för att behandla tjocktarmscancer. Potentialen hos dessa glykopolymerer är dock avsevärt större än så och förhoppningsvis kan deras mångsidiga medicinska egenskaper bidra till utvecklingen av nya behandlingar mot svåra sjukdomstillstånd. 



\section{Acknowledgements}

Although mine is the only name appearing on the cover of this thesis, it would never have seen the light of day without the help and support of my supervisors, collaborators, colleagues, family and friends. You all helped me get through this in different ways and, although I sometimes struggled, it resulted in a thesis of which I am very proud. I would therefore like to extend my deepest of thanks to the following people:

My main supervisor, Peter Konradsson, for helping me become a $\mathrm{PhD}$ student and providing the means necessary to make it all the way. Although we did not start with a full squad, the game was still won.

My co-supervisor, May Griffith, for always being supportive and believing in this project and my ideas.

My co-supervisor, Peter Påhlsson, for always being supportive and helpful. You showed me the right direction when everything felt the most difficult.

My original main supervisor, Bo Liedberg, for guiding me in my early days as a $\mathrm{PhD}$ student and helping me prioritize.

Jöns Hilborn, for always being helpful and making me understand the field of polymer chemistry. The short time I spent in Uppsala was instrumental to the work described herein.

My collaborator at Örebro University, Magnus Grenegård, for a very interesting collaboration, your interest in my polymers and teaching me all I need to know about platelets.

My collaborator at Uppsala University, Oommen, for interesting discussions and helpful suggestions. Although some ideas did not make it all the way, we still got a nice paper out of it.

My other collaborators in Linköping, Örebro and Uppsala, Chyan-Jang, Queenie, Deepanjali, Caroline, and Knut, for nice collaborations that, luckily, also resulted in papers. 
Lill-Matte, for all the fruitful discussions over the years. You have an amazing mind for both chemistry and clever "ordvitsar". Keep it up!

Rogga, for being one of the best "bollplank" imaginable. I hope we can hit more conferences in the future.

Timmy, for introducing me to the world of carbohydrates and giving me invaluable help in the early years. You are one of the best chemists I have ever met.

My other colleagues, past and present, at organic chemistry, Bäck, Jeff, Leffe, Andreas, Alma, Katinka, Bisse, Bettan, Linda, Katriann, Hamid, Wu, Jun, Veronica, Gunilla, Annika, and Stefan, for your help when I struggled with my syntheses and for all the discussions about chemistry and whatnot.

My other colleagues, past and present, at the Chemistry department, Karin, Roz, Cissi, Markus, Patricia, Alexandra, Patrik, Magda, Helena, Henke, Johan, Elke, Fredrik, Maria L, Rita, PetNi, Per, Sofie, Jutta, Anki, Lasse M, Nalle, and Sara, for your help whenever I needed it and for brightening up my days at the department.

Thomas Ederth, for patiently helping me run and interpret the DLS and for putting up with all my questions.

Jaywant, for interesting collaborations and ideas. It is a shame we do not have a joint publication yet.

My other colleagues past and present in the MolPhys and SurfNano groups, Caroline, Ranjith, Daniel, Abeni, Camilla, Karin, Kajsa, and Erik, for your help to look beyond the borders of organic synthesis and understand the applications.

Stefan Klinström and all the other staff and members of Forum Scientium, for helping me keep a wider view of science.

Susanne, for patiently guiding me in the jungle of paperwork and forms.

The members of the PhD Reference Group, past and present, for all the hard work and dedication over the years. 
The Friday Beer Club (FÖK), Staffan, Robban, Chris, and Skalle-Per, for brightening the end of my weeks.

My friends, Oskar, John, Erik, Helena, Eddie, Jonas, Linus, Isak, Gustav, Niclas, Svante, Gita, Saja, Jacopp, Markus, Johanna, Stefan, Carina, and Thord, for helping me keep my mind off work every now and then.

My family, Mamma, Pappa, Niklas, Mormor, Kjell, and Elizabeth, for always supporting me no matter what I decided to do.

Lina, the love of my life and the main reason this book ever saw the light of day. Thank you for always supporting me and helping me find my way in life.

Theo, since you came into my life every day has become brighter. I love you with all my heart and I am so happy to be your dad. 



\section{Papers Included in the Thesis}

I. Synthesis and Biological Evaluation of Fucoidan-Mimetic Glycopolymers through Cyanoxyl-Mediated Free-Radical Polymerization

Mattias Tengdelius, Chyan-Jang Lee, Magnus Grenegård, May Griffith, Peter Påhlsson, and Peter Konradsson.

Biomacromolecules, 2014, 15, 2359-2368.

II. Synthesis and Anticancer Properties of Fucoidan-Mimetic Glycopolymer Coated Gold Nanoparticles

Mattias Tengdelius*, Deepanjali Gurav*, Peter Konradsson, Peter Påhlsson, May Griffith, and Oommen P. Oommen.

Chemical Communications, 2015, 51, 8532-8535.

III. Fucoidan-Mimetic Glycopolymers as Tools for Studying Molecular and Cellular Responses in Human Blood Platelets

Mattias Tengdelius, Caroline Kardeby, Knut Fälker, May Griffith, Peter

Påhlsson, Peter Konradsson, and Magnus Grenegård.

Macromolecular Bioscience, 2016, accepted manuscript.

IV. Improved Antiviral Properties of Chain End Hydrophobic FucoidanMimetic Glycopolymers Synthesized by RAFT Polymerization

Mattias Tengdelius, Cheung Kwan Yee, May Griffith, Peter Påhlsson, and Peter Konradsson.

Manuscript.

*These authors contributed equally. 



\section{Contribution to Included Papers}

I. Planned and performed all the synthetic work and chemically characterized all synthesized compounds. Took part in planning the biological analyses. Wrote most of the paper.

II. Planned and performed the synthesis and chemical characterization of the glycopolymers. Took part in planning the nanoparticle synthesis and the biological analyses. Wrote part of the paper.

III. Planned and performed the synthesis and chemical characterization of the glycopolymers. Took part in planning the biological analyses. Wrote most of the paper.

IV. Planned and performed all the synthetic work and chemically characterized all synthesized compounds. Took part in planning the biological analyses. Wrote most of the paper. 



\section{Papers Not Included in the Thesis}

Impact of Nanotoxicology towards Technologists to End Users

Chan Oeurn Chey*, Hirak Patra*, Mattias Tengdelius*, Mohsen Golabi*, Onur Parlak*, Roghayeh Imani*, Sami Elhag*, Wetra Yandi* and Ashutosh Tiwari. Advanced Materials Letters, 2013, 4, 591-597.

*These authors contributed equally. 



\section{Conference Contributions}

Fucoidan-Mimetic Glycopolymers

Mattias Tengdelius, Chyan-Jang Lee, Magnus Grenegård, May Griffith, Peter Påhlsson and Peter Konradsson.

$27^{\text {th }}$ International Carbohydrate Symposium, 2014, Bangalore, India.

Fucoidan-Mimetic Glycopolymers for Biomaterial Applications

Mattias Tengdelius, Chyan-Jang Lee, Magnus Grenegård, May Griffith, Peter Påhlsson and Peter Konradsson.

Organikerdagarna, 2014, Stockholm, Sweden.

Fucoidan-Mimetic Glycopolymers for Biomedical Applications

Mattias Tengdelius, Deepanjali Gurav, Chyan-Jang Lee, Magnus Grenegård, Peter Påhlsson, May Griffith, Oommen P. Oommen and Peter Konradsson.

European Polymer Congress, 2015, Dresden, Germany.

Fucoidan-Mimetic Glycopolymers: Multi Tools for Biomedical Applications

Mattias Tengdelius, Deepanjali Gurav, Chyan-Jang Lee, Magnus Grenegård, Peter Påhlsson, May Griffith, Oommen P. Oommen and Peter Konradsson. Warwick Polymer Conference, 2016, Coventry, United Kingdom. 



\section{Thesis Committee}

\section{SUPERVISOR}

Peter Konradsson, Professor

Division of Organic Chemistry, Department of Physics, Biology and Chemistry

Linköping University, Sweden

\section{CO-SUPERVISORS}

May Griffith, Professor

Division of Cell Biology, Department of Clinical and Experimental Medicine

Linköping University, Sweden

Peter Påhlsson, Professor

Division of Cell Biology, Department of Clinical and Experimental Medicine

Linköping University, Sweden

\section{FACULTY OPPONENT}

Mats Johansson, Professor

Division of Coating Technology, Department of Fibre and Polymer Technology

Royal Institute of Technology, Sweden

COMMITTEE BOARD

Ulf Nilsson, Professor

Centre for Analysis and Synthesis, Department of Chemistry

Lund University, Sweden

Jorma Hinkula, Professor

Division of Virology, Department of Clinical and Experimental Medicine

Linköping University, Sweden

Birgitta Rasmusson, Professor

Swedish National Forensic Centre, Sweden

Division of Applied Microbiology, Department of Chemistry

Lund University, Sweden 



\section{Abbreviations}

$\begin{array}{ll}\text { AIBN } & \text { 2,2'-Azobis(2-methylpropionitrile) } \\ \text { Ac } & \text { Acetyl } \\ \text { ACVA } & 4,4 \text { '-Azobis(4-cyanovaleric acid) } \\ \text { APS } & \text { Ammonium persulfate } \\ \text { ATRP } & \text { Atom transfer radical polymerization } \\ \text { AuNPs } & \text { Gold nanoparticles } \\ \text { BCBDBA } & N \text {-[8-((+)-biotinamido)-3,6-dioxaoctyl]-4-(phenylcarbonothioylthio)-4- } \\ & \text { cyanopentanamide } \\ \text { BnMAM } & \text { N-benzyl methacrylamide } \\ \text { Boc } & \text { tert-Butoxycarbonyl } \\ \text { BPO } & \text { Benzoyl peroxide } \\ \text { CAC } & \text { Critical aggregation concentration } \\ \text { CLEC-2 } & \text { C-type lectin-like receptor 2 } \\ \text { CMRP } & \text { Cyanoxyl-mediated free-radical polymerization } \\ \text { CPBDT } & \text { 2-Cyano-2-propyl benzodithioate } \\ \text { CS } & \text { Chondroitin sulfate } \\ \text { CTA } & \text { Chain transfer agent } \\ \text { DCM } & \text { Dichloromethane } \\ \text { DLS } & \text { Dynamic light scattering } \\ \text { DMF } & N, N \text {-Dimethylformamide } \\ \text { DS } & \text { Degree of sulfation } \\ Ð & \text { Molecular weight dispersity } \\ \text { EtOAc } & \text { Ethyl acetate } \\ \text { FMG } & \text { Fucoidan-mimetic glycopolymer } \\ \text { FucMAM } & \text { 2-Methacrylamidoethyl } \alpha \text {-L-fucopyranoside } \\ \text { GM } & \text { Glycidyl methacrylate } \\ \text { GPC } & \text { Gel permeation chromatography } \\ \text { GPVI } & \text { Glycoprotein VI } \\ \text { HCECs } & \text { Human corneal epithelial cells } \\ \text { HSV-1 } & \text { Herpes Simplex Virus-1 } \\ \text { HSV-2 } & \text { Herpes Simplex Virus-2 } \\ \text { I } & \text { Initiator } \\ \text { IUPAC } & \text { International Union of Pure and Applied Chemistry } \\ \text { KPS } & \text { Potassium persulfate } \\ \text { LAMP-3 } & \text { Lysosomal-associated membrane protein-3 } \\ & \end{array}$




$\begin{array}{ll}\text { M } & \text { Monomer } \\ \text { Me } & \text { Methyl } \\ M_{n} & \text { Number average molecular weight } \\ M_{w} & \text { Weight average molecular weight } \\ \text { MOI } & \text { Multiplicity of infection } \\ \text { MWCO } & \text { Molecular weight cut-off } \\ \text { NIPMAM } & \text { N-isopropyl methacrylamide } \\ \text { NMP } & \text { Nitroxide-mediated radical polymerization } \\ \text { NMR } & \text { Nuclear magnetic resonance } \\ \text { OctMAM } & \text { N-n-octyl methacrylamide } \\ \text { PBS } & \text { Phosphate-buffered saline } \\ \mathrm{P}_{\mathrm{n}} & \text { Polymer chain } \\ R_{\mathrm{f}} & \text { Retention factor } \\ \mathrm{R}_{\mathrm{h}} & \text { Hydrodynamic radius } \\ \text { RAFT } & \text { Reversible addition-fragmentation chain transfer polymerization } \\ \text { RDRP } & \text { Reversible-deactivation radical polymerization } \\ \text { SAR } & \text { Structure-activity relationship } \\ \text { SCPDB } & \text { 4-Cyano-4-(phenylcarbonothioylthio)pentanoic acid } N \text {-succinimidyl ester } \\ \text { SEM } & \text { Scanning electron microscope } \\ \text { SO } • P y r & \text { Sulfur trioxide-pyridine complex } \\ \text { TBAB } & \text { Tetrabutylammonium bromide } \\ \text { TFA } & \text { Trifluoroacetic acid } \\ \text { TLC } & \text { Thin-layer chromatography } \\ \text { WST-1 } & \text { Water-soluble tetrazolium salt-1 } \\ & \end{array}$




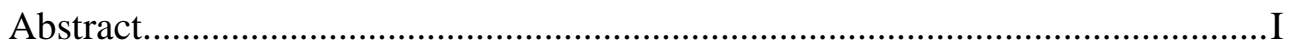

Populärvetenskaplig Sammanfattning .......................................................... III

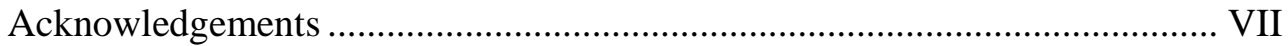

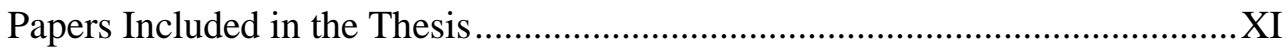

Contribution to Included Papers.....................................................................

Papers Not Included in the Thesis ............................................................... XV

Conference Contributions..........................................................................

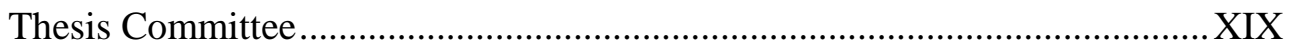

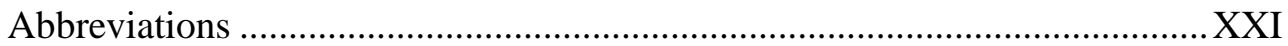

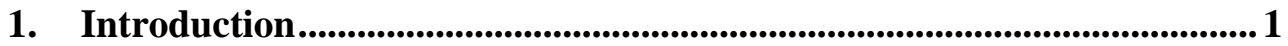

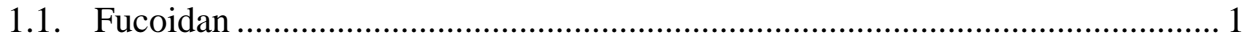

1.1.1. Structural Features ..................................................................... 2

1.1.2. Fucoidan-Mimetic Oligosaccharides .................................................. 4

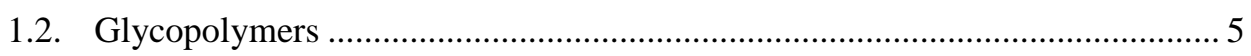

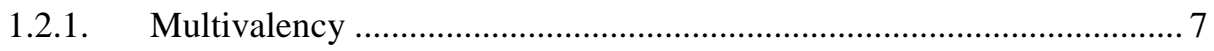

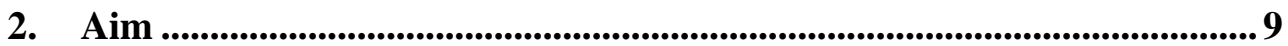

3. Glycopolymer Synthesis (Paper I, II and III) ......................................... 11

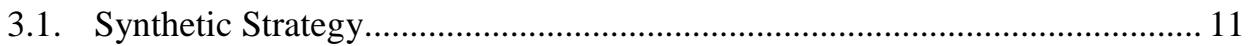

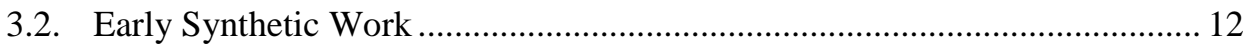

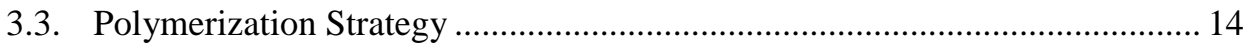

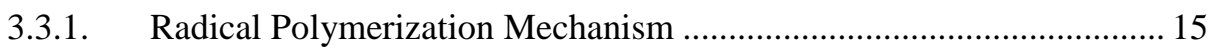

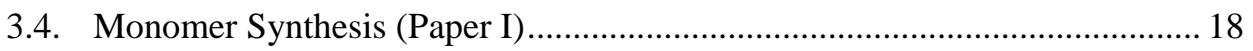

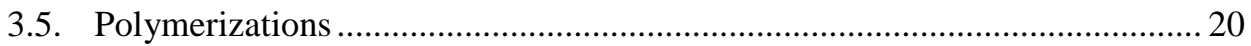

3.5.1. Cyanoxyl-Mediated Free-Radical Polymerizations (Paper I) ................ 20

3.5.2. Thiol-Mediated Chain Transfer Radical Polymerizations (Paper II).... 24

3.5.3. RAFT Polymerizations (Paper III) ................................................... 27

4. Fucoidan-Mimetic Properties (Paper I and III) ..........................................33

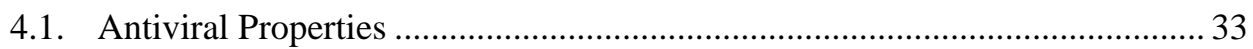

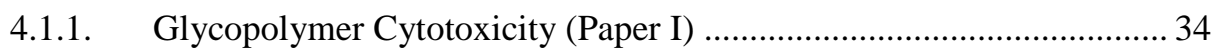

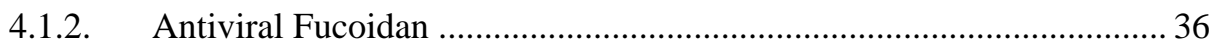

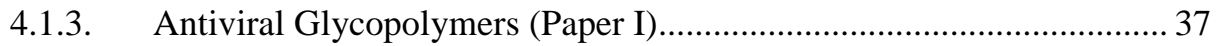

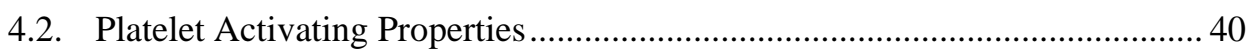

4.2.1. Platelet Activating Fucoidan ............................................................. 40

4.2.2. Platelet Activating Glycopolymers (Paper I and III) ............................. 41 
5. Amphiphilic FMGs (Paper IV).

5.1. Amphiphiles in Biomedical Applications ……........................................... 47

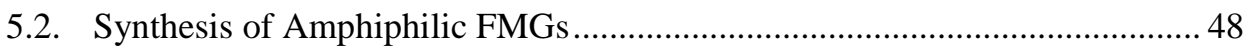

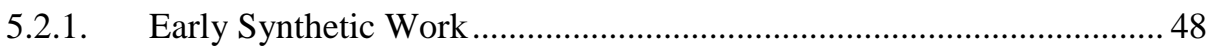

5.2.2. Synthesis of Hydrophobic RAFT Agents (Paper IV) …………............ 52

5.2.3. Polymerizations Using Hydrophobic RAFT Agents (Paper IV) .......... 54

5.3. Antiviral Properties of Amphiphilic FMGs (Paper IV) .................................... 61

6. FMG-Coated Gold Nanoparticles (Paper II) ........................................67

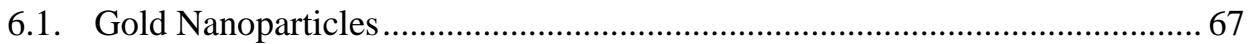

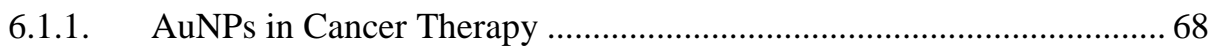

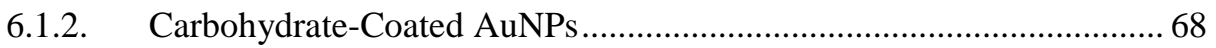

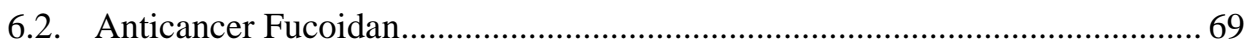

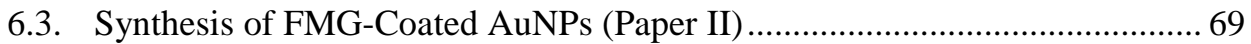

6.3.1. Anticancer Properties ................................................................... 71

7. Conclusions and Future Prospects .................................................................... 73

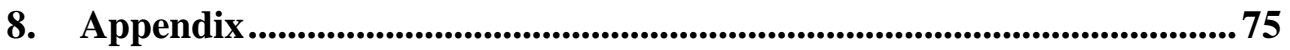

8.1. General Synthetic Procedures ………….................................................... 75

8.2. Experimentals for Compounds Described in Section 3.2 ……..................... 75

8.3. Experimentals for Compounds Described in Section 5.2.1 …........................ 76

8.4. Summary of All Synthetic Glycopolymers ………...................................... 78

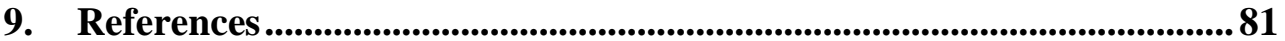




\section{Introduction}

In the recent decades a shift of focus has been seen in the biomedical research disciplines. Rather than focusing primarily on conventional pharmaceuticals, increased effort has been put into exploring functional biomaterials and other macromolecular systems for, e.g., drug delivery and tissue engineering. Just as the early modern pharmaceutical industry turned to natural products in the pursuit of new drugs, contemporary biomedical researchers have shown an increased interest in natural compounds. In particular, natural polymers and other macromolecules have been investigated as potential components for biomaterials and in other biomedical applications, due to their biocompatibility and often inherent bioactive properties. One such natural polymer is the marine polysaccharide fucoidan.

\subsection{Fucoidan}

Fucoidan, or sulfated fucan, is a complex sulfated polysaccharide mainly containing L-fucose and is found in brown seaweeds, marine invertebrates (such as sea cucumbers and sea urchins) [1], and recently in seagrasses [2]. In seaweeds, fucoidans are found in the cell-wall matrix whereas they are found in the egg jelly coat of sea urchins and in the body wall of sea cucumbers [3]. Fucoidan has been extensively studied due to its many interesting biological properties such as being anticoagulant, antithrombotic, antiviral, anticancer, and anti-inflammatory [1,2,4]. Moreover, fucoidan has shown to 
be antioxidative and anticomplementary [1] and to provide cardio-, neuro- and gastric protection [4]. It also has the ability to induce platelet activation [2,3] and has shown promising results as a potential drug against Parkinson's disease [4] and diabetes [5]. In addition, fucoidan appears to be non-toxic in vitro and in vivo [6].

These factors ought to make fucoidan ideal as a building block in biomedical applications such as biomaterials. There have been some works published where fucoidan has been used for drug delivery [2,7-13], stem cell growth [2], wound healing $[2,7,8,14]$, bone regeneration [2,15-18], and in anti-bacterial [19] and cell culture hydrogels [20]. However, compared to the number of reports on the structure and bioactivities of fucoidan, the use of fucoidan in biomedical applications other than as a conventional drug is far less common. This can be largely attributed to the structural complexity of fucoidan.

\subsubsection{Structural Features}

As mentioned, fucoidan mainly consists of sulfated L-fucose (a deoxy hexose [4]) linked through either $\alpha(1 \rightarrow 2), \alpha(1 \rightarrow 3)$, or $\alpha(1 \rightarrow 4)$ glycosidic bonds [21], but also other saccharides such as galactose, mannose, glucose, xylose, and uronic acid [1,21,22], as well as acetyl groups and proteins [1]. Different species have shown to produce fucoidans with different structures (see Figure 1.1) regarding glycosidic linkage and sulfation patterns, degree of sulfation (DS), saccharide content, branching, and molecular weight [23]. Some recurring structural motifs regarding glycosidic linkage and sulfation patterns have been found in fucoidans from the same species (see Figure 1.1), but these may vary somewhat in different studies [1,3]. In general, fucoidan from seaweeds shows more structural irregularities than fucoidan from invertebrates [1]. The structural complexity of fucoidan does not only stem from which species it is extracted from, but factors such as the extraction procedure [1,4,21], climatic conditions [4], and season of harvest [24] have shown to influence the structural composition as well.

These structural differences clearly influence the biological properties as it has been shown that fucoidan from different species exhibit different bioactivities with varying potencies $[23,25]$. It has been more difficult, however, to conclude which exact differences in glycosidic linkage and sulfation patterns, as well as DS, influence certain biological properties $[1,23,25]$. Furthermore, modification of fucoidan through acidic and enzymatic fragmentation [21], as well as chemical oversulfation, has shown that the DS [22] and molecular weight clearly influences the biological properties [26,27]. 
Despite these efforts, the details on the structure-activity relationship (SAR) of the different biological properties of fucoidan remain largely unknown.

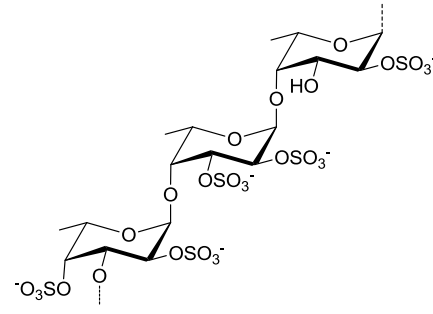

Fucus vesiculosus

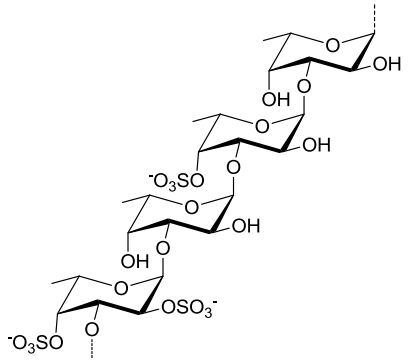

Pearsonothuria graeffei

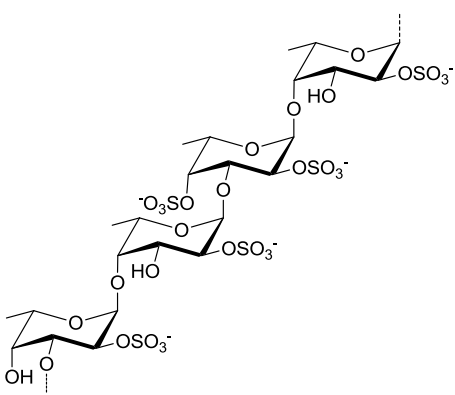

Fucus evanescens

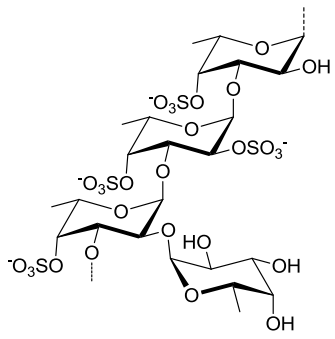

Laminaria saccharina

Figure 1.1. Examples of structures of fucoidan fragments from the brown seaweeds Fucus vesiculosus [21], Fucus evanescens [22], and Laminaria saccharina [25] and the sea cucumber Pearsonothuria graeffei [28].

The structural complexity along with the poorly known SAR of fucoidan poses an issue when applying fucoidan in a biomedical context. The structural complexity gives a very low structural reproducibility, which in turn might result in poor reproducibility of the biological properties. High reproducibility is a necessity in clinical applications. This would make fucoidan a poor candidate for use in biomaterials and other biomedical applications, despite its many interesting biological properties. To circumvent these issues we hypothesized that synthetic fucoidan-mimetics might be the key to gain the necessary structural, and in turn biological, reproducibility. Such synthetic fucoidan-mimetic compounds would thus be more suitable than fucoidan from a natural source for use in biomedical and clinical applications. 


\subsubsection{Fucoidan-Mimetic Oligosaccharides}

Although they have never been known by that particular phrase, there has been some reports on the synthesis of fucoidan-mimetic oligosaccharides. In 1990 Jain et al synthesized $\alpha(1 \rightarrow 2)$ di-L-fucosides monosulfated in various positions (see Figure 1.2 A) $[29,30]$. Hua et al produced in 2004 a non-sulfated and a fully sulfated $\alpha(1 \rightarrow 3)$ tetra-L-fucoside, along with a partially sulfated alternately $\alpha(1 \rightarrow 3)$ - and $\alpha(1 \rightarrow 4)$-linked penta-L-fucoside (see Figure 1.2 B). All three compounds were tested for anticancer activity in vivo and it was deduced that the presence of sulfate esters enhance the anticancer activity, but no significant difference between the two sulfated oligosaccharides were observed [31,32]. This trail was recently picked up by the Toshima group who synthesized $\alpha(1 \rightarrow 3)$ tetra-L-fucosides and alternately $\alpha(1 \rightarrow 3)$ - and $\alpha(1 \rightarrow 4)$-linked tetra-L-fucosides (see Figure 1.2 E) with various sulfation degrees and patterns along with a partially sulfated $\alpha(1 \rightarrow 4)$ di-L-fucoside and alternately $\alpha(1 \rightarrow 3)$ and $\alpha(1 \rightarrow 4)$-linked hexa-L-fucoside [33,34]. The tetra-L-fucosides showed the most promising anticancer properties, but only the alternately $\alpha(1 \rightarrow 3)$ - and $\alpha(1 \rightarrow 4)$-linked tetra-L-fucosides were simultaneously non-toxic to normal cells.

The most extensive work by far on synthesizing fucoidan-mimetic oligosaccharides has been done by the Nifantiev group. Since 2000 this group has synthesized a broad series of mono-, di-, tri-, tetra-, hexa-, octa-, dodeca-, and hexadeca- $\alpha$-L-fucosides (see Figure 1.2 C) bearing various glycosidic linkage patterns, branching, and sulfation degree and patterns [35-42]. Recently, this group synthesized a fragment from the brown seaweed Chordaria flagelliformis containing an $\alpha$-L-fucofuranosyl unit (see Figure 1.2 D), which is unusual compared to the $\alpha$-L-fucopyranosyl conformation that constitutes the vast majority of the L-fucosides found in fucoidan [43]. The conformation of all of these fucosides have been carefully studied by NMR spectroscopy, but their biological properties have remained almost entirely unpublished [35-43]. As an exception a recent study showed that a fully sulfated $\alpha(1 \rightarrow 3)$ octa-L-fucoside displayed no or decreased antibacterial phagocytic activity compared to fucoidan of larger molecular weights from natural sources [44].

Oligosaccharides, however, do not offer the most theoretically accessible route to synthetic fucoidan-mimetic compounds. Saccharide synthesis is generally time-consuming and often results in poor total yields, especially with growing chain length. We believed that a more rapid approach would be to synthesize fucoidan-mimetics through the formation of glycopolymers. 
A

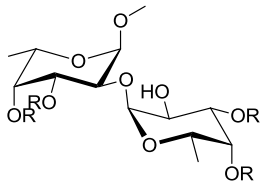

$\mathrm{R}=\mathrm{H}$ or $\mathrm{SO}_{3} \mathrm{Na}$

C

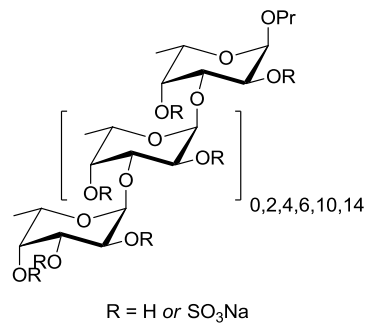

D

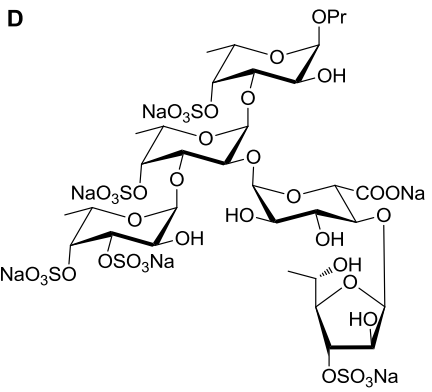

B

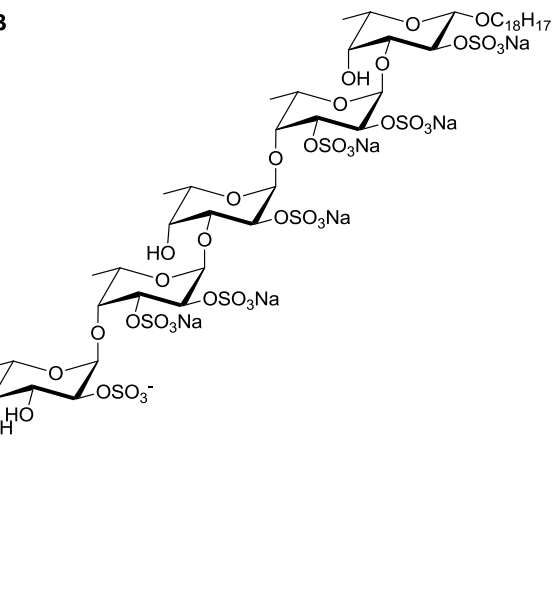

E

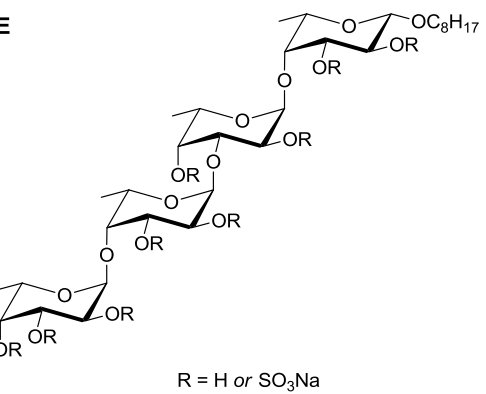

Figure 1.2. Structures of various fucoidan-mimetic oligosaccharides: A [29,30], B [32], C [42], D [43], and E [33].

\subsection{Glycopolymers}

Glycopolymers are generally defined as synthetic polymers with pendant carbohydrates [45-51]. This is a rather loose definition and glycopolymers could be further categorized, e.g. by the method of synthesis. This results in four distinct types of glycopolymers (see Figure 1.3). Type I are glycopolymers in which a polysaccharide has been coupled to a synthetic polymer [52-54]. In type II glycopolymers, a modified polysaccharide has been used either as an initiator or as a chain transfer agent (CTA) to synthesize polymers with the modified polysaccharide as platform [55-61]. Type III glycopolymers utilizes synthetic polymers with pendant functional groups to which, predominantly, mono- or disaccharides are coupled covalently through, e.g., 'click-' and thiol chemistries or nucleophilic acyl substitution $[45,46,49,51,62]$. The polymerization of monomers with pendant saccharides (such as glucose, mannose, galactose, and lactose) gives type IV glycopolymers [45-51,63]. 


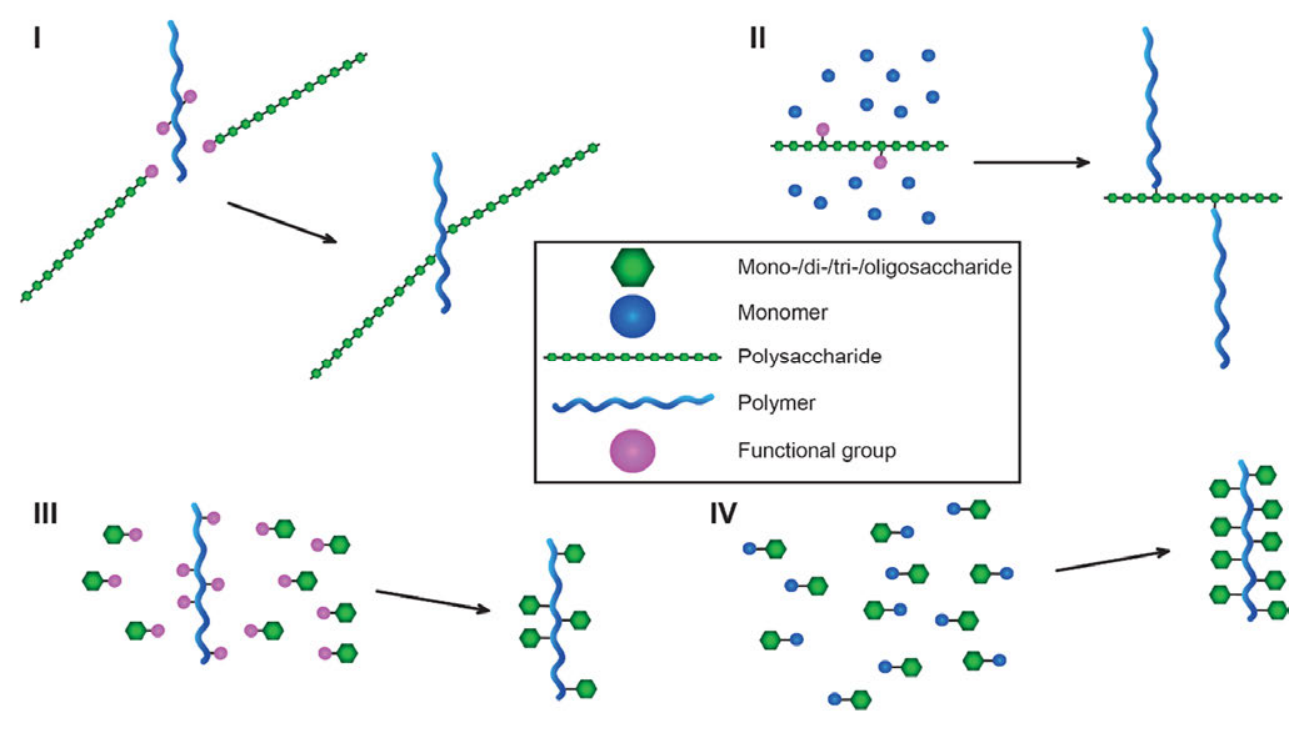

Figure 1.3. The four different types of glycopolymers: coupling of polysaccharides with synthetic polymers (I), polymerization from a saccharide chain (II), coupling small saccharides to a synthetic polymer (III), and polymerization of saccharide-pendant monomers (IV).

The first glycopolymers were synthesized in the 1940's and have since evolved alongside the development of new polymerization techniques. From little control in the 1940's, the glycopolymers of today display well-defined molecular weights and advanced architectures [45,46]. Type III and IV glycopolymers of various architectures (e.g. linear, block, star-shaped, and dendritic) differ structurally from polysaccharides (see Figure 1.4) [49,50,63]. In general, though, glycopolymers are not only biocompatible, but can mimic the biological properties and activities of polysaccharides through specific interactions [45,63] and multivalency [46-50,63].

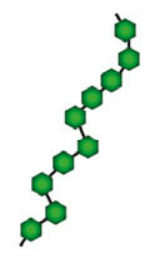

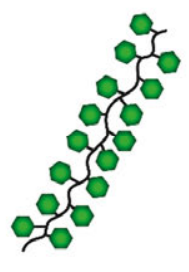

Linear

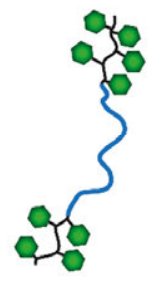

Block

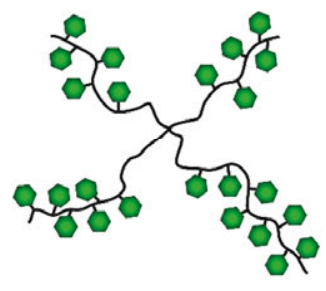

Star-shaped

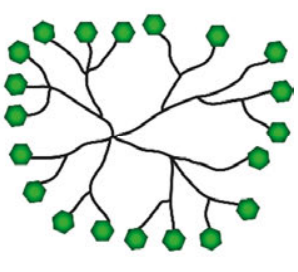

Dendritic

Figure 1.4. Structural comparison of polysaccharides to glycopolymers of various architectures. 


\subsubsection{Multivalency}

A

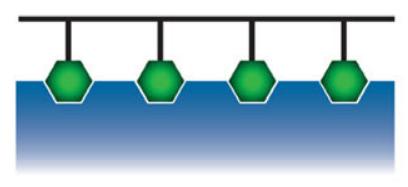

B

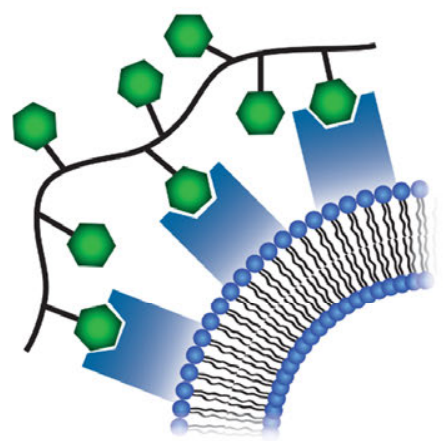

C

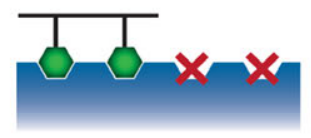

$\mathbf{F}$

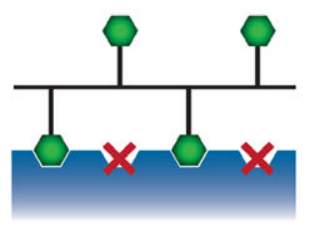

D

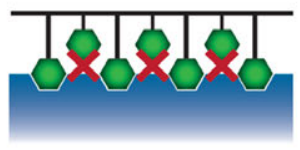

G

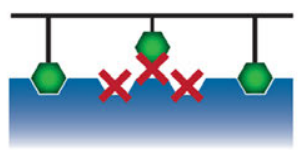

E

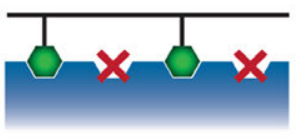

H

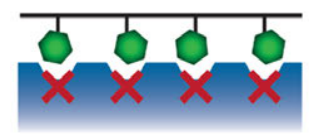

Figure 1.5. Illustration of multivalent interactions towards single (A) or multiple (B) proteins and the factors determining the glycopolymer-protein binding affinity; chain length (C), too high carbohydrate density (D), too low carbohydrate density (E), spatial arrangement $(\mathrm{F})$, carbohydrate distance $(\mathrm{G})$, and linker flexibility $(\mathrm{H})$.

It is well known that carbohydrates display significantly enhanced interactions with proteins when clustered or aggregated, a phenomenon known as the "cluster glycosidic effect". This stems from the weak binding and interaction of saccharides to proteins being amplified by multiple, or multivalent, bindings and interactions [47-50]. This is known simply as multivalency, the use of several connected "keys" to interact with certain proteins comprising several "locks", compared to a single "key" fitted for the single "lock" found on most proteins [64]. Lectins (carbohydrate-binding proteins), antibodies, and receptor proteins with affinity for carbohydrates commonly have multiple carbohydrate-binding sites. The number of, and distance between, these sites therefore become key factors when synthesizing saccharide-mimetic glycopolymers [49,50]. Hence, there are several structural features that need to be considered to gain glycopolymers with good multivalent interaction towards single (see Figure $1.5 \mathrm{~A}$ ) or multiple proteins (see Figure $1.5 \mathrm{~B}$ ). The size of the polymers clearly affects the 
biological properties, as larger glycopolymers generally display higher protein affinity (see Figure 1.5 C) [47,49-51]. The biological properties also depend on the carbohydrate density (see Figure 1.5 D for an example of too high, and Figure 1.5 E for an example of too low, carbohydrate density) and relative spatial arrangement (see Figure $1.5 \mathrm{~F}$ ) [48-51]. The distance between the carbohydrate moieties (see Figure $1.5 \mathrm{G}$ ) and the flexibility of the linker between the carbohydrate and the polymer backbone (see Figure $1.5 \mathrm{H}$ ) have also shown to influence the glycopolymer-protein binding affinity $[49,50]$. 
The aim of the work described in this thesis has been to examine if a synthetic glycopolymer can mimic the biological properties of native fucoidan. If a fucoidan-mimetic glycopolymer (FMG) was obtained, its SAR, biological mechanisms of action, and potential biomedical applications were to be explored. The idea was to elucidate the SAR of the FMGs by varying structural factors such as chain length, carbohydrate density, carbohydrate distance and the chemical structure of the pendant carbohydrates. The biological mechanisms of the FMGs and their potential as building blocks in biomaterials, and other biomedical applications, were to be simultaneously explored by tailoring the FMGs for the application in question. 



\section{Glycopolymer Synthesis (Paper I, II and III)}

Some of the synthetic macromolecules described in this thesis should by IUPAC definition [65] be labeled as oligomers rather than polymers. For convenience, in this thesis, all synthetic macromolecules will be labeled as polymers, glycopolymers, or FMGs.

A summary of the structures and characterization of all synthetic glycopolymers described in this thesis are found in Section 8.4.

\subsection{Synthetic Strategy}

When planning the first synthetic work, the main question posed was how to structurally design the FMGs. As mentioned in Section 1.1.1 the SAR of fucoidan is poorly known regarding glycosidic linkage and sulfation patterns as well as sulfation degree. What is known, however, is that the general structure of fucoidan is mainly a linear chain of sulfated $\alpha$-L-fucosides asserting biological activity through multivalency. We therefore chose a more general strategy, rather than put time and focus on structural details that might not prove important for the fucoidan-mimetic properties. Based on the common structural features of all fucoidans, the idea was to synthesize linear, multivalent polymers with pendant sulfated mono- $\alpha$-L-fucosides. No polymer bearing those general 
structural features had previously been reported. Since polymers are inherently multivalent and most commonly have a linear architecture, much of the original focus was put on synthesizing a suitable sulfated $\alpha$-L-fucoside.

The structure of the $\alpha$-L-fucoside depended on which type of glycopolymer was to be synthesized. Type I and II glycopolymers would either consist of native fucoidan, with all its structural issues, or a different polysaccharide, which might cause unnecessary influence on the biological properties of the resulting glycopolymer. These two types were therefore deemed unfit. The initial studies focused on examining if the bioactivity of fucoidan could be mimicked. Of the remaining type III and IV glycopolymers, type III was therefore chosen for the early synthetic work as it was considered the most direct approach.

\subsection{Early Synthetic Work}

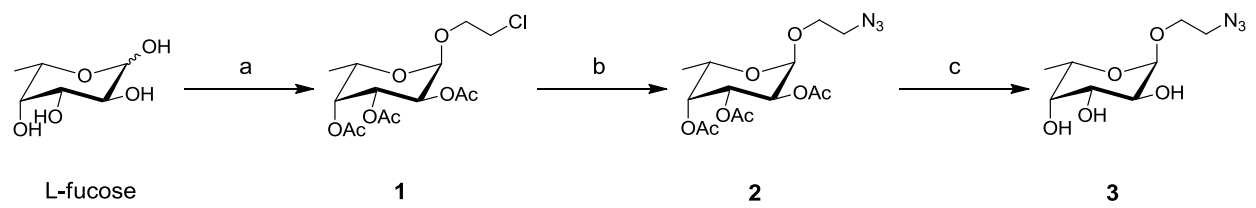

Scheme 3.1. Synthesis of azide-functionalized $\alpha$-L-fucosides. Reagents and conditions: (a) (i) Dowex $\left(\mathrm{H}^{+}\right), 2$-chloroethanol, $80^{\circ} \mathrm{C}, 2 \mathrm{~h}$; (ii) pyridine, acetic anhydride, rt, $2 \mathrm{~h}, 44 \%$ (over two steps); (b) $\mathrm{NaN}_{3}$, NaI, DMF, $80^{\circ} \mathrm{C}, 18$ h, $98 \%$; (c) $\mathrm{NaOMe}, \mathrm{MeOH}, \mathrm{rt}, 30 \mathrm{~min}, 95 \%$ [66].

The choice of glycosylation method was an obstacle to overcome when choosing an appropriate $\alpha$-L-fucoside with a functional group for covalent coupling to a polymer. It was considered necessary to have an ethylene or propylene spacer between the fucoside and the functional group to achieve flexibility. However, glycosylations using L-fucose as the glycosyl donor and a short linear alcohol as the glycosyl acceptor yields mixtures of the $\alpha$ - and $\beta$-anomers that are difficult to separate [66-68]. Ni et al reported a method using L-fucose as the glycosyl donor and 2-chloroethanol as the acceptor that yields predominantly the $\alpha$-anomer $(\alpha / \beta \approx 9: 1)$. Upon acetylation of the hydroxyl groups the major $\alpha$-anomer 1 can be conveniently separated from the minor $\beta$-anomer in relatively good yield (see Scheme 3.1). The terminal chloride can then be substituted for an azide functionality to give fucoside 2. De-protection of the hydroxyl groups yields the versatile azido $\alpha$-L-fucoside 3 [66], which was consequently chosen as the starting material in the synthesis of type III glycopolymers. 


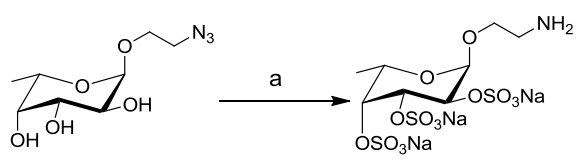

3

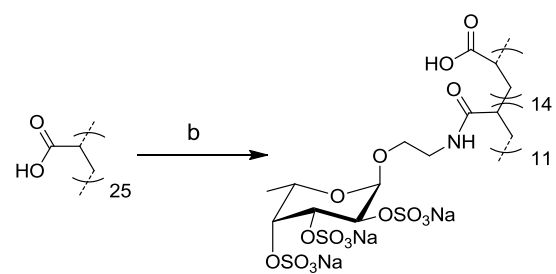

5

6

Scheme 3.2. Synthesis of glycopolymer 6. Reagents and conditions: (a) (i) $\mathrm{SO}_{3} \bullet P y r, D M F, r t, 20$ h; (ii) $\mathrm{NaHCO}_{3}, \mathrm{rt}, 1 \mathrm{~h}$; (iii) $\mathrm{Pd} / \mathrm{C}, \mathrm{H}_{2}(\mathrm{~g}$ ), $\mathrm{MeOH}, \mathrm{rt}, 19 \mathrm{~h}, 39 \%$ (over three steps); (b) (i) $\mathrm{SOCl}_{2}, 80^{\circ} \mathrm{C}, 21 \mathrm{~h}$; (ii) 4, $\mathrm{Et}_{3} \mathrm{~N}, \mathrm{DMF}, \mathrm{rt}, 40$ h; (iii) $\mathrm{H}_{2} \mathrm{O}$, rt, $2 \mathrm{~h}$.

The azide functionality provided two options for covalent coupling of the fucoside to a polymer backbone. Either via Cu-mediated azide alkyne 'click' chemistry or through nucleophilic acyl substitution by reducing the azide to an amine. The latter option was chosen since $\mathrm{Cu}^{2+}$ has greater affinity than $\mathrm{Na}^{+}$to sulfates [69] and might therefore be difficult to remove during purification, which could affect the bioactivity screenings. Fucoside 3 was hence $O$-sulfated using sulfur trioxide-pyridine complex $\left(\mathrm{SO}_{3} \bullet \mathrm{Pyr}\right)$ as the reagent. The resulting pyridinium ions on the resulting $O$-sulfates were then exchanged for sodium ions by adding sodium bicarbonate. This method had previously been employed by the Nifantiev group in the synthesis of fucoidan-mimetic oligosaccharides [37-39,41]. It proved somewhat troublesome, though, as the sulfate esters turned out to be labile and purification became difficult. The azide functionality was then reduced to an amine by catalytic hydrogenation. This gave amine-functionalized fucoside 4 (see Scheme 3.2), a sulfated $\alpha$-L-fucoside suitable for coupling to a polymer backbone via nucleophilic acyl substitution. As linear polymer backbone, the commercially available short $\left(M_{\mathrm{n}}=1800 \mathrm{~g} / \mathrm{mol}\right)$ polyacrylic acid 5 was chosen. The acid groups on polymer $\mathbf{5}$ were converted to acid chlorides according to a previously described procedure [70]. The acid chlorides were then readily coupled under basic conditions with the nucleophilic amine of fucoside 4 . Addition of water converted all unreacted acid chlorides to acids which gave glycopolymer $\mathbf{6}$ as the final product. ${ }^{1} \mathrm{H}$ NMR showed loss of peak splitting and broadening of the peaks stemming from the pendant $\alpha$-L-fucosides, which confirmed successful covalent binding of the amino fucosides to the polymer backbone (see Figure 3.1). Comparison of the integral ratios of the fucoside specific peaks and the polymer backbone peaks indicated that $45 \%$ of the acid groups on the polymer backbone had been covalently coupled with a sulfated amino $\alpha$-L-fucoside. Full experimental details for compounds $\mathbf{4}$ and $\mathbf{6}$ can be found in Section 8.1. 


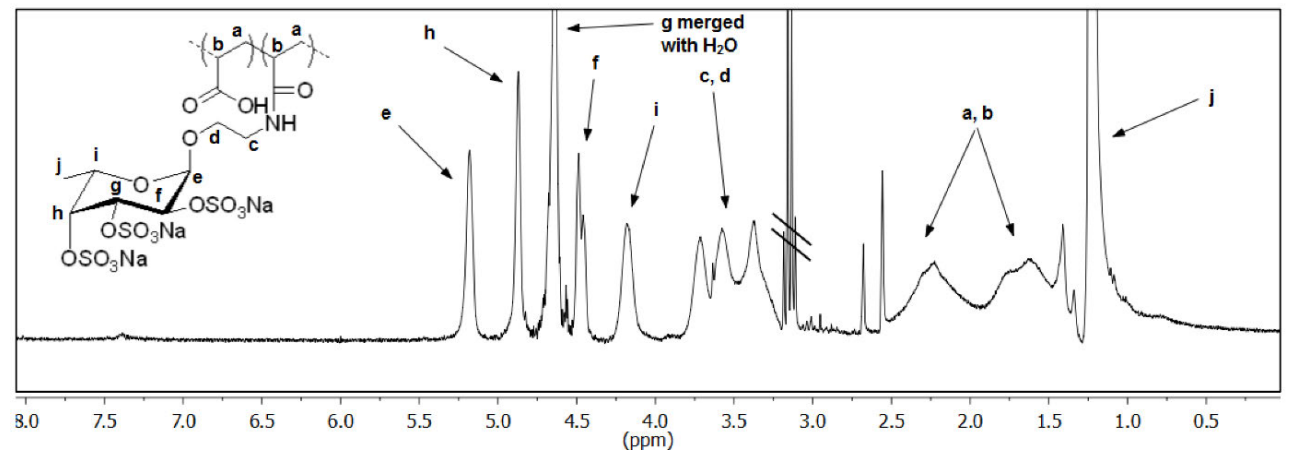

Figure 3.1. ${ }^{1} \mathrm{H}$ NMR spectrum of glycopolymer 6 in $\mathrm{D}_{2} \mathrm{O}, 300 \mathrm{MHz}$.

As glycopolymer 6 fulfilled the structural criteria set in Section 3.1 (a linear, multivalent polymer with pendant sulfated mono- $\alpha$-L-fucoside) it was evaluated in biological assays to determine its fucoidan-mimetic properties. Polymer 5 was used as reference to determine the influence of the pendant sulfated $\alpha$-L-fucosides on the biological properties. Preliminary results showed good antiviral activity by glycopolymer 6 against Herpes Simplex Virus-1 (HSV-1) infections, whereas polymer 5 was inactive. However, an assay to determine the anti-inflammatory properties showed a slight increase in inflammatory response by glycopolymer 6 rather than an anti-inflammatory response. Polymer $\mathbf{5}$ showed a similar increase in inflammatory response. These results lead to the conclusion that the free carboxylic acids along the polymer backbone posed a possible obstacle in gaining glycopolymers with fucoidan-mimetic properties. The results were still encouraging enough, though, to pursue the project further, but spending time optimizing the reaction conditions to gain a glycopolymer fully coupled with sulfated fucosides along the backbone was not considered the right way to go. Instead, focus was turned to synthesizing type IV glycopolymers.

\subsection{Polymerization Strategy}

Switching to type IV glycopolymers meant a polymerization step became part of the synthesis. The criteria in Section 3.1 were set to make sure the glycopolymers have fucoidan-mimetic properties, which was still the main focus in the synthetic work. However, with the addition of a polymerization step three secondary criteria for the characteristics of the glycopolymer chains were added. First, control of the chain length of the glycopolymers was deemed necessary to deduce the mechanisms of action of the FMGs and to possibly control the potency of their biological properties. Second, for the same reasons a target value of $\leq 1.5$ was set for the dispersity $(\bigoplus)$. Third, the ability to 
tailor the FMGs' chain end functionality was desirable to serve as an anchor for covalent linkage to, e.g., biomaterials.

Glycopolymers have previously been synthesized by such diverse methods as cationic, anionic, ring-opening, and radical polymerization. The former three were initially popular, but in the 1990's radical polymerization became the primary polymerization method in glycopolymer synthesis [45,63]. The emergence of various reversible-deactivation radical polymerization (RDRP) (formerly known as living/controlled radical polymerization) techniques around that time enabled precision synthesis of well-defined glycopolymers with complex architectures [71]. Due to this versatility and the wide range of different techniques available, we decided on a radical polymerization approach in the attempt to synthesize type IV FMGs.

\subsubsection{Radical Polymerization Mechanism}

By IUPAC definition a radical polymerization is a polymerization where radicals are the kinetic-chain carriers, which usually means that the growing (or active) chain end bears an unpaired electron [65]. Like other polymerization processes, a radical polymerization undergoes three steps: initiation, propagation and termination. The initiation involves the degradation of a radical initiator to form free radical species (see Figure 3.2 (1)). This degradation can occur through the addition of heat or redox reagents or UV, visible, or ionizing light or electrochemically. Various types of compounds can serve as radical initiators (see Figure 3.3) such as azo compounds (e.g. AIBN and ACVA), peroxides (e.g. BPO and dicumyl peroxide), persulfates (e.g. APS and KPS), and various benzophenone derivatives. The free radical then reacts with the monomers in the propagation step (see Figure 3.2 (2)). In radical polymerization the most commonly used monomers are various olefins (see Figure 3.3) such as alkenes, styrenes, (meth)acrylates, and (meth)acryl amides. The free radical reacts with the double bond on the olefin monomer through an addition reaction. The free radical and one of the $\pi$-electrons from the double bond form a stable carbon-carbon bond, whereas the remaining $\pi$-electron moves to the more branched (and hence more stable) of the olefinic carbons, thus creating a new free radical. This radical in turn reacts through the same mechanism with another monomer, and so on, to form an ever growing polymer chain bearing a radical on the active chain end [72]. 
Initiation: Initiator $\longrightarrow 21^{\circ}$

Propagation: $\mathrm{I}^{\cdot}+\mathrm{nM} \longrightarrow \mathrm{I}-\mathrm{P}_{\mathrm{n}} \cdot$

(2)
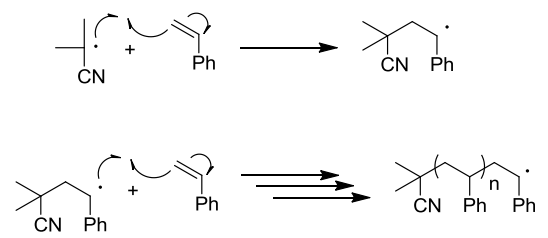

Termination: $\mathrm{I}-\mathrm{P}_{\mathrm{n}}{ }^{\prime}+{ }^{\cdot} \mathrm{P}_{\mathrm{n}}-\mathrm{I} \longrightarrow \mathrm{I}-\mathrm{P}_{\mathrm{n}}-\mathrm{P}_{\mathrm{n}}-\mathrm{I}$

(3)

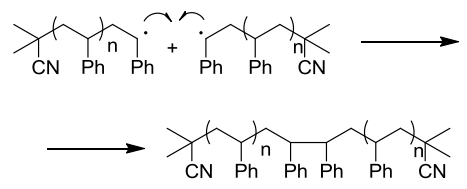

(4)

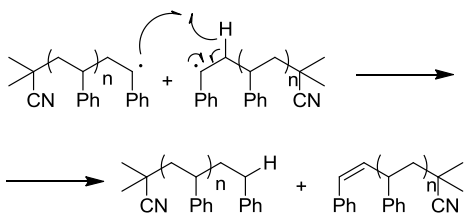

$\mathrm{I}-\mathrm{P}_{\mathrm{n}}{ }^{+}+\mathrm{I} \longrightarrow \mathrm{I}-\mathrm{P}_{\mathrm{n}}-1$

(5)

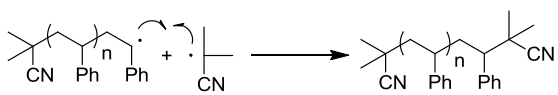

$\mathrm{I}-\mathrm{P}_{\mathrm{n}} \cdot+\mathrm{H}-\mathrm{CTA} \longrightarrow \mathrm{I}-\mathrm{P}_{\mathrm{n}}-\mathrm{H}+{ }^{\cdot} \mathrm{CTA}$

(6)

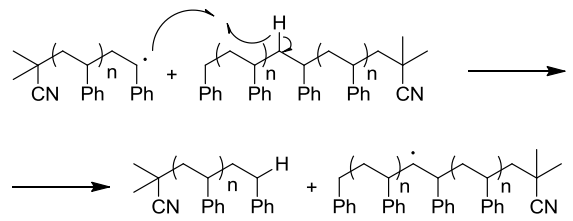

Figure 3.2. The steps involved in the radical polymerization mechanism (left) with AIBN-initiated polymerization of styrene as an example (right): initiation (1), propagation (2), and termination through either coupling of macroradicals (3), disproportionation (4), coupling of the active chain-end with an initiator radical (5), or chain transfer (6).

The radical polymerization process ends with the termination step. This can occur through the coupling of two macroradicals, two polymer chains with free radicals on one of their respective chain ends (see Figure 3.2 (3)). Two macroradicals might also terminate through disproportionation, a process in which a hydrogen is transferred from one of the macroradicals to the other, resulting in one polymer with a saturated chain 
end and one with an unsaturated chain end (see Figure 3.2 (4)). Termination might also occur through the coupling of a macroradical with an initiator radical (see Figure 3.2 (5)) or through chain transfer, in which the radical is transferred from the macroradical to the solvent, initiator, monomers, impurities, additives, or polymer chains, by the transfer of a hydrogen atom (see Figure 3.2 (6)). Intra- or intermolecular chain transfer to a polymer chain positions the radical away from the chain ends causing branched polymer chains [72].

Initiators:
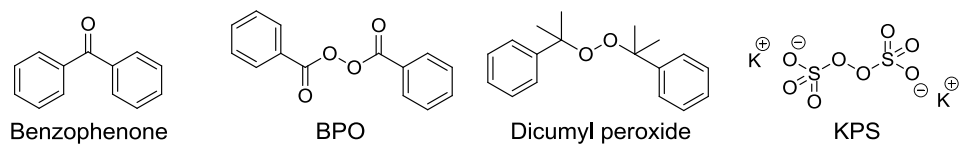

BPO

Dicumyl peroxide KPS

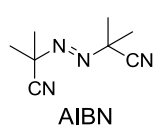<smiles>CC(C#N)(CCC(=O)O)N=NC(C)(C#N)CCC(=O)O</smiles>

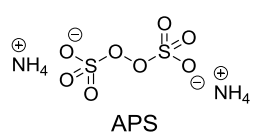

\section{Monomers:}
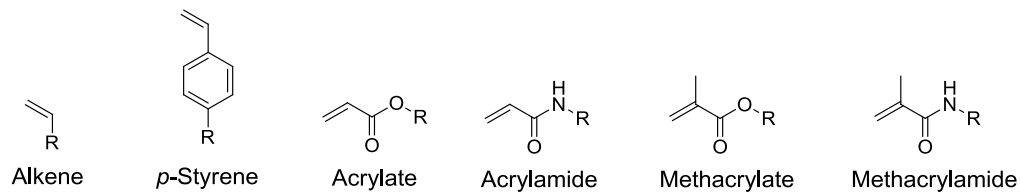

Figure 3.3. Examples of initiators and monomers used in radical polymerization $[71,72]$.

The mechanism described here is a general one for radical polymerizations and usually gives poor control over the polymer chain length with a broad dispersity due to seemingly random termination. Several methods to control the chain length and yield a narrow dispersity by controlling the termination step have been explored by adding CTAs such as thiols and halocarbons [72]. The 1990's saw the emergence of RDRP techniques in which active macroradicals can be deactivated reversibly to form an active-dormant polymer chain equilibria in the propagation step. In theory, RDRP eliminates the termination step and gives polymers with good chain length control and narrow dispersity. These polymers also readily react upon the addition of more monomers (hence being formerly known as living radical polymerizations). Some RDRP techniques such as nitroxide-mediated radical polymerization (NMP), cyanoxyl-mediated free-radical polymerization (CMRP), atom transfer radical polymerization (ATRP), and reversible addition-fragmentation chain transfer polymerization (RAFT) have been especially prolific in the synthesis of glycopolymers [71]. 


\subsection{Monomer Synthesis (Paper I)}

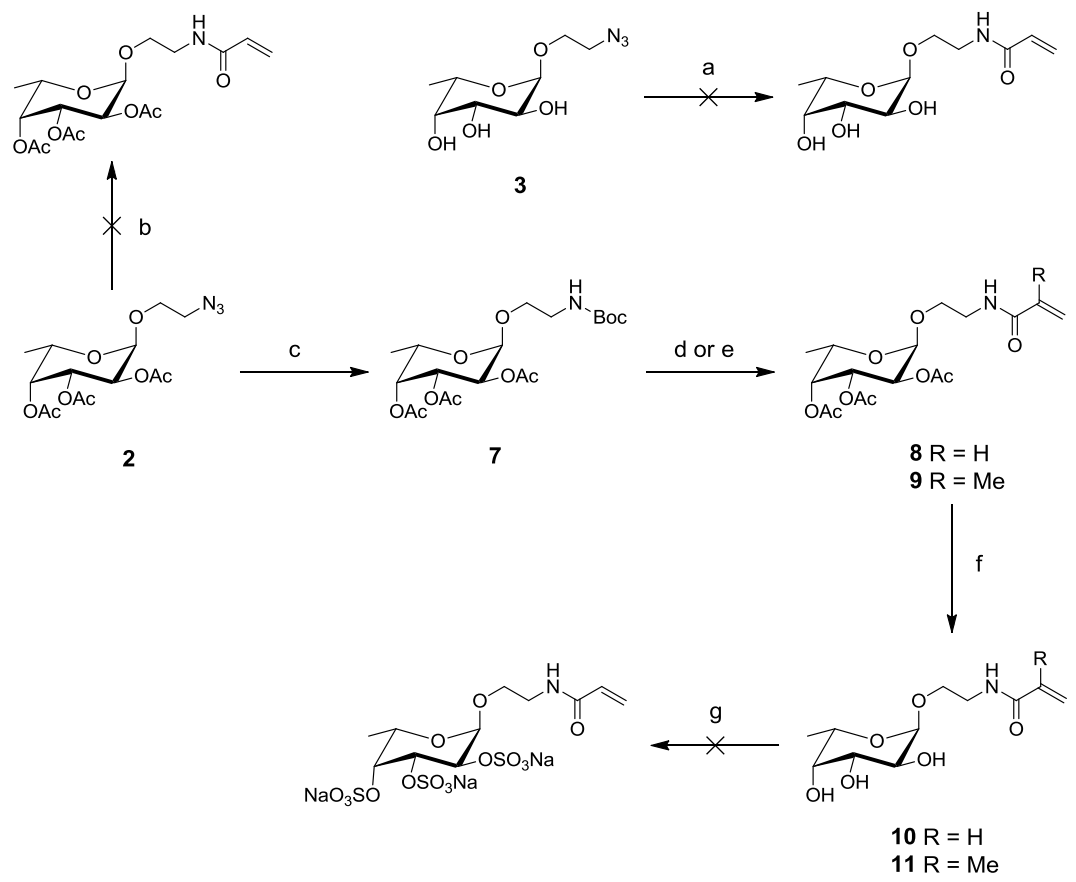

Scheme 3.3. Synthesis of (meth)acrylated $\alpha$-L-fucoside monomers. Reagents and conditions: (a) (i) $\mathrm{Pd} / \mathrm{C}, \mathrm{H}_{2}(\mathrm{~g}), \mathrm{MeOH}, \mathrm{rt}, 23 \mathrm{~h}$; (ii) acryloyl chloride, $\mathrm{Et}_{3} \mathrm{~N}, \mathrm{MeOH}, \mathrm{DCM}, 0^{\circ} \mathrm{C} \rightarrow \mathrm{rt}, 4 \mathrm{~h}$; (b) (i) $\mathrm{Pd} / \mathrm{C}$, $\mathrm{H}_{2}(\mathrm{~g})$, EtOH, rt, $2 \mathrm{~h}$; (ii) acryloyl chloride, $\mathrm{Et}_{3} \mathrm{~N}, \mathrm{DCM}, 0^{\circ} \mathrm{C} \rightarrow \mathrm{rt}, 3 \mathrm{~h}$; (c) $\mathrm{Pd} / \mathrm{C}, \mathrm{Boc}_{2} \mathrm{O}, \mathrm{H}_{2}$ (g), EtOAc, rt, 28 h, 91\%; (d) (i) TFA, DCM, rt, $1.5 \mathrm{~h}$; (ii) acryloyl chloride, $\mathrm{Et}_{3} \mathrm{~N}, \mathrm{DCM}, 0^{\circ} \mathrm{C} \rightarrow \mathrm{rt}, 3.5 \mathrm{~h}, 69 \%$ (over two steps); (e) (i) TFA, DCM, rt, 1 h; (ii) NHS-methacrylate, $\mathrm{Et}_{3} \mathrm{~N}$, DCM, rt, 2 h, 81\% (over two steps); (f) NaOMe, $\mathrm{MeOH}, \mathrm{rt}, 0.5-3 \mathrm{~h}$, $99 \%(\mathrm{R}=\mathrm{H}), 94 \%(\mathrm{R}=\mathrm{Me})$; (g) (i) $\mathrm{SO}_{3} \cdot \mathrm{Pyr}, \mathrm{DMF}, \mathrm{rt}, 19 \mathrm{~h}$; (ii) $\mathrm{NaHCO}_{3}, \mathrm{rt}, 3 \mathrm{~h}$.

When planning the synthesis of a suitable sulfated $\alpha$-L-fucoside monomer for radical polymerization it seemed wise to use already explored fucoside 3 . As azido functionalities are readily converted to amines by reduction, the obvious choice of functional groups to undergo radical polymerization were acrylamide or methacrylamide. The azide on fucoside $\mathbf{3}$ was initially reduced by catalytic hydrogenation and the resulting amine coupled with acryloyl chloride (see Scheme 3.3). The polarity of the hydroxyl groups, though, made purification difficult and this approach was hence abandoned. To facilitate purification, the peracetylated fucoside 2 was reduced and acrylated in a similar fashion. However, this approach revealed an unexpected problem with the catalytic hydrogenation. Two distinct spots with close $R_{\mathrm{f}}$ 
were observed by TLC. NMR $\left({ }^{1} \mathrm{H}\right.$ and ${ }^{13} \mathrm{C}$ ) confirmed one of these spots to be a fucoside dimer, a side-reaction sometimes observed during reduction of azides via catalytic hydrogenation $[73,74]$. Separating the desired product from the dimer proved difficult and different batches of $\mathrm{Pd} / \mathrm{C}$ with different $\mathrm{Pd}$ concentrations all gave the same result. $O \rightarrow N$ acetyl group migration was also observed as a minor by-product. To circumvent both these issues a different approach was once again tested.

The new approach (which is described in Paper I) relied on trapping the amine through Boc-protection before dimerization and acetyl group migration could occur [75]. This proved successful as only one distinct spot was observed on TLC. Purification then readily gave Boc-protected amino fucoside 7. NMR confirmed the success as no traces of the dimer were found. Having served its purpose, the $N$-Boc-group was removed by treatment with TFA and the resulting free amine was coupled with acryloyl chloride to give peracetylated acrylamide fucoside $\mathbf{8}$. This compound was however difficult to purify sufficiently as several by-products were formed that resulted in a lower yield. Removal of the acetyl groups by basic ester hydrolysis then gave acrylamide fucoside 10. Acrylamide $\mathbf{1 0}$ was, however, susceptible to undergo self-polymerization, which was observed when dissolved in protic solvents (particularly $\mathrm{MeOH}$ and $\mathrm{H}_{2} \mathrm{O}$ ) and subjected to temperatures above room temperature. The stability increased when fucoside 10 was carefully protected from both heat and light during work-up and storage.

To primarily increase the yield and ease purification, a second set of monomers (methacrylamides) were synthesized, again using the Boc-protected amine 7. The $N$-Boc-group was removed upon treatment with TFA and the amine coupled with NHS-methacrylate. This gave methacrylamide fucoside 9, which showed less by-products compared to acrylamide $\mathbf{8}$ and was, hence, far less difficult to purify. This in turn resulted in an improved yield. The peracetylated fucoside $\mathbf{9}$ was then deprotected, again by basic ester hydrolysis, which gave methacrylamide $\mathbf{1 1}$ with free hydroxyl groups. As with acrylamide 10, methacrylamide $\mathbf{1 1}$ proved unstable and prone to self-polymerize under similar conditions. Again though, careful protection from heat and light showed an increase in stability. As will be shown in Section 3.5, methacrylamides 9 and $\mathbf{1 1}$ became the monomers of choice in the attempts to synthesize FMGs. This eventually called for an up-scaled synthesis of monomer $\mathbf{9}$ during which instability, similar to that of monomers $\mathbf{1 0}$ and 11, started to show. As a result, washing with water and $\mathrm{NaHCO}_{3}$ (aq., sat.) was added to the work-up along with protection from heat. These measures greatly increased the stability of the up-scaled monomer $\mathbf{9}$, even though it would continue to show some tendencies to self-polymerize. 
To furnish the (meth)acrylamide $\alpha$-L-fucoside monomers according to the structural criteria set in Section 3.1, attempts were made to sulfate the hydroxyl groups of monomers 10 and $\mathbf{1 1}$ under the conditions described in Section 3.2. $O$-sulfation was observed by TLC, but the $O$-sulfated monomers proved very difficult to isolate and showed even greater tendencies to self-polymerize than monomers $\mathbf{1 0}$ and 11. Flash column chromatography showed loss of $O$-sulfates and isolation of the $O$-sulfated monomers by dialysis or size exclusion chromatography proved unsuccessful, due to their relatively small sizes. The attempts to synthesize $O$-sulfated monomers were therefore abandoned in favor of sulfating the hydroxyl groups post-polymerization. The end result was a set of four monomers with pendant $\alpha$-L-fucosides available for radical polymerizations: peracetylated acrylamide $\mathbf{8}$, acrylamide $\mathbf{1 0}$ with free hydroxyl groups, peracetylated methacrylamide $\mathbf{9}$ and methacrylamide $\mathbf{1 1}$ with free hydroxyl groups.

\subsection{Polymerizations}

\subsubsection{Cyanoxyl-Mediated Free-Radical Polymerizations (Paper I)}

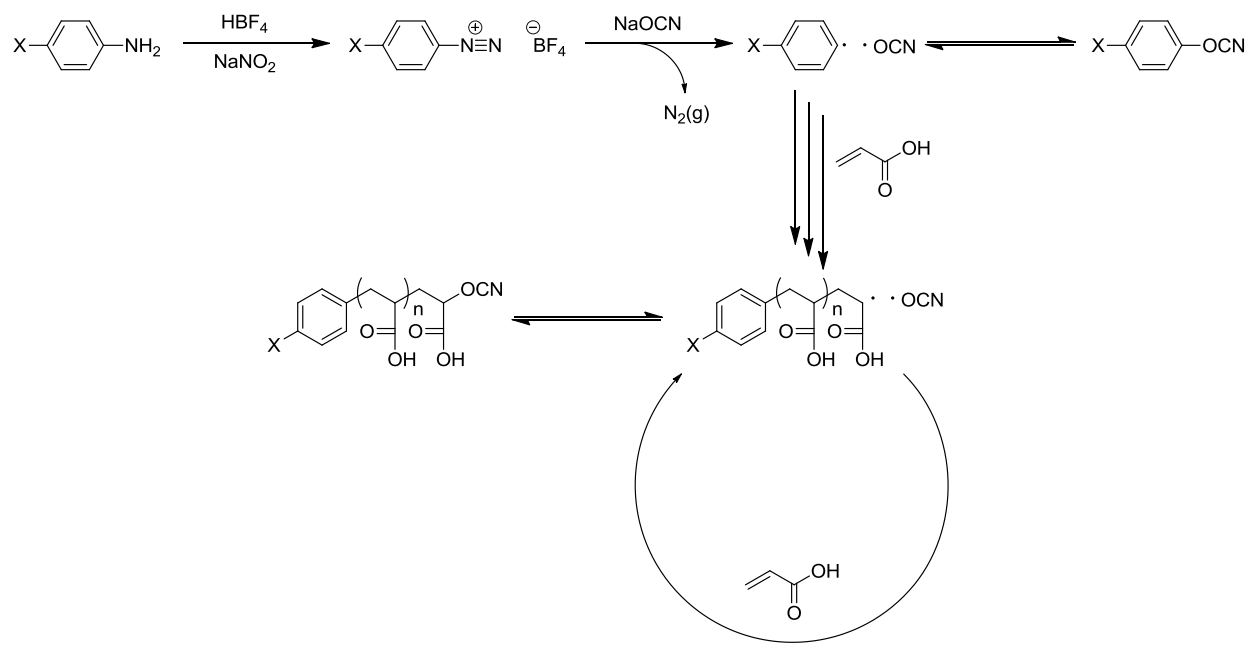

Figure 3.4. The mechanism of cyanoxyl-mediated free-radical polymerization $[76,77]$.

In CMRP the radical initiator is generated in situ from $p$-aniline derivatives (See Figure 3.4). The $p$-aniline is converted to an arenediazonium salt which, upon treatment with cyanate anions, fragments at its inner central azo moiety to generate an aryl radical and a cyanoxyl radical. These two radicals show distinct differences in reactivity with the aryl radical being the far more reactive of the two species. The aryl 
radical consequently initiates the propagation whereas the persistent cyanoxyl radical acts as moderator by controlling the chain growth. By reversibly trapping an active growing chain cyanoxyl radicals can form dormant species, which creates deactivation-activation cycles that allows the polymer chains to grow at even rates and eliminates much of the irreversible termination [76,77].

CMRP has previously been successfully used in the synthesis of various sulfated glycopolymers under mild conditions in good yields with $\oslash<1.6$. CMRP has also shown good tolerance against functional groups such as hydroxyls and $O$-sulfates [77-82]. Moreover, this technique showed good versatility in tailoring the chain end functionality through the synthesis of various $p$-aniline derivatives $[81,82]$. This feature was particularly contributing to the choice of exploring CMRP as a method for synthesizing type IV glycopolymers.

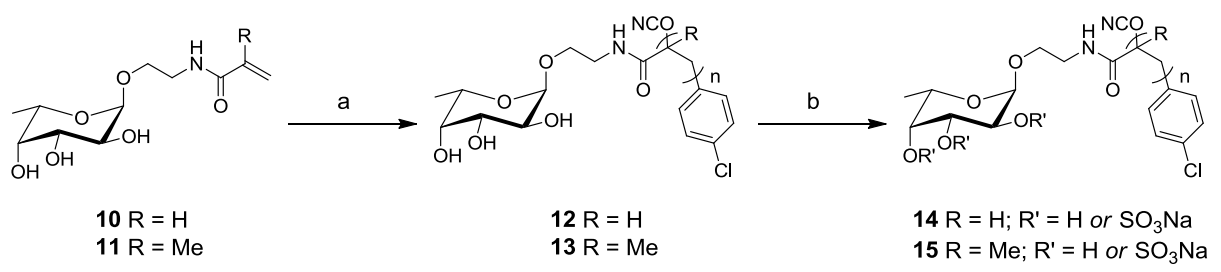

Scheme 3.4. Synthesis of glycopolymers 12, 13, 14 and 15 by cyanoxyl-mediated free-radical polymerization. Reagents and conditions: (a) $p$-chloroaniline, $\mathrm{HBF}_{4}, \mathrm{NaNO}_{2}, \mathrm{NaOCN}, \mathrm{H}_{2} \mathrm{O}$, $0^{\circ} \mathrm{C} \rightarrow 55^{\circ} \mathrm{C}, 18 \mathrm{~h}$; (b) (i) $\mathrm{SO}_{3} \bullet \mathrm{Pyr}, \mathrm{DMF}, \mathrm{rt}, 2$ days; (ii) $\mathrm{NaHCO}_{3}, \mathrm{H}_{2} \mathrm{O}$, $\mathrm{rt}, 24 \mathrm{~h}$.

In Paper I both monomers 10 and $\mathbf{1 1}$ were polymerized through CMRP under conditions described by Hou et al (see Scheme 3.4) [82]. $p$-Chloroaniline was chosen as the initiating aryl compound due to previously reported high yields [82], but also because it was estimated that the relatively unreactive and stable chloride would cause few side-reactions in these first studies. ${ }^{1} \mathrm{H}$ NMR confirmed the successful polymerizations as the alkene protons of monomers $\mathbf{1 0}$ and $\mathbf{1 1}$ showed an upfield move in shift in the spectra for glycopolymers $\mathbf{1 2}$ and 13, respectively (see Figure 3.5). Confirmation also came through the general widening of the peaks in the spectra for glycopolymers $\mathbf{1 2}$ and 13, along with the loss of peak splitting. Both glycopolymers displayed peaks corresponding to the aryl protons on the chain end aryl groups, which indicated polymerization through CMRP. Both glycopolymers $\mathbf{1 2}$ and $\mathbf{1 3}$ were formed in moderate yields, 58 and $47 \%$, respectively (see Table 3.1). The slightly lower yield of glycopolymer $\mathbf{1 3}$ compared to glycopolymer $\mathbf{1 2}$ could be attributed to the known lower reactivity of methacrylamides compared to acrylamides in radical polymerizations. 

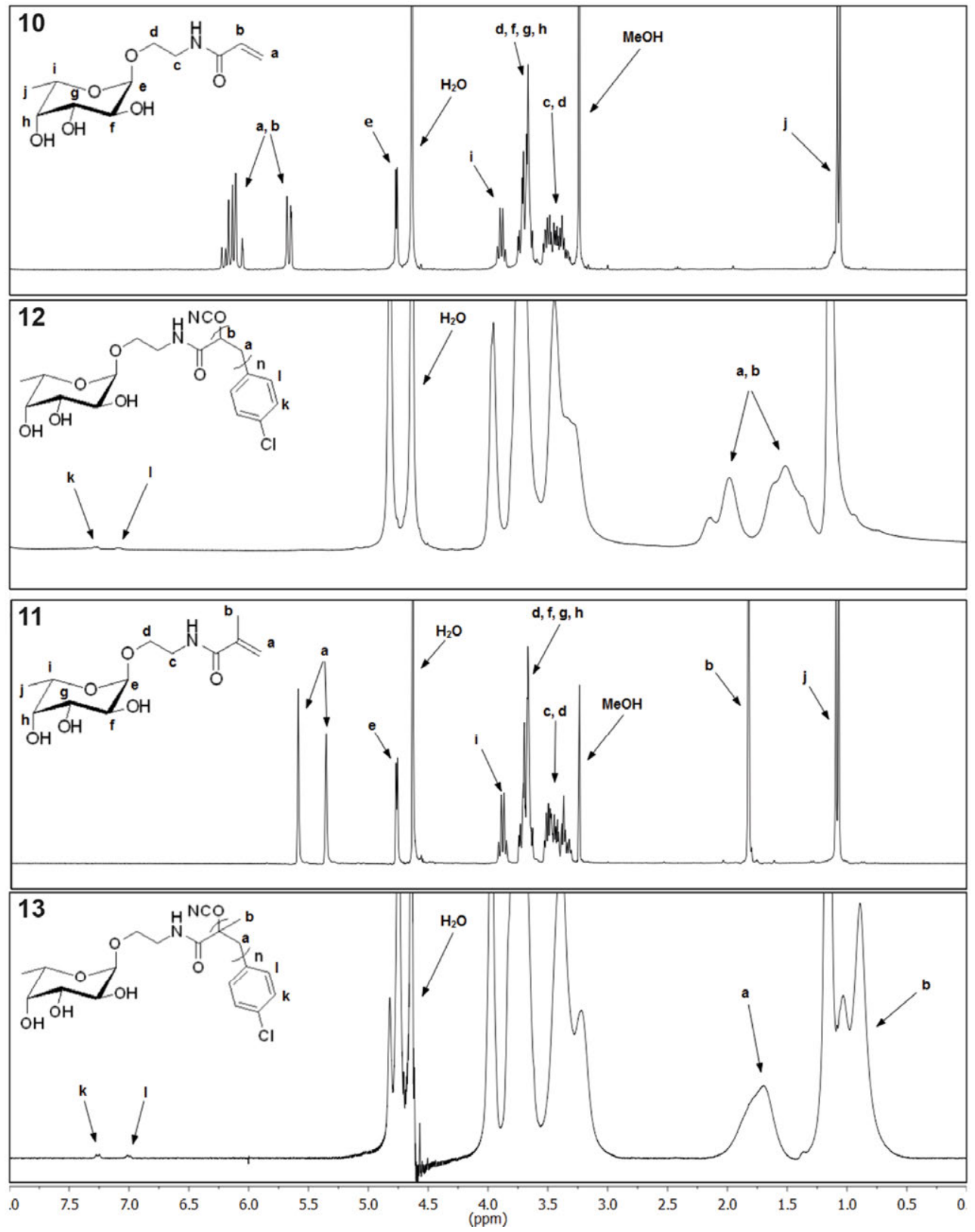

Figure 3.5. ${ }^{1} \mathrm{H}$ NMR spectra for (from top to bottom) monomer 10, polymer 12, monomer 11, and polymer 13 in $\mathrm{D}_{2} \mathrm{O}, 300 \mathrm{MHz}$. Adapted with permission from [83]. Copyright 2014 American Chemical Society.

Characterization by GPC showed a more troublesome side of the story (see Figure 3.6). Glycopolymer $\mathbf{1 3}$ displayed a rather broad monomodal distribution, whereas 
glycopolymer 12 showed a distinct bimodal distribution. Both polymer 12 and $\mathbf{1 3}$ showed fairly similar $M_{n}(26800$ and $30200 \mathrm{~g} / \mathrm{mol}$, respectively) (see Table 3.1), but both had far wider $D$ (2.83 and 2.15 , respectively) than the previously reported glycopolymers $(\Theta<1.6)$. The bimodal distribution of glycopolymer 12 in particular, caused for speculation if the polymerization proceeded entirely through a CMRP mechanism. As both monomers $\mathbf{1 0}$ and $\mathbf{1 1}$ showed tendencies to self-polymerize under heat in protic solvents, a hypothesis was formed that such a polymerization mechanism occurred simultaneously with the CMRP mechanism, since the polymerization proceeded in water at $55^{\circ} \mathrm{C}$. Extensive kinetic studies would, however, be necessary to confirm that hypothesis. Unfortunately, we lacked the sufficient analysis equipment to perform such studies.

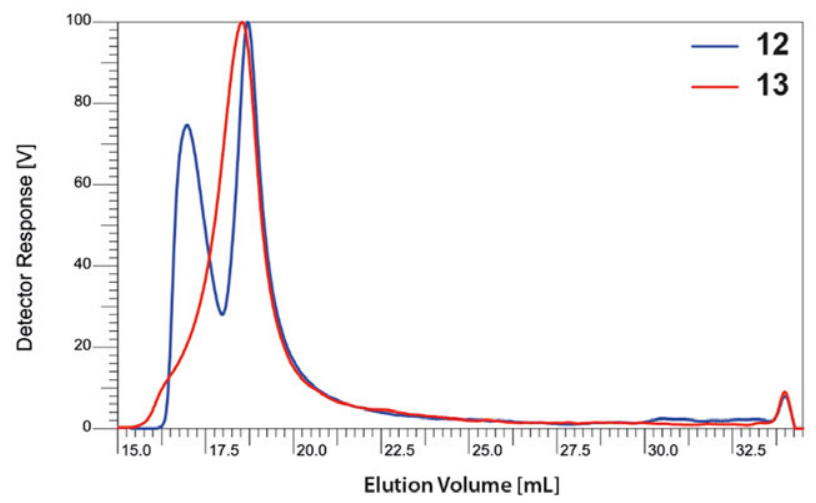

Figure 3.6. GPC traces for glycopolymers $\mathbf{1 2}$ (blue) and $\mathbf{1 3}$ (red) with DMSO as eluent and dextran/pullulan standards. Adapted with permission from [83]. Copyright 2014 American Chemical Society.

Despite the shortcomings of these polymerizations, both glycopolymers 12 and 13 were furnished by $O$-sulfation to fulfil the structural criteria set in Section 3.1. The aim was originally to fully sulfate both glycopolymers and reach a DS of near $100 \%$. Conditions similar to those explored in the synthesis of glycopolymer 6 were used in the $O$-sulfation of both glycopolymers. Somewhat surprising, both the resulting sulfated glycopolymers $\mathbf{1 4}$ and $\mathbf{1 5}$ precipitated out of solution during this process thus preventing a near 100\% DS. ${ }^{1} \mathrm{H}$ NMR confirmed the partial $O$-sulfation as the peaks of the protons neighboring the sulfated hydroxyl groups on the pendant fucosides showed a downfield move in shift, compared to the spectra of glycopolymers $\mathbf{1 2}$ and 13. Elemental analysis showed 62 and 66\% DS for glycopolymers $\mathbf{1 4}$ and $\mathbf{1 5}$, respectively (see Table 3.1), which indicated this sulfation protocol was fairly reproducible. 
Table 3.1. Characterization of glycopolymers 12, 13, 14, and 15.

\begin{tabular}{|c|c|c|c|c|c|c|c|}
\hline Polymer & $\begin{array}{c}\text { Yield } \\
(\%)\end{array}$ & $\begin{array}{c}M_{n}^{\mathrm{a}} \\
(\mathrm{g} / \mathrm{mol})\end{array}$ & $\boldsymbol{Ð}^{\mathbf{a}}$ & Polymer & $\begin{array}{c}\text { Carbon }^{b} \\
(w t \%)\end{array}$ & $\begin{array}{c}\text { Sulfur }^{b} \\
(w t \%)\end{array}$ & $\begin{array}{l}D^{\mathbf{c}} \\
(\%)\end{array}$ \\
\hline 12 & 58 & 26800 & 2.83 & 14 & 20.30 & 9.12 & 62 \\
\hline 13 & 47 & 30200 & 2.15 & 15 & 23.01 & 10.18 & 66 \\
\hline
\end{tabular}

a Determined by GPC. ${ }^{b}$ Determined by elemental analysis. ${ }^{\mathrm{c}}$ Percentage sulfated hydroxyl groups per available hydroxyl group.

Glycopolymers 14 and 15 both met the structural criteria set in Section 3.1, but only partially the structural criteria set in Section 3.3. Chain end functionality was successfully incorporated as confirmed by ${ }^{1} \mathrm{H}$ NMR (see Figure 3.5), but neither glycopolymer could be asserted a controlled chain length. Also, the $Ð$ of glycopolymers 12 and 13 were wider than aimed for. These issues were largely attributed to the uncertainty of the exact mechanism(s) behind the polymerization. As the lability of monomers 10 and 11 were believed to be part of this issue, attempts were made to polymerize monomer 9 in a $\mathrm{THF} / \mathrm{H}_{2} \mathrm{O}$ system using otherwise similar conditions as with monomers $\mathbf{1 0}$ and 11. Unfortunately, this yielded no reaction.

However, glycopolymer 15 did, as will be closer described in Chapter 4, turn out to possess fucoidan-mimetic properties and was concluded to be an FMG. These results were encouraging enough to continue down this path and try to circumvent the issues with the polymerizations by exploring a different radical polymerization technique. This time by utilizing thiols as chain transfer agents.

\subsubsection{Thiol-Mediated Chain Transfer Radical Polymerizations (Paper II)}

Thiols were used early on as modifiers of polymer molecular weights, by acting through a chain transfer mechanism with an irreversible termination of the growing polymer chain (see Figure 3.2 (6)) [84]. Due to the relatively weak S-H bond and the high reactivity of thiyl radicals [85], thiols generally display large (albeit significantly varying) chain transfer constants $[72,85,86]$. This generally gives polymers of low $M_{n}$, but with greatly varied $Ð$ (ranging from 1.3 and above), when using thiols as CTAs [87-92]. The chain transfer mechanism also ensures the thiyl radical is incorporated into the polymer chain as a sulfide at the chain end [86]. 


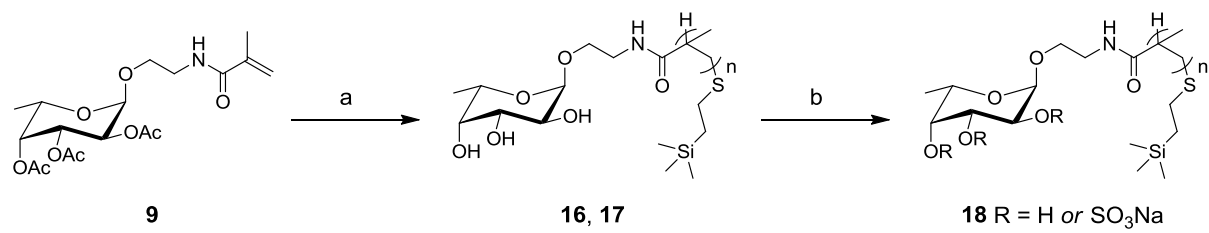

Scheme 3.5. Synthesis of glycopolymers 16, 17, and 18 through thiol-mediated chain transfer radical polymerization. Reagents and conditions: (a) (i) 2-(trimethylsilyl)-ethanethiol, AIBN, 1,4-dioxane, 80 $\mathrm{C}$, 3-6 h; (ii) $\mathrm{NaOMe}, \mathrm{MeOH}, \mathrm{rt}, 2$ days; (b) (i) $\mathrm{SO}_{3} \cdot \mathrm{Pyr}, \mathrm{DMF}$, rt, 2 days; (ii) $\mathrm{NaHCO}_{3}, \mathrm{H}_{2} \mathrm{O}$, rt, $24 \mathrm{~h}$.

Potential tailoring of the chain end and low $M_{n}$ made radical polymerization using thiols as CTAs seem like a reasonable method to explore in the synthesis of FMGs (which is described in Paper II). Lessons learnt from the CMRP polymerizations made 9 the monomer of choice and the polymerization therefore had to be done in an organic solvent, of which 1,4-dioxane was chosen. As initiator by thermal decomposition, the commonly employed AIBN was used. The choice of CTA fell upon 2-(trimethylsilyl)-ethanethiol as the trimethylsilyl protons would be easily spotted by ${ }^{1} \mathrm{H}$ NMR and therefore serve as a good model to confirm incorporation of chain end functionality. The chain transfer mechanism dictates that the $[\mathrm{M}]:[\mathrm{CTA}]$ ratio will control the polymer chain length (given a significantly larger chain transfer constant of the thiol compared to the monomer, polymer, and solvent) $[84,86,88]$. Therefore two different $[\mathrm{M}]:[\mathrm{CTA}]$ ratios were employed: $25: 1$ and 50:1 in the synthesis of glycopolymers 16 and $\mathbf{1 7}$, respectively.

Under these conditions monomer 9 was successfully polymerized and glycopolymers $\mathbf{1 6}$ and $\mathbf{1 7}$ were then furnished by basic ester hydrolysis of the acetyl protective groups on the pendant $\alpha$-L-fucosides (see Scheme 3.5). The ${ }^{1} \mathrm{H}$ NMR spectrum of glycopolymer 16 (see Figure 3.7 (top)) was well-comparable to that of glycopolymer $\mathbf{1 3}$ (see Figure 3.5 (bottom)) and clearly showed the trimethylsilyl protons at $\delta 0.00$, thus confirming a polymerization with successful incorporation of the thiol CTA at the polymer chain end. The ${ }^{1} \mathrm{H}$ NMR spectrum of glycopolymer 17 showed the same results. Analysis by GPC (see Figure 3.7 (bottom)) showed monomodal distributions with rather high and fairly similar $M_{n}$ for both glycopolymers $\mathbf{1 6}$ and $\mathbf{1 7}(90600$ and $109000 \mathrm{~g} / \mathrm{mol}$, respectively) (see Table 3.2). This showed the chain transferring properties of the chosen thiol were rather unsatisfactory as the desired control over the chain length was not gained. The reasons for this remain unclear, but kinetic experiments might show a rather low chain transfer constant for the chosen thiol. On the positive side, both 
glycopolymers $\mathbf{1 6}$ and $\mathbf{1 7}$ showed quite narrow $Ð$ (1.32 and 1.33, respectively) and the conditions used had good reproducibility regarding $M_{n}$ and $Ð$.
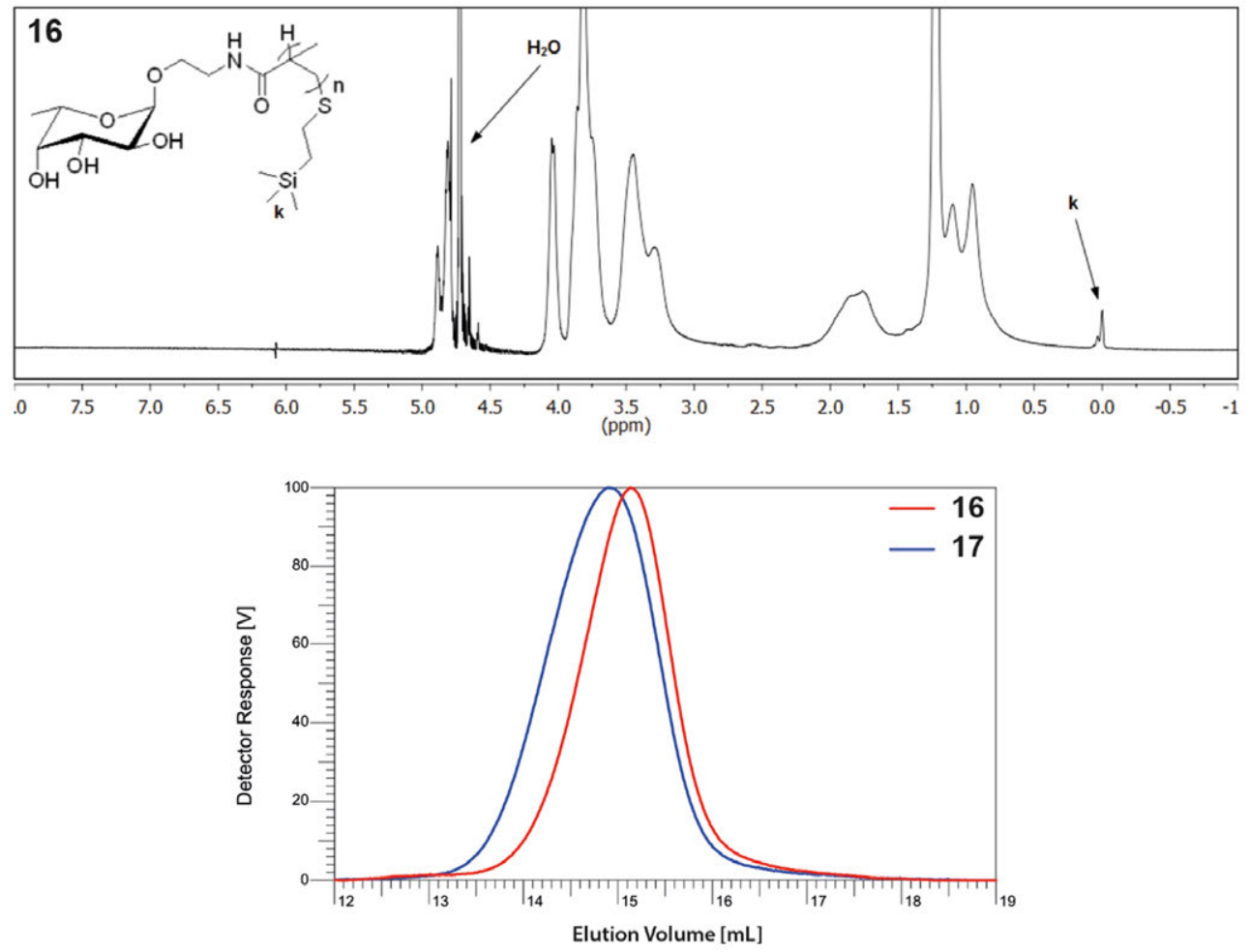

Figure 3.7. Characterization of glycopolymers 16 and 17: ${ }^{1} \mathrm{H}$ NMR spectrum for glycopolymer 16 in $\mathrm{D}_{2} \mathrm{O}, 300 \mathrm{MHz}$ (top); GPC traces for glycopolymers 16 (red) and 17 (blue) using water as eluent and dextran/pullulan standards (bottom). Adapted from [93] with permission from the Royal Society of Chemistry.

Due to the similar characteristics of glycopolymers 16 and $\mathbf{1 7}$, only glycopolymer 16 was furnished as an FMG by partial $O$-sulfation of the hydroxyl groups on the pendant fucosides. Using the same reagents and conditions as described in Section 3.5.1 glycopolymer 18 was successfully synthesized. This polymer showed carbon and sulfur contents of 24.9 and $14.4 \mathrm{wt} \%$, respectively, which corresponds to a DS of $87 \%$. This was an increase in DS compared to glycopolymers 14 and $\mathbf{1 5}$, the reasons for which remain unclear. However, the DS of glycopolymer 18 also turned out to be well-reproducible. 
Table 3.2. Characterization of glycopolymers 16 and 17.

\begin{tabular}{ccccc}
\hline Polymer & {$[\mathbf{M}]:[\mathbf{C T A}]:[\mathbf{I}]^{\mathbf{a}}$} & Yield $^{\mathbf{b}}(\boldsymbol{\%})$ & $\boldsymbol{M}_{\boldsymbol{n}}{ }^{\mathrm{c}}(\mathbf{g} / \mathbf{m o l})$ & $\boldsymbol{Ð}^{\mathbf{c}}$ \\
\hline $\mathbf{1 6}$ & $25: 1: 0.25$ & 53 & 90600 & 1.32 \\
$\mathbf{1 7}$ & $50: 1: 0.5$ & 50 & 109000 & 1.33 \\
\hline
\end{tabular}

${ }^{\mathrm{a}} \mathrm{M}=\mathbf{9}, \mathrm{CTA}=2$-(trimethylsilyl)-ethanethiol and I = AIBN. ${ }^{\mathrm{b}}$ Over multiple steps. ${ }^{\mathrm{C}}$ Determined by GPC.

As will be described in Chapter 4, glycopolymer 18 showed fucoidan-mimetic properties similar to those of glycopolymer 15. This demonstrated that changes in polymerization techniques kept yielding FMGs as long as the structural criteria described in Section 3.1 were met. As for the structural criteria described in Section 3.3, radical polymerization using 2-(trimethylsilyl)-ethanethiol as CTA demonstrated both successful incorporation of chain end functionalities as well as satisfactory $Ð$. However, sufficient control over the chain length was yet to be gained. It is likely the use of a different thiol as CTA would have given that control. This would, however, require optimization of the polymerization conditions for each new thiol being employed. Attention was hence shifted back towards the more general RDRP techniques of which RAFT polymerization was chosen as the next polymerization technique to be investigated in the synthesis of FMGs.

\subsubsection{RAFT Polymerizations (Paper III)}

The RAFT process was first patented in 1998 and has since become one of the most popular RDRP techniques [94]. RAFT polymerization is closely related to conventional free radical polymerizations regarding the initiation and propagation steps (see Figure 3.2.). The difference lies in the addition of a thiocarbonyl thio compound for control over the polymer chain length. These RAFT CTAs, or simply RAFT agents, act by suppressing the different termination steps [95]. Although the details on the RAFT mechanism are debatable [96-98], RAFT agents generally react quickly with macroradicals in an addition reaction to form a radical intermediate (see Figure $3.8 \mathrm{~B}$ ) stabilized by the Z-group (see Figure $3.8 \mathrm{~A}$ ). This process is known as the pre-equilibrium. The intermediate then fragments to form a polymer with a thiocarbonyl thio group (also known as a macro-RAFT agent) and an R-leaving group carrying the radical. The $\mathrm{R}$-group radical then initiates and propagates a new polymer chain in a process known as reinitiation until it encounters another RAFT agent (pre-equilibrium) or macro-RAFT agent (main equilibrium), upon which further addition and fragmentation occurs. Different types of monomers require different RAFT agents with 
different structures for this mechanism to occur predominantly, e.g. the stabilizing effect of the phenyl group on dithiobenzoates is ideal for polymerizing methacrylates and methacrylamides [95]. Numerous RAFT agents of various structures have consequently been reported (see Figure 3.8 C) [71]. The RAFT mechanism also ensures that polymers synthesized by this technique carry thiocarbonyl thio end groups. Therefore, by tailoring both the Z- and the R-group of the RAFT agent, chain end functionalities can be obtained in both chain ends.

A<smiles>[R]SC([Z])=S</smiles>

B Pre-equilibrium:

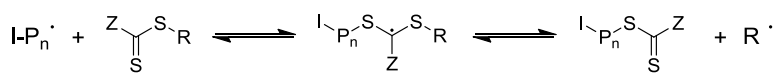

Reinitiation:

$\mathrm{R}^{\cdot}+\mathrm{nM} \longrightarrow \mathrm{R}-\mathrm{P}_{\mathrm{m}}$

Main equilibrium:

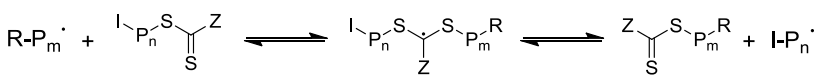

C<smiles>CC(C)(C#N)SC(=S)c1ccccc1</smiles><smiles>N#CCSC(C#N)(CCC(=O)O)SC(=S)c1ccccc1</smiles><smiles>CC(SC(=S)c1ccccc1)(c1ccccc1)c1ccccc1</smiles><smiles>C=NC(=S)SC(C)(C)C(=O)O</smiles><smiles>CCOC(=S)SC(C)C(=O)OC</smiles><smiles>CCN(CC)C(=S)SC(C#N)(C#N)CCC(=O)O</smiles><smiles>CCCSC(=S)SC(C#N)(CS)CCC(=O)O</smiles><smiles>S=C(SCc1ccccc1)c1ccccn1</smiles>

Figure 3.8. General structure of a RAFT agent (A), the mechanism of RAFT polymerization (B) [94-98], and various RAFT agents (C) [71].

RAFT polymerization has been extensively used in the synthesis of glycopolymers and generally yields polymers with narrow $D$ and control over the polymer chain length $[71,95]$. This, in combination with extensive possibilities to tailor the RAFT agents [71,99], made RAFT a seemingly suitable polymerization technique for synthesizing FMGs. The successful conditions from the synthesis of FMGs through thiol-mediated chain transfer radical polymerization were used as the basis for the synthesis of FMGs via RAFT polymerization (as described in Paper III). Monomer 9 was hence polymerized in 1,4-dioxane using AIBN as the initiator (see Scheme 3.6). The choice of 
RAFT agent fell upon CPBDT due to its previously successful use in the synthesis of glycopolymers [71]. The peracetylated fucoside pendant polymers yielded under these conditions all bore benzodithioate groups at the terminating chain end. These end groups would be hydrolyzed to thiols during the deprotection of the pendant $\alpha$-L-fucosides, which could cause coupling of the polymer chains by the formation of disulfides. To avoid this, the benzodithioate end groups were removed by treatment with excess AIBN as originally described by Perrier et al [100]. The RAFT-derived glycopolymers were then furnished by deprotection of the fucoside hydroxyl groups through basic ester hydrolysis under the same conditions as described for glycopolymers $\mathbf{1 6}$ and $\mathbf{1 7}$. To determine the extent of the chain length control asserted by RAFT polymerization, different $[\mathrm{M}]:[\mathrm{CTA}]$, i.e. monomer to RAFT agent, ratios were used in the polymerization step. [M]:[CTA] ratios of 48:1, 103:1 and 197:1 yielded glycopolymers 19, 20 and 21, respectively, after modifications and work-up.

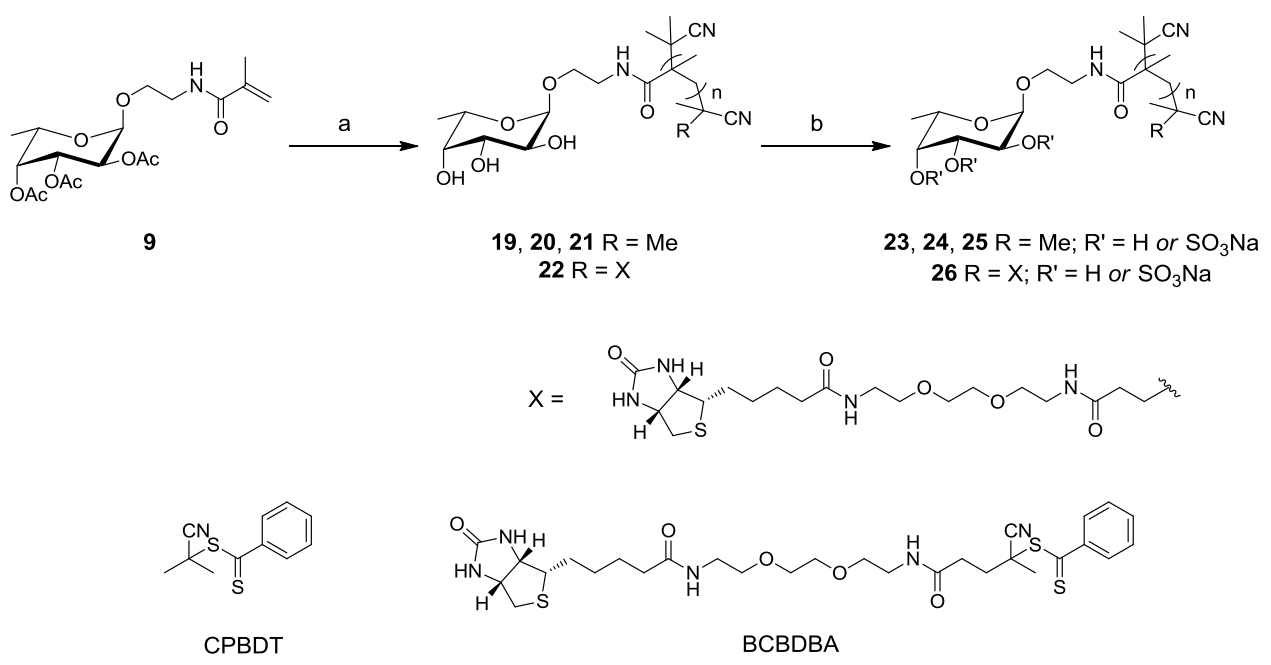

Scheme 3.6. Synthesis of glycopolymers 19-26 via RAFT polymerization. Reagents and conditions: (a) (i) CPBDT or BCBDBA, AIBN, 1,4-dioxane, $90^{\circ} \mathrm{C}, 24 \mathrm{~h}$; (ii) AIBN, 1,4-dioxane, $90^{\circ} \mathrm{C}, 18 \mathrm{~h}$; (iii) $\mathrm{NaOMe}, \mathrm{MeOH}, \mathrm{rt}, 24 \mathrm{~h}$; (b) (i) $\mathrm{SO}_{3} \cdot \mathrm{Pyr}, \mathrm{DMF}, \mathrm{rt}, 2$ days; (ii) $\mathrm{NaCl}, \mathrm{H}_{2} \mathrm{O}$, rt, 2 days.

Glycopolymer 19 displayed a ${ }^{1} \mathrm{H}$ NMR spectrum (see Figure 3.9 (top)) well-comparable to those of glycopolymers $\mathbf{1 6}$ (see Figure 3.7 (top)) and $\mathbf{1 3}$ (see Figure 3.5 (bottom)), thus confirming a successful polymerization. Glycopolymers 20 and 21 displayed similar spectra. 

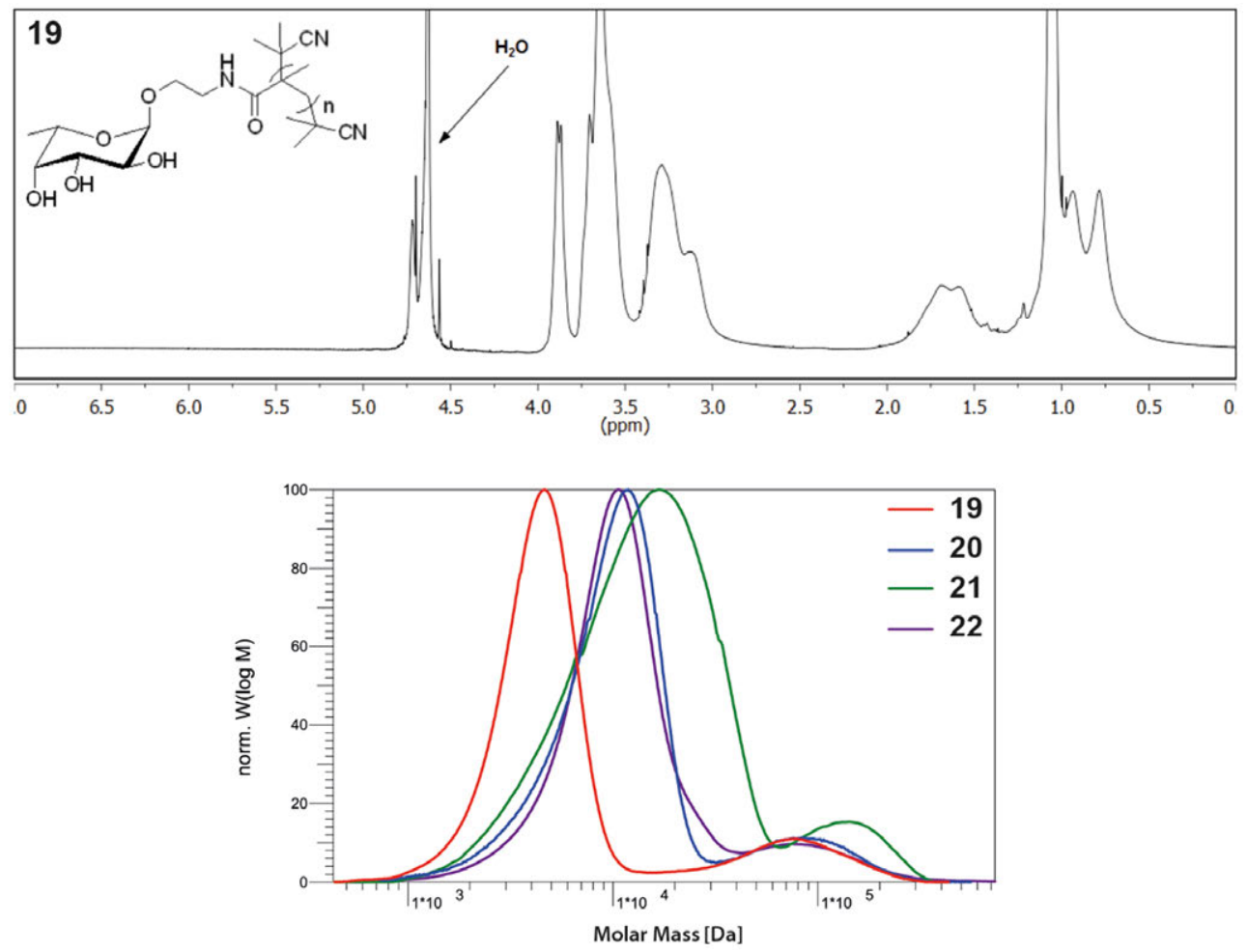

Figure 3.9. Characterization of glycopolymers 19-22: ${ }^{1} \mathrm{H}$ NMR spectrum for glycopolymer 19 in $\mathrm{D}_{2} \mathrm{O}, 300 \mathrm{MHz}$ (top); GPC molecular weight distribution for glycopolymers 19 (red), 20 (blue), 21 (green) and 22 (purple) using DMSO as eluent and dextran/pullulan standards (bottom). Adapted from [101] with permission from WILEY-VCH Verlag.

GPC analysis showed all three glycopolymers had bimodal distributions with a major peak containing low-molecular weight polymers and a minor peak containing high-molecular weight polymers. The minor peaks corresponded to 14,12 , and $9 \mathrm{wt} \%$ of the total polymer composition of glycopolymers $\mathbf{1 9}, \mathbf{2 0}$, and $\mathbf{2 1}$, respectively. The minor peaks showed $M_{n}$ and $Ð$ as follows: glycopolymer $19\left(M_{n}=57100 \mathrm{~g} / \mathrm{mol}\right.$, $Ð=1.47), 20\left(M_{n}=75000 \mathrm{~g} / \mathrm{mol}, \emptyset=1.29\right)$, and $21\left(M_{n}=124100 \mathrm{~g} / \mathrm{mol}, \emptyset=1.16\right)$. On the other hand, the molecular weight $M_{n}$ of the major peaks corresponded fairly well to the theoretical $M_{n}$ calculated according to the RAFT mechanism (see Table 3.3). As such, the major products were believed to be the results of successful polymerization via the RAFT mechanism. The polymers in the minor peaks probably stem from self-polymerization of monomer 9, either prior to or during the RAFT polymerization, but through a different mechanism. The chain lengths of these glycopolymers were significantly shorter $\left(M_{n}=3\right.$ 690, 7400 , and $9440 \mathrm{~g} / \mathrm{mol}$ for glycopolymers 19, 20, and 
21, respectively) than those of the glycopolymers synthesized by the other polymerization techniques $\left(M_{n}=26800,30200,90600\right.$, and $109000 \mathrm{~g} / \mathrm{mol}$ for glycopolymers 12, 13, 16, and 17, respectively). This indicated that some control over the polymer chain length had been obtained, which was further confirmed by the direct effect shown on the $M_{n}$ of the glycopolymers upon altering the [M]:[CTA] ratio. The fairly narrow $\oslash$, however, increased with increasing [M]:[CTA] ratio (see Table 3.3). This is not an unknown phenomena as long reaction times ( $\geq 24$ hours) and increasing $[\mathrm{M}]:[\mathrm{CTA}]$ ratio previously has shown to increase the otherwise narrow $D$ obtained during RAFT polymerizations [102-104].

Table 3.3. Characterization of the major products of glycopolymers 19-22.

\begin{tabular}{ccccccc}
\hline Polymer & CTA & {$[\mathbf{M}]:[\mathbf{C T A}]:[\mathbf{I}]^{\mathbf{a}}$} & $\begin{array}{c}\text { Yield }^{\mathbf{b}} \\
(\boldsymbol{\%})\end{array}$ & $\begin{array}{c}\boldsymbol{M}_{\boldsymbol{n}, \text { theo }} \mathbf{c} \\
(\mathbf{g} / \mathbf{m o l})\end{array}$ & $\begin{array}{c}\boldsymbol{M}_{\boldsymbol{n}, \boldsymbol{G P C}^{\mathbf{d}}} \\
(\mathbf{g} / \mathbf{m o l})\end{array}$ & $\boldsymbol{Ð}^{\mathbf{d}}$ \\
\hline $\mathbf{1 9}$ & CPBDT & $48: 1: 0.2$ & 37 & 5030 & 3690 & 1.23 \\
$\mathbf{2 0}$ & CPBDT & $103: 1: 0.2$ & 45 & 12900 & 7400 & 1.42 \\
$\mathbf{2 1}$ & CBPDT & $197: 1: 0.2$ & 20 & 10980 & 9440 & 1.79 \\
$\mathbf{2 2}$ & BCBDBA & $101: 1: 0.2$ & 41 & 11950 & 8060 & 1.41 \\
\hline
\end{tabular}

${ }^{\mathrm{a}} \mathrm{M}=\mathbf{9}$ and $\mathrm{I}=\mathrm{AIBN} .{ }^{\mathrm{b}}$ Over multiple steps. ${ }^{\mathrm{c}} M_{n, \text { theo }}=([\mathrm{M}] /[\mathrm{CTA}]) *$ $\mathrm{M}_{\text {monomer }} 9 *$ Yield $+\mathrm{M}_{\text {chain ends }}$; where $\mathbf{M}_{\text {monomer }} \mathbf{9}=275.30 \mathrm{~g} / \mathrm{mol}, \mathbf{M}_{\text {chain }}$ ends $=136.19 \mathrm{~g} / \mathrm{mol}$ for polymers 19, 20 and 21 and $\mathrm{M}_{\text {chain ends }}=550.71$ $\mathrm{g} / \mathrm{mol}$ for polymer $22 .{ }^{\mathrm{d}}$ Determined by GPC.

Incorporation of biotin into the FMG chain could yield useful tools to study the biological mechanisms of the FMGs. The biotinylated RAFT agent BCBDBA (see Scheme 3.6) was therefore synthesized, according to the protocol developed by Jiang et al [105], and used to polymerize monomer 9 under conditions similar to those of glycopolymer $\mathbf{2 0}$ (see Table 3.3). This gave glycopolymer 22, following the same modification protocols as developed for the other RAFT derived glycopolymers. Glycopolymer 22 showed a ${ }^{1} \mathrm{H}$ NMR spectra and a GPC profile similar to those of glycopolymers 19, 20, and $\mathbf{2 1}$. The polymers in the minor peak made up $10 \mathrm{wt} \%$ of the total polymer mixture with $M_{n}=85100 \mathrm{~g} / \mathrm{mol}$ and $Ð=1.32$. Again though, the $M_{n}$ of the polymers in the major peak in the GPC trace corresponded fairly well to the theoretical $M_{n}$. Also, the $M_{n}$ of glycopolymer 22 was comparable and the $\oslash$ corresponded significantly well to those of glycopolymer $20\left(M_{n}=8060\right.$ and $7400 \mathrm{~g} / \mathrm{mol} ; Ð=1.41$ and 1.42 for glycopolymers 22 and 20, respectively). Even though glycopolymer 22, or its sulfated derivative $\mathbf{2 6}$, was not used in any of the biological assays described in this theses, its synthesis serves a good purpose confirming the 
obtained control over the polymer chain length given by RAFT polymerization. It also serves a purpose showing that RAFT agents bearing the same Z-group, but different R-groups, will yield polymers with similar chain lengths under similar conditions.

Table 3.4. Characterization of glycopolymers 23-26.

\begin{tabular}{cccc}
\hline Polymer & Carbon $^{\mathbf{a}}(\mathbf{w t} \%)$ & Sulfur $^{\mathbf{a}}(\mathbf{w t} \%)$ & $\mathbf{D S}^{\mathbf{b}}(\boldsymbol{\%})$ \\
\hline $\mathbf{2 3}$ & 23.1 & 13.7 & 89 \\
$\mathbf{2 4}$ & 24.0 & 13.7 & 86 \\
$\mathbf{2 5}$ & 25.5 & 14.8 & 87 \\
$\mathbf{2 6}$ & 26.1 & 14.1 & 81 \\
\hline
\end{tabular}

a Determined by elemental analysis. ${ }^{b}$ Percentage sulfated hydroxyl groups per available hydroxyl group.

Glycopolymers 19, 20, 21, and 22 were then partially $O$-sulfated to yield glycopolymers $\mathbf{2 3}, \mathbf{2 4}, \mathbf{2 5}$, and 26, respectively. The conditions used were similar to those of the other FMGs synthesized, with the exception of $\mathrm{NaCl}$ being used instead of $\mathrm{NaHCO}_{3}$ for ion-exchange. The reason for this will be described in Section 5.2.1. The DS obtained for glycopolymers 19, 20, and $\mathbf{2 1}$ (see Table 3.4) were in the close region of that of glycopolymer 18. This confirmed the sulfation procedure to be robust and reproducible despite big differences in the polymer chain lengths. The biotinylated glycopolymer $\mathbf{2 6}$ showed a slightly lower DS of $81 \%$. This could be attributed to the biotin end group being less soluble in the reaction solvent DMF, than the polymer main chain, and therefore causing an earlier precipitation of the sulfated glycopolymer, resulting in a lower DS.

As with the other polymerization techniques, the glycopolymers obtained by RAFT polymerization fulfilled all the structural criteria set in Section 3.1. However, RAFT polymerization turned out to be the technique that finally fulfilled the last criteria set in Section 3.3 as control over the polymer chain length had finally been obtained. As will be described in Chapter 4, this enabled deeper studies on the FMGs biological mechanisms of action. Furthermore, it opened new doors for synthesizing tailored FMGs for specific biomedical applications as will be described in Chapter 5 . 


\section{Fucoidan-Mimetic Properties (Paper I and III)}

To determine if the synthesized glycopolymers did indeed possess fucoidan-mimetic properties they were subjected to a series of biological assays, in which their abilities to induce platelet activation and inhibit HSV-1 infection were assessed. In these assays both non-sulfated and sulfated glycopolymers, including sulfated glycopolymers of different chain lengths, were examined to gain some insight into their SAR (a summary of the structures and characterization of the synthetic glycopolymers can be found in Section 8.4). Several reference compounds were also used in the assays: a commercially available fucoidan from the brown seaweed Fucus Vesiculosus for direct comparison of the biological properties; the sulfated polysaccharides heparin and dextran sulfate for distinguishing the biological properties of fucoidan from those of sulfated polysaccharides in general; and polyacrylamide to rule out possible interference from the polymer backbone.

\subsection{Antiviral Properties}

Sulfated polysaccharides, including fucoidan, have shown broad spectrum antiviral properties against enveloped viruses, such as HSV-1 [106-108]. HSV-1 infection in the eye, particularly the cornea, is the most frequently occurring serious eye infection caused by a virus in developed countries and the leading cause of corneal blindness 
caused by an infectious agent $[109,110]$. It was therefore interesting to study the inhibitory effect of the glycopolymers on HSV-1 infection in human corneal endothelial cells (HCECs). As a first step, the cytotoxicity of the glycopolymers towards the HCECs was evaluated.

\subsubsection{Glycopolymer Cytotoxicity (Paper I)}

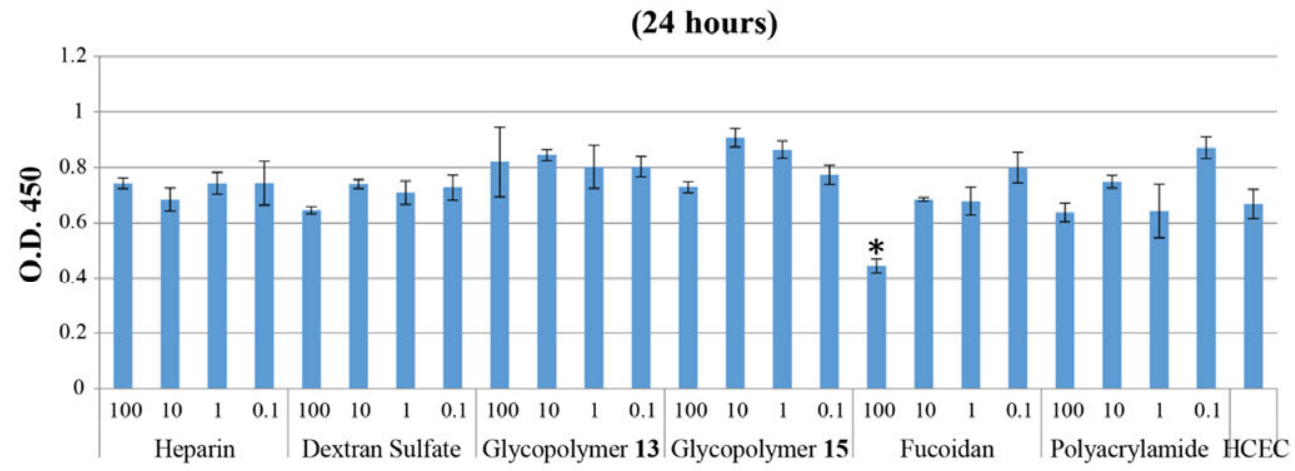

Concentration $(\mu \mathrm{g} / \mathrm{mL})$

(48 hours)

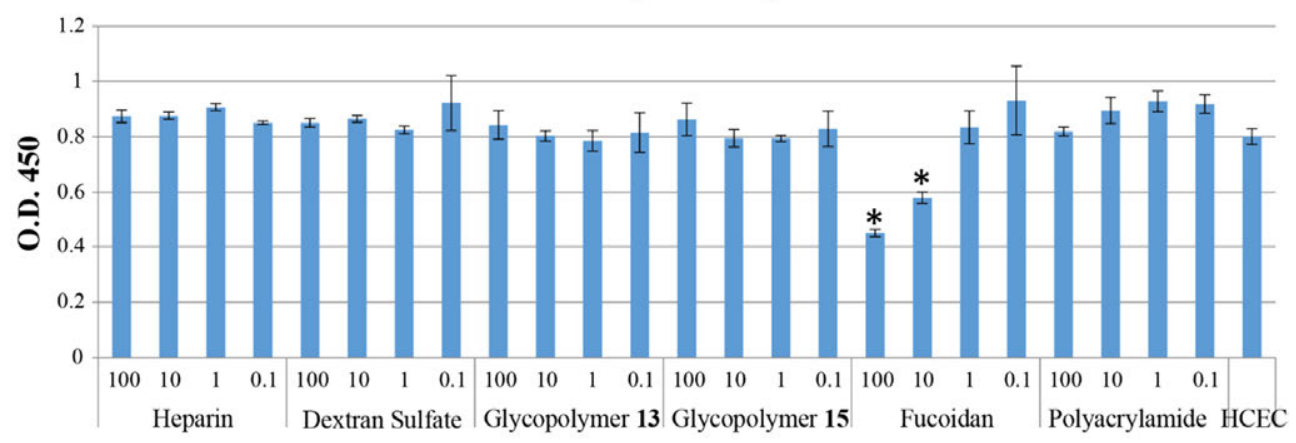

Concentration $(\mu \mathrm{g} / \mathrm{mL})$

Figure 4.1. Cell viability by WST-1 assay of HCECs treated with glycopolymers $\mathbf{1 3}$ or $\mathbf{1 5}$ or reference compounds. Adapted with permission from [83]. Copyright 2014 American Chemical Society.

Cytotoxic compounds causes an unwanted decrease in cell viability (the ability to actively grow and divide). The cytotoxicity was determined by treating the HCECs with the synthetic glycopolymers and the reference compounds and adding a tetrazolium compound, WST-1. In this standardized assay, the tetrazolium ring in WST-1 is reduced to its corresponding formazan by cellular oxidoreductases which gives rise to a 
colorimetric change. This reduction is dependent on cells actively producing these reductive enzymes. Thus, cells with low metabolism or reduced cell viability, e.g. from treatment with a cytotoxic compound, will not cause a colorimetric change. Loss of colorimetric response from reduced WST-1 is therefore a direct indicator of cytotoxicity [111].

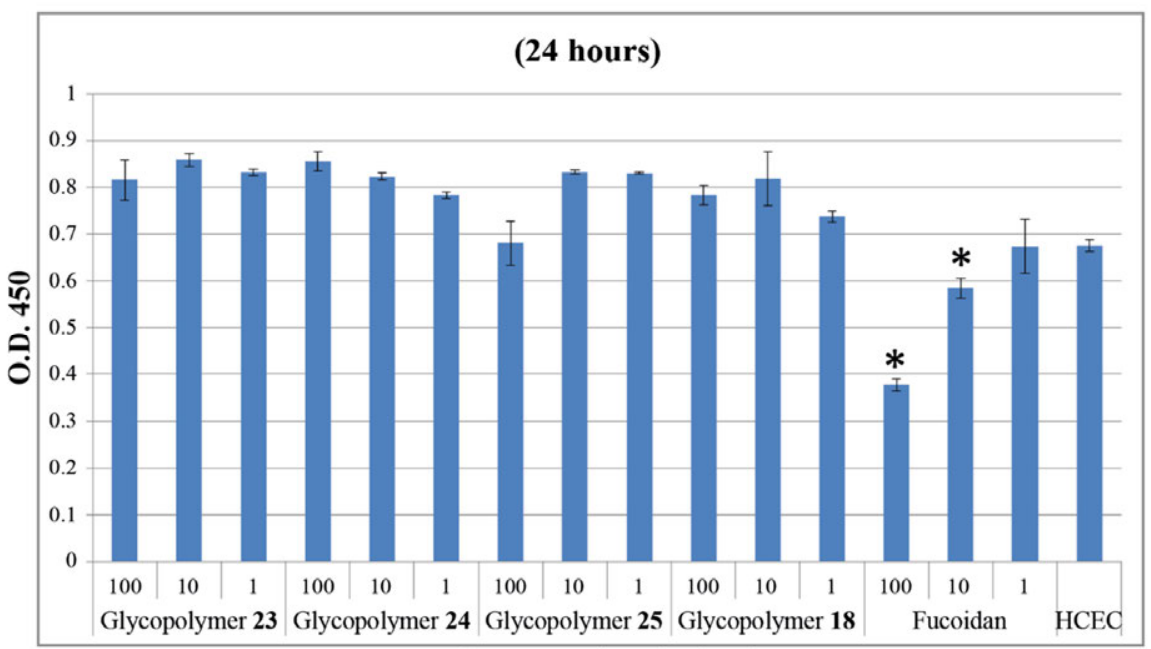

Concentration $(\mu \mathrm{g} / \mathrm{mL})$

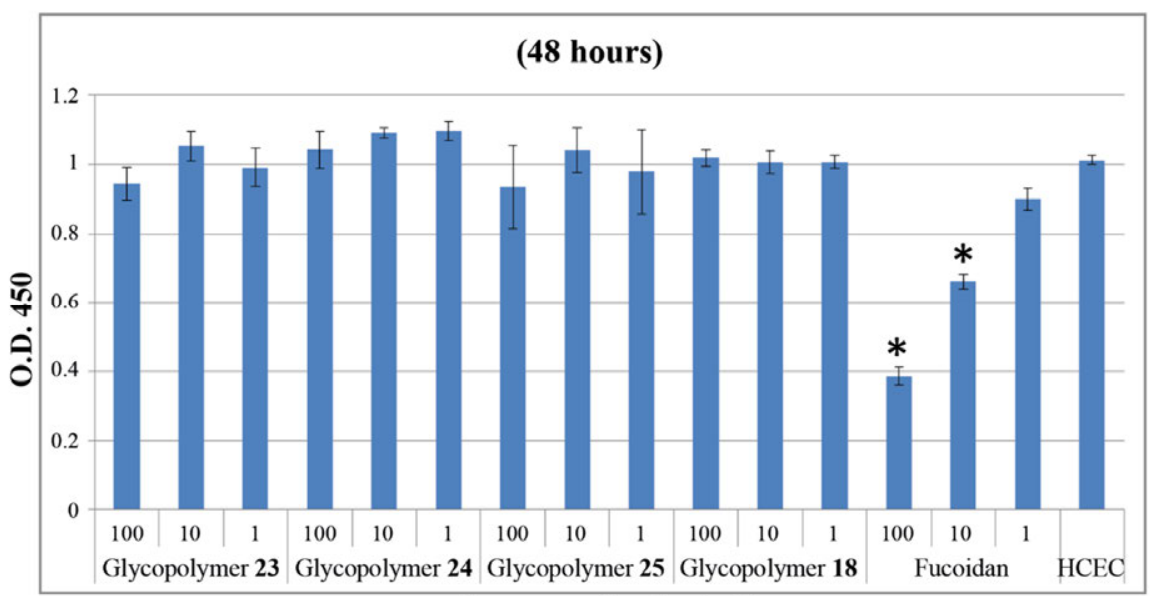

Concentration $(\mu \mathrm{g} / \mathrm{mL})$

Figure 4.2. Cell viability by WST-1 assay of HCECs treated with glycopolymers $\mathbf{1 8}, \mathbf{2 3}, \mathbf{2 4}$, or $\mathbf{2 5}$ or fucoidan.

In Paper I the cytotoxicity of the non-sulfated glycopolymer $\mathbf{1 3}$ and its sulfated derivative glycopolymer $\mathbf{1 5}$, along with the reference compounds, were tested after 24 and 48 hours (see Figure 4.1). As expected neither of the heparin, dextran sulfate, nor 
polyacrylamide references showed any decrease in cell viability. The same results were observed when the HCECs were treated with glycopolymers 13 or 15. Somewhat surprisingly, though, the fucoidan reference showed toxicity by decreasing the cell viability at $100 \mu \mathrm{g} / \mathrm{mL}$, after 24 and 48 hours, and at $10 \mu \mathrm{g} / \mathrm{mL}$ after 48 hours. The cause of this cytotoxicity remains unknown, but might stem from impurities as the commercially available fucoidan reference is labeled as a crude compound and was not further purified before use in the biological assays.

Later studies of the cytotoxicity of the sulfated high $M_{n}$ glycopolymer $\mathbf{1 8}$ and the sulfated low $M_{n}$ glycopolymers $\mathbf{2 3}, \mathbf{2 4}$, and $\mathbf{2 5}$ (see Figure 4.2) displayed results similar to those obtained by treating HCECs with glycopolymer 13 or 15. In short, neither of the synthetic glycopolymers displayed any decrease in cell viability and were thus non-cytotoxic. The fucoidan reference, though, again displayed decreased cell viability.

These results demonstrated, by the lack of cytotoxicity, that the synthetic glycopolymers exhibit good biocompatibility towards HCECs. The antiviral properties of the glycopolymers could hence be examined.

\subsubsection{Antiviral Fucoidan}

The antiviral properties of sulfated polysaccharides are highly dependent on the presence of sulfate ester groups, where the higher the DS, the better the antiviral potency $[112,113]$. Sulfated polysaccharides with high average molecular weight generally display better antiviral properties than those with low average molecular weight. Low molecular weight sulfated polysaccharides can possess strong antiviral properties though, especially when the DS is high [113]. Although fucoidan exhibit antiviral properties both in vitro and in vivo, they have shown no direct (or on a few occasions very weak) virucidal activity $[1,112,114]$.

The general mechanism of action of antiviral sulfated polysaccharides is exerted by inhibiting virus entry into the host cell $[1,106,107,112]$. HSV-1 gains entry into host cells by fusion of the virus envelope and the cell membrane through a complex process [108]. This process is initiated by specific electrostatic interactions between positively charged regions of viral envelope glycoproteins and negatively charged heparan sulfate, or less commonly chondroitin sulfate, chains on host-cell-surface receptors. By mimicking the heparan sulfate chains on the cell-surface receptors, sulfated polysaccharides can inhibit HSV-1 entry into host cells by competitive binding to the viral envelope glycoproteins. However, the antiviral mechanism of action of fucoidan 
has shown to be somewhat more complex. Activity against HSV-1 may depend not only on the charge density, i.e. the DS, but also on the structure of the uncharged regions of a sulfated polysaccharide, e.g. the methyl groups on the fucosides in fucoidan seem important for binding to HSV-1 glycoprotein C through interaction with its hydrophobic pocket [113]. Fucoidan has also shown to enhance the immune responses against HSV-1 infection by stimulating the phagocytic activity of macrophages in vitro and increase the activity of cytotoxic $\mathrm{T}$ lymphocytes, which are critical for the control and spread of a HSV-1 infection, in mice [108].

\subsubsection{Antiviral Glycopolymers (Paper I)}
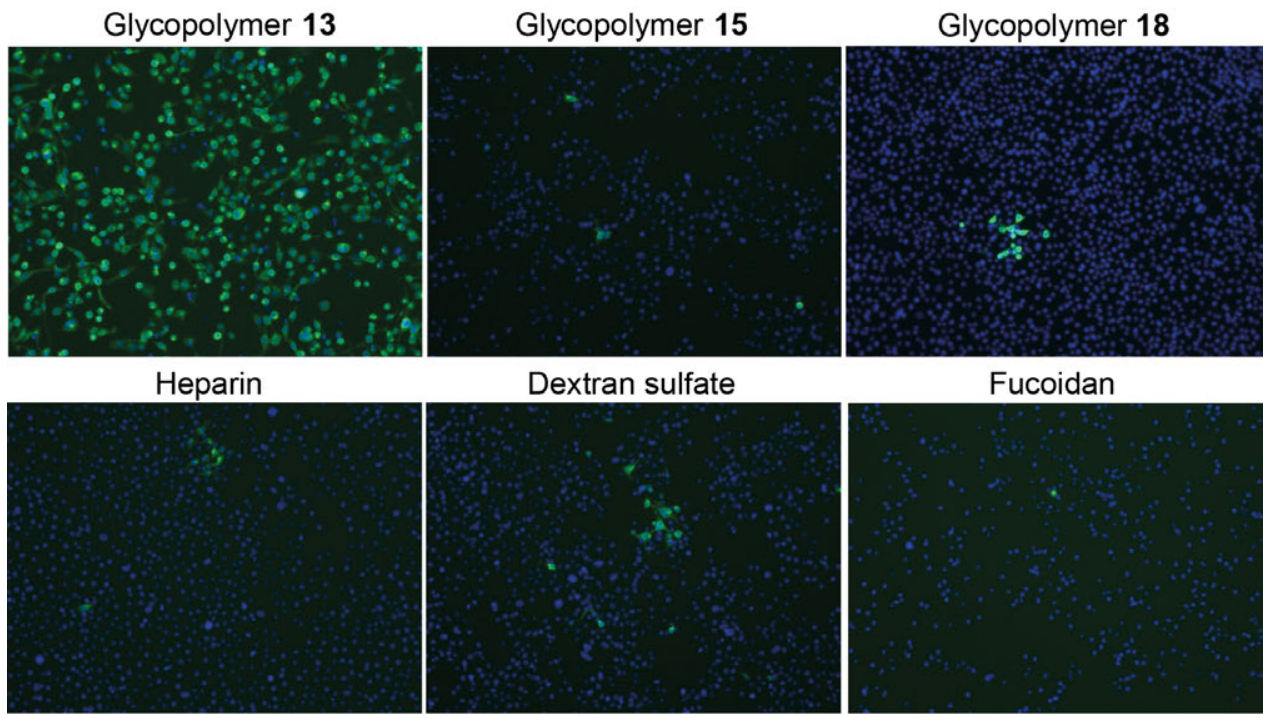

Fucoidan
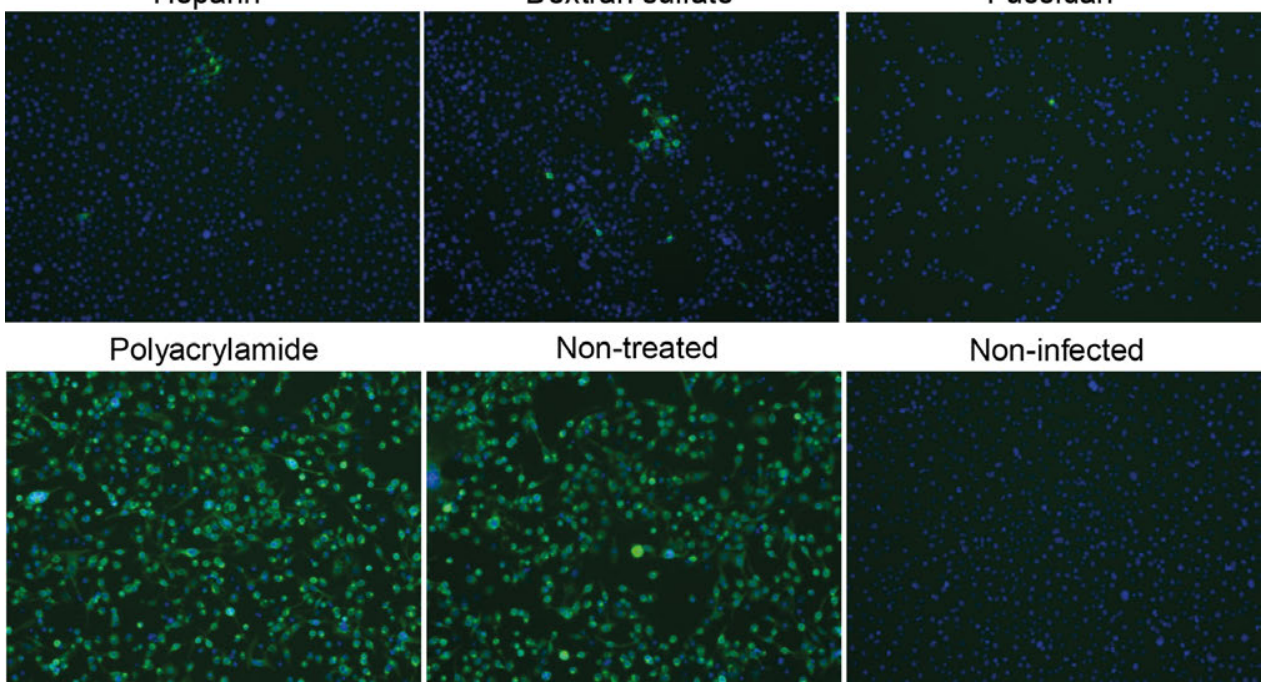

Non-infected

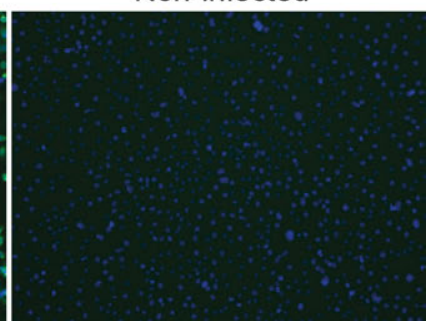

Figure 4.3. Inhibitory effect of glycopolymers 13, 15, and 18 and reference compounds on HSV-1 infection of HCECs. Infected cells stained with HSV-1/2 antibody (green) and HCEC nuclei stained with DAPI (blue). Adapted with permission from [83]. Copyright 2014 American Chemical Society. 
The antiviral properties of non-sulfated glycopolymer 13, sulfated glycopolymer 15, and all reference compounds are described in Paper I. At a later stage, the sulfated glycopolymer 18 was examined using the same assays. The initial studies on the inhibitory effect on HSV-1 infection were performed on a culture of HCECs by adding the glycopolymers to the culture, which was then infected with HSV-1. The compounds were added in doses of $100 \mu \mathrm{g} / \mathrm{mL}$, except for glycopolymer 18 which was added in doses of $50 \mu \mathrm{g} / \mathrm{mL}$. In accordance with the literature, the results showed that all sulfated polysaccharides (heparin, dextran sulfate, and fucoidan) blocked the viruses from infecting the HCECs (see Figure 4.3). The sulfated glycopolymers $\mathbf{1 5}$ and $\mathbf{1 8}$ displayed similar antiviral properties, whereas the non-sulfated glycopolymer 13 showed no antiviral activity. From these results we concluded that sulfate esters are an essential part of the structure of the antiviral glycopolymers. The polyacrylamide reference also displayed no antiviral properties indicating the backbone in itself do not affect the biological properties of the glycopolymers. This in turn showed that the issue with the backbone, seen with glycopolymer 6 (see Section 3.2), might have been resolved. All compounds, except for glycopolymer $\mathbf{1 8}$, were also added in doses of $10 \mu \mathrm{g} / \mathrm{mL}$ with no significant changes to the antiviral activity compared to the $100 \mu \mathrm{g} / \mathrm{mL}$ doses.

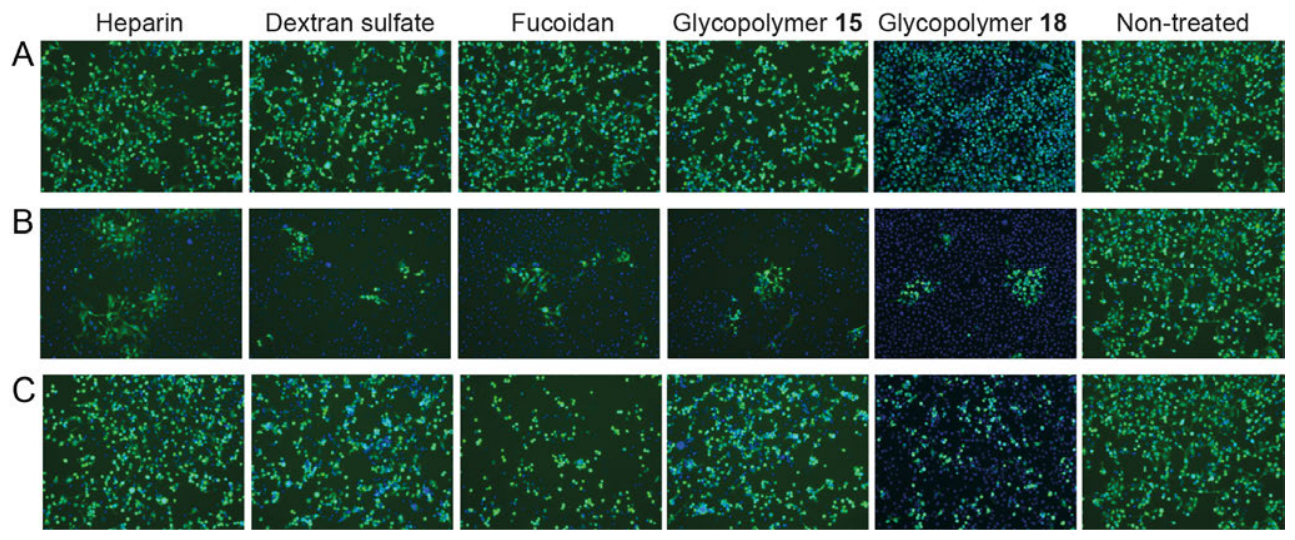

Figure 4.4. Inhibitory effect of glycopolymers 15 and 18 and reference compounds on HSV-1 infection of HCECs when; HCECs were pretreated with compounds before viral infection (A), compounds were added during the viral adsorption (B), or compounds were added after the viral adsorption (C). Infected cells stained with HSV-1/2 antibody (green) and HCEC nuclei stained with DAPI (blue). Adapted with permission from [83]. Copyright 2014 American Chemical Society.

In the initial assay the glycopolymers, or the reference compounds, were added to the cell culture in three different steps: first, they were added to the cells before the viral adsorption followed by washing; second, they were added during the viral infection; and 
third, they were added post-viral infection. To roughly examine the mechanism of action, the inhibitory effect of all the antiviral compounds from the first assay was studied by adding the compounds in only one of these three steps. Pre-treatment of the HCECs with any of the antiviral compounds, followed by a washing step, gave no results compared to non-treated HCECs (see Figure 4.4 A). Neither did treatment of already infected cells by adding the compounds post-viral adsorption (see Figure $4.4 \mathrm{C}$ ). However, adding the compounds to the culture in the viral infection step showed significant reduction in infection compared to non-treated cells (see Figure 4.4 B). These results strongly indicate that sulfated glycopolymers $\mathbf{1 5}$ and $\mathbf{1 8}$, and the reference polysaccharides, exert their antiviral properties by binding to the viral particles and thus interfere with viral entry of the HCECs, which is in accordance with the proposed general antiviral mechanism of sulfated polysaccharides (see Section 4.1.2). The lack of antiviral activity when pre-treating the HCECs with the antiviral compounds likely stems from removal of the compounds during the washing step, due to lack of interactions between the compounds and the HCECs.

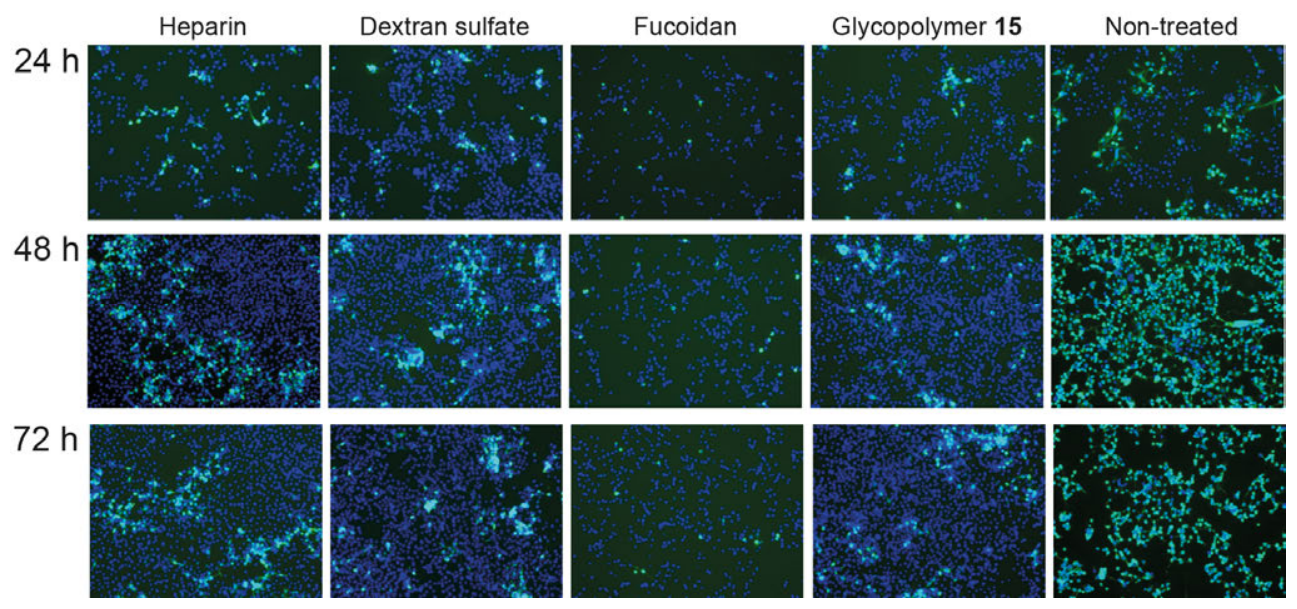

Figure 4.5. Inhibitory effect of glycopolymer 15 and reference compounds on HSV-1 spreading at 24, 48, and 72 hours when compounds were added 1 hour after infection of HCECs. Infected cells stained with HSV-1/2 antibody (green) and HCEC nuclei stained with DAPI (blue). Adapted with permission from [83]. Copyright 2014 American Chemical Society.

In both these assays the multiplicity of infection (MOI) was set to 1.0. To closer examine the effect of the antiviral compounds on viral spreading, MOI was lowered to 0.1 and the compounds added 1 hour post-infection. After 48 hours, all HCECs were infected without treatment (see Figure 4.5). However, treatment with sulfated glycopolymer 15, 
or any of the reference polysaccharides, greatly reduced the number of infected cells after both 48 and 72 hours compared to the non-treated cells. The presence of infected cells after 72 hours indicates glycopolymer $\mathbf{1 5}$ is not a virucidal compound, but although the viral spreading did not stop completely it was slowed down significantly. These results further strengthens the notion that glycopolymer $\mathbf{1 5}$ exerts its antiviral activity by interfering with the viral entry of the cells.

The antiviral studies showed the sulfated glycopolymers exhibit antiviral properties comparable to fucoidan regarding both potency and mechanism of action. However, the antiviral activity was also similar to those of heparin and dextran sulfate. Thus, no clear distinction could be made between the biological properties of fucoidan and the other sulfated reference polysaccharides from these assays.

\subsection{Platelet Activating Properties}

\subsubsection{Platelet Activating Fucoidan}

The anticoagulant properties of fucoidan were discovered early on in 1957 and has since been extensively studied. When Dürig et al reported concentration-dependent platelet aggregating, i.e. procoagulant, properties of fucoidan from Fucus vesiculosus, this was in direct contrast to its anticoagulant properties. In this report, an inverse relationship between the platelet activating and the anticoagulant properties was observed. Fucoidan fractions of different molecular weights were studied, with the high molecular weight fractions showing maximum platelet aggregation [115]. Later studies have demonstrated superior procoagulant properties of fucoidan, compared to other sulfated polysaccharides [116], and have also paid closer attention to the SAR. Zhang et al concluded that a minimum of 0.5 sulfate esters per fucoside unit and a minimum chain length of $\sim 70$ saccharide units were required for fractions from Fucus vesiculosus to display procoagulant properties, in contrast to the anticoagulant properties which required a minimum chain length of $\sim 200$ saccharide units for full efficacy [117]. Their initial claim that the saccharide composition did not play a crucial role for the procoagulant activity was later revised when the same group compared procoagulant fucoidan from four different brown algae sources. This study demonstrated that monosaccharide composition, heterogeneity, and impurities (e.g. alginate) affect the procoagulant behavior of fucoidan [118].

Dürig et al claimed, in their groundbreaking paper, that platelet activation induced by fucoidan was a direct effect of binding to a fucoidan-binding site on the platelet 
membrane [115]. Even though later studies demonstrated fucoidan to have procoagulant properties even in platelet poor plasma, through inhibition of the anticoagulant protein tissue factor pathway inhibitor [116-118], the initial theory of a fucoidan-binding site on platelet membranes was confirmed when fucoidan showed agonistic activity for C-type lectin-like receptor 2 (CLEC-2) [119]. Alshehri et al concluded that platelet activation by fucoidan primarily stems from activation of CLEC- 2 and, to a lesser extent, glycoprotein VI (GPVI). This study also demonstrated binding of fucoidan to additional platelet surface receptors, but these interactions did not induce platelet activation [120]. However, platelet activation induced by fucoidan is likely a complex process and other studies showed fucoidan to interact with platelet latent transforming growth factor- $\beta 1$ [121] and P-selectin on activated platelets [122].

\subsubsection{Platelet Activating Glycopolymers (Paper I and III)}
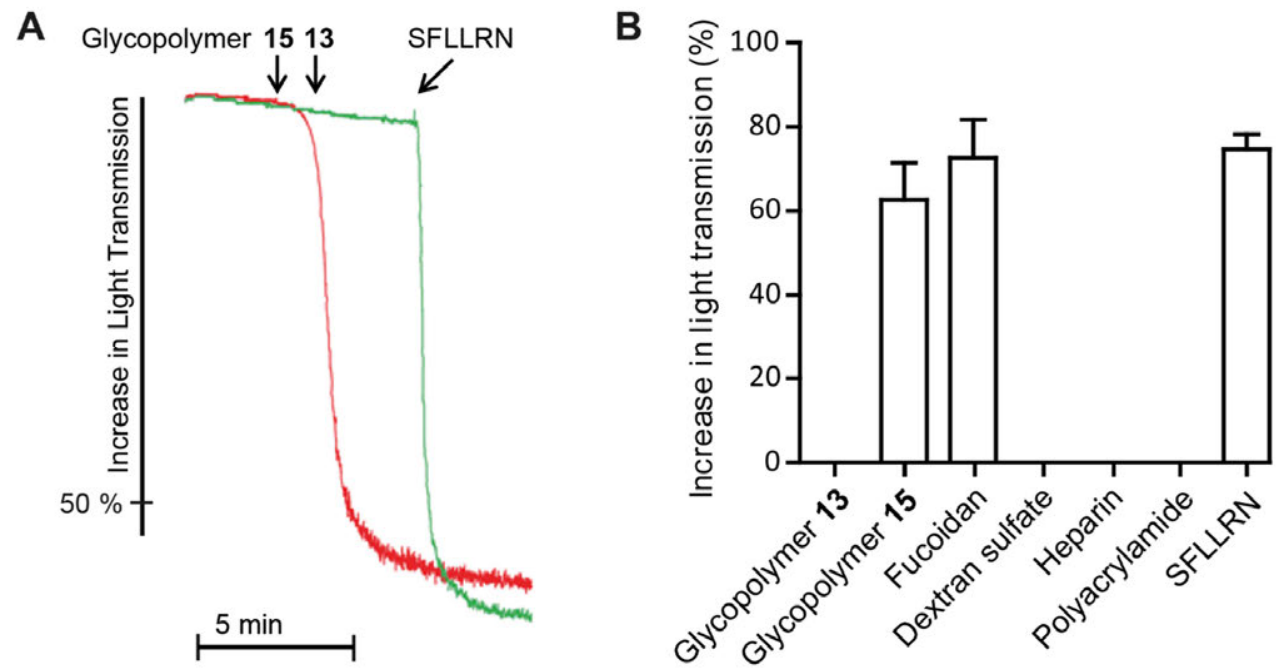

Figure 4.6. Platelet aggregating properties of glycopolymers $\mathbf{1 3}$ and $\mathbf{1 5}$ determined by aggregometric analysis: The increase in light transmission when glycopolymer $\mathbf{1 3}(100 \mu \mathrm{g} / \mathrm{mL}$, green traces) or $\mathbf{1 5}$ $(100 \mu \mathrm{g} / \mathrm{mL}$, red traces) was added to a suspension of isolated human platelets (A). Summary of the increase in light transmission induced by all compounds tested (B). Thrombin receptor agonist hexapeptide SFLLRN was used as platelet aggregation reference. Adapted with permission from [83]. Copyright 2014 American Chemical Society.

As the platelet aggregating properties of fucoidan are superior compared to other sulfated polysaccharides, it was interesting to study if the synthetic sulfated 
glycopolymer 15 displayed similar properties. Non-sulfated glycopolymer 13 was also tested to determine the influence of the sulfate esters on the platelet aggregating properties. These studies (which are described in Paper I) were performed by aggregometric analysis, in which the glycopolymers and reference compounds were added to a solution of isolated human platelets. Aggregation of platelets led to an increase in light transmission, which was then measured to quantify the platelet activating properties. Non-sulfated glycopolymer $\mathbf{1 3}$ showed no sign of inducing platelet aggregation and the platelets responded normally to activation via thrombin receptor-activating peptide SFLLRN, which was added to the glycopolymer 13-treated platelet solution (see Figure 4.6 A, green traces). In contrast, the sulfated glycopolymer 15 induced an immediate platelet aggregation response in doses of $100 \mu \mathrm{g} / \mathrm{mL}$ (see Figure 4.6 A, red traces), but the effect could be detected down to doses of $0.3 \mu \mathrm{g} / \mathrm{mL}$. The reference fucoidan induced an expected aggregation of platelets whereas dextran sulfate, heparin, and polyacrylamide showed no platelet aggregating properties (see Figure 4.6 B).

These results clearly demonstrate that only the sulfated glycopolymer $\mathbf{1 5}$ and fucoidan have the ability to induce platelet aggregation. As this assay distinguished the biological properties of glycopolymer $\mathbf{1 5}$ from those of dextran sulfate and heparin, we concluded that glycopolymer 15 possesses fucoidan-mimetic properties, making it an FMG. The lack of response from the polyacrylamide indicated the backbone of the glycopolymers have no impact on the biological properties, and thereby showed the problem associated with glycopolymer 6 (see Section 3.2) had been solved. Furthermore, both the antiviral and platelet activation assays demonstrated that sulfate esters are necessary to obtain fucoidan-mimetic biological properties, as the non-sulfated glycopolymer $\mathbf{1 3}$ showed none of the biological properties displayed by the sulfated glycopolymer 15. Also, the difference between fucoidan, dextran sulfate and heparin lies in the formers high content of L-fucosides. It was therefore concluded that pendant sulfated L-fucosides are the key structural elements to give polymers fucoidan-mimetic properties, thus making them FMGs.

Following the successful synthesis of glycopolymers with different $M_{n}$ via RAFT polymerization, the influence of the polymer chain length on the platelet aggregating properties could be studied (which is described in Paper III). The increase in light transmission from aggregometric analyses, upon treatment of platelets with the low $M_{n}$ FMG 23 or 25, was studied and compared to the results from the significantly larger FMG 18. Dose-response (weight/volume) curves of all three FMGs showed fairly similar results (see Figure $4.7 \mathrm{~A}$ ). These results demonstrated that higher molar 
concentrations are needed of low $M_{n}$ FMGs 23 and 25 to give the same platelet aggregation potency as the high $M_{n}$ FMG 18. This indicates that the platelet aggregation potency of the polymer chains primarily correlates to the number of available sulfated fucosides, i.e. the chain length. The slightly higher potency of high $M_{n}$ FMG 18, compared to low $M_{n}$ FMGs in equivalent doses (weight/volume), may be attributed to additional multivalent binding and/or cluster formation by the longer polymer chains. The results in Figure 4.7 A might, however, be affected by the presence of the minor products in FMGs 23 and 25 containing longer polymer chains.
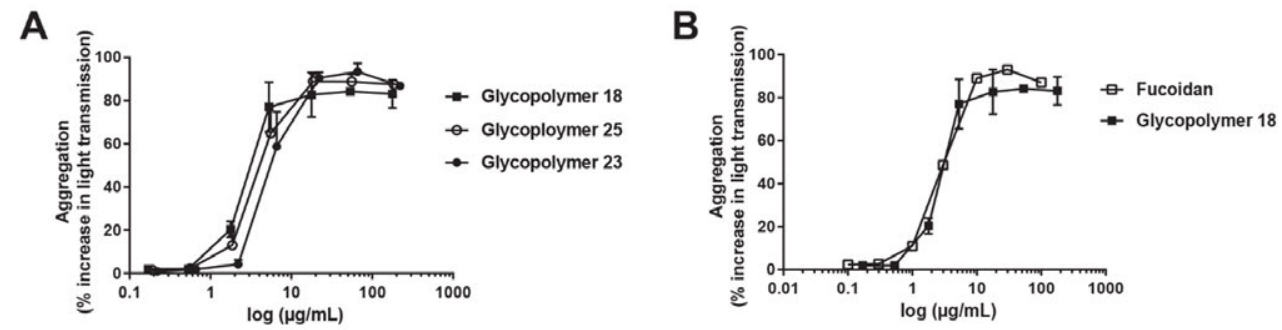

Figure 4.7. The platelet aggregating properties of synthetic FMGs determined by aggregometric analysis: Dose-response curves of glycopolymers 18, 23, and 25 (A). Dose-response curves of glycopolymer $\mathbf{1 8}$ and fucoidan (B). Adapted from [101] with permission from WILEY-VCH Verlag.

As reference, the platelet aggregating properties of FMG 18 were compared to those of fucoidan. Both compounds displayed almost identical dose-response curves (see Figure 4.7 B).

A

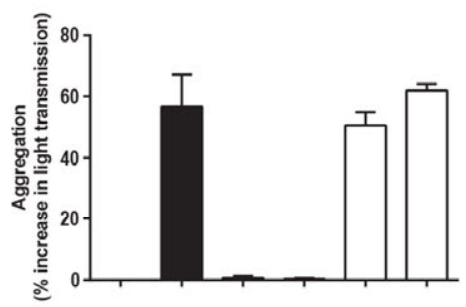

Glycopolymer $18(\mu \mathrm{g} / \mathrm{mL}) \quad 30$ Glycopolymer $16(\mu \mathrm{g} / \mathrm{mL})$

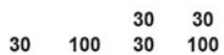

B

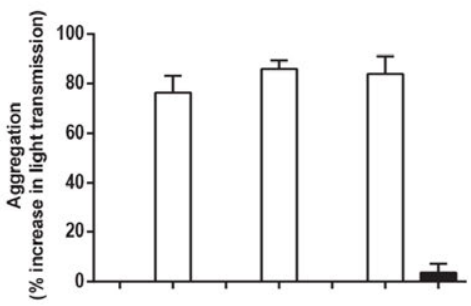

Glycopolymer $18(\mu \mathrm{g} / \mathrm{mL}) \quad 50 \quad 50$

Glycopolymer $25(\mu \mathrm{g} / \mathrm{mL})$ Glycopolymer $23(\mu \mathrm{g} / \mathrm{mL})$ Tirofiban $(\mu \mathrm{g} / \mathrm{mL})$

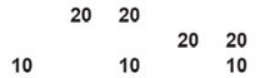

Figure 4.8. Characterization of FMG-induced platelet aggregation by aggregometric analysis: Aggregation induced by FMG 18 of platelets pre-treated with glycopolymer 16 (A). Inhibition of FMG-induced platelet aggregation by tirofiban (B). Adapted from [101] with permission from WILEY-VCH Verlag. 
It was shown in Paper I that non-sulfated glycopolymers do not induce platelet aggregation (see Figure 4.6). There was, however, the possibility that non-sulfated glycopolymers have an antagonistic effect on the platelet aggregation induced by their sulfated derivatives, i.e. the FMGs. In Paper III, this possibility was tested by pre-treating platelets with 30 or $100 \mu \mathrm{g} / \mathrm{mL}$ of non-sulfated glycopolymer $\mathbf{1 6}$. Those platelets were then treated with $30 \mu \mathrm{g} / \mathrm{mL}$ of the sulfated derivative of glycopolymer $\mathbf{1 6}$, FMG 18. The pre-treatment did not affect the platelet aggregation induced by FMG 18 (see Figure $4.8 \mathrm{~A}$ ), which further confirmed the necessity of sulfate esters to achieve fucoidan-mimetic properties. Another phenomenon not investigated in Paper I was the possibility that FMG-induced platelet aggregation is caused by agglutination, rather than through intracellular signaling. Agglutination is the process where platelets adjacent to each other are linked, e.g. by large macromolecules, causing aggregation without the intracellular signaling transduction seen when the aggregation is caused by platelet activation. A key step in normal platelet aggregation is the formation of the fibrinogen-binding glycoprotein complex integrin $\alpha_{\mathrm{II}} \beta_{\mathrm{III}}[123,124]$. Several drugs, e.g. tirofiban, prevents platelet aggregation by inhibiting activation of integrin $\alpha_{\text {IIb }} \beta_{\text {III }}$ [123]. Such drugs would, however, have no effect on preventing aggregation of platelets via agglutination. To exclude the possibility that FMGs cause platelet aggregation via agglutination, platelets were pre-treated with the integrin $\alpha_{\mathrm{II}} \beta_{\mathrm{III}}$ antagonist tirofiban and then treated with FMG 18, 23, or $\mathbf{2 5}$ (also described in Paper III). The presence of tirofiban clearly abolished the platelet aggregation induced by FMGs (see Figure 4.8 B). This confirmed that platelet aggregation stimulated by FMGs is not caused by agglutination, but through platelet activation.

Several changes occur on the surface when platelets are activated. Apart from the activation of integrin $\alpha_{\mathrm{IIb}} \beta_{\mathrm{III}}, \mathrm{P}$-selectin, and lysosomal-associated membrane protein-3 (LAMP-3) are, for instance, expressed through secretion [125]. To compare surface changes associated with platelet activation by fucoidan and FMG 18 a flow cytometric protocol was used with the snake venom convulxin, a GPVI agonist [126], as positive control (described in Paper III). The surface expression of P-selectin and LAMP-3 was measured, along with the activation of integrin $\alpha_{\text {IIb }} \beta_{\text {III }}$ (indirectly measured by binding of the PAC-1 antibody [127]). The results showed that FMG 18 induced surface changes in dose intervals almost identical to those of fucoidan (see Figure 4.9). Furthermore, these changes occurred in the same dose intervals where both FMG 18 and fucoidan stimulated platelet aggregation (see Figure $4.7 \mathrm{C}$ ). 


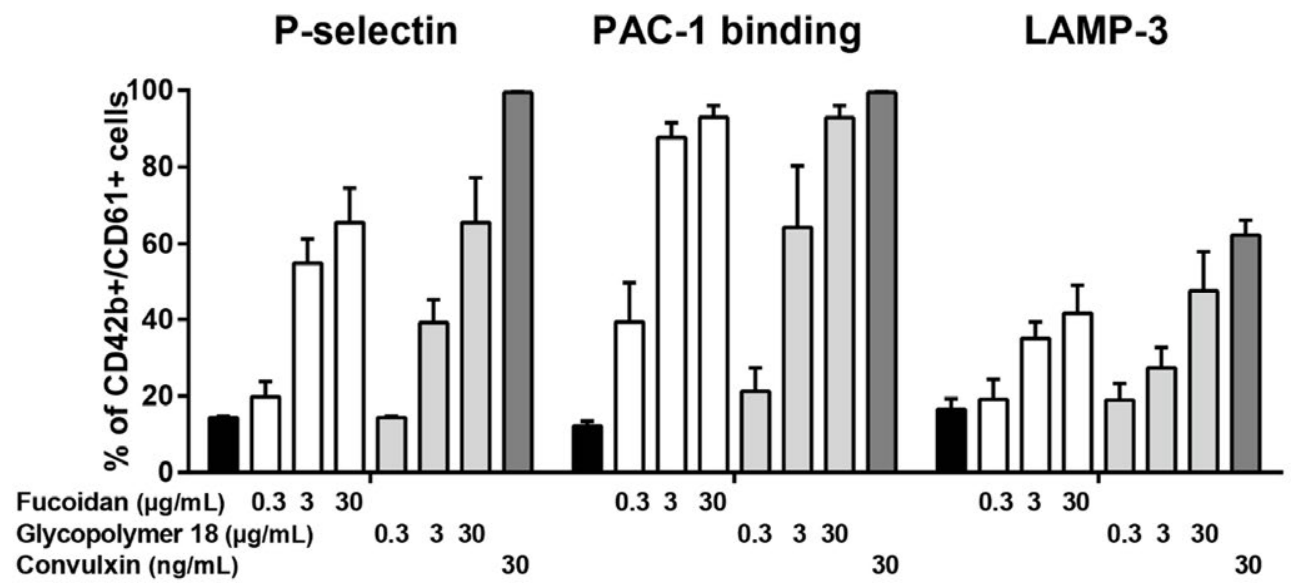

Figure 4.9. Surface changes on platelets activated by fucoidan, glycopolymer 18, or convulxin analyzed by flow cytometry. Platelets were identified as CD42b and CD61 positive cells. GPVI agonist convulxin was used as positive control. Adapted from [101] with permission from WILEY-VCH Verlag.

On a molecular basis platelet activation includes complex intracellular signaling, e.g. a large number of both low, intermediate, and high molecular weight proteins are subjected to protein tyrosine phosphorylation. This occurs in a time-dependent fashion, specifically through relatively clear time waves [128].
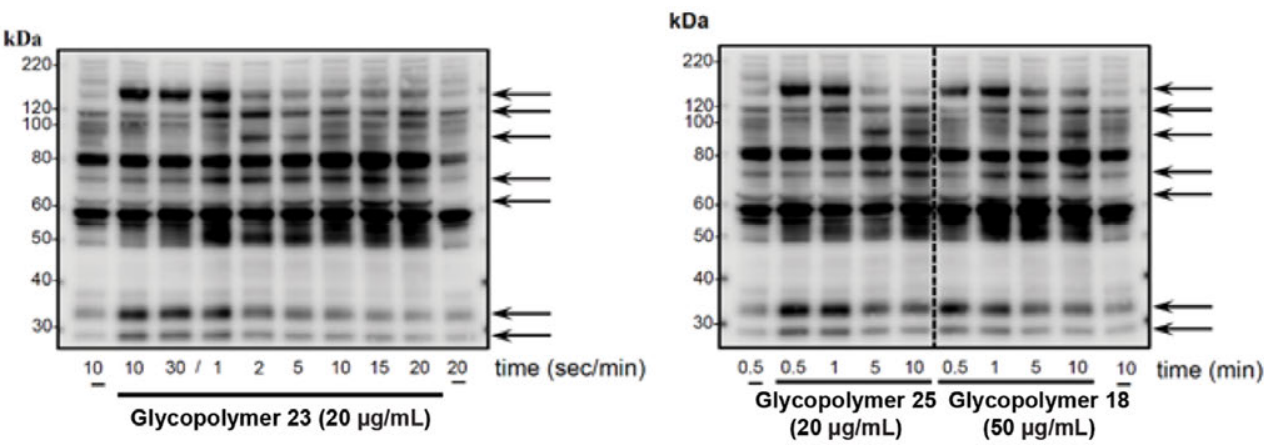

Figure 4.10. Western blotting analyses of protein tyrosine phosphorylation in platelets exposed to glycopolymers 18, 23, and 25. Adapted from [101] with permission from WILEY-VCH Verlag.

To study the intracellular signaling induced by platelet activating FMGs, Western blotting analyses of protein tyrosine phosphorylation were performed on platelets treated with either FMG 18, 23, or 25 (see Figure 4.10). This is described in Paper III. The results clearly showed a wide range of proteins, of different molecular weights, 
were subjected to phosphorylation in distinct time waves (indicated by arrows in Figure 4.10). Even though it remains to be investigated which specific proteins are phosphorylated, the results showed that FMGs induce platelet aggregation via intracellular signaling.

The studies performed in Paper III collectively concluded that FMGs induce platelet aggregation through platelet activation, not agglutination, via intracellular signaling. FMGs additionally induce platelet aggregation and platelet surface changes in dose-responses almost identical to those of fucoidan. Compared to fucoidan though, FMGs have homogeneous structures with significantly better reproducibility. FMGs are thus suitable as tools for studying the molecular and intracellular processes associated with the unique platelet activating properties of fucoidan. 


\section{Amphiphilic FMGs (Paper IV)}

\subsection{Amphiphiles in Biomedical Applications}

In nature, certain lipids, such as phospholipids, are important amphiphilic small molecules. In sufficient concentration they readily undergo self-assembly to form (depending on the hydrophobic/hydrophilic ratio [129,130]) micelles, bilayers or vesicles [131]. If the latter consist primarily of phospholipids, these self-assembled structures are known as liposomes [129,131]. Semisynthetic amphiphiles have been produced through formation or modification of polypeptides, polynucleotides, or polysaccharides [130]. The most common way to yield amphiphiles today is, perhaps, to synthesize copolymers. These are primarily block copolymers, with at least one hydrophilic and one hydrophobic block. Amphiphilic block copolymers tend to self-assemble, as seen with amphiphilic lipids, into micelles or vesicles. The latter are generally referred to as polymerosomes [130-132]. The advances made in various RDRP techniques have yielded a wide range of different amphiphilic block copolymers, e.g. cross-linked polymerosomes and polymers of various architectures that self-assemble into different morphologies [130].

Both liposomes and polymerosomes have been used as simple cell models to examine intricate processes over very complex biological cell membranes, e.g. cellular uptake by endocytosis [131]. The use of amphiphiles as delivery systems is the most explored biomedical application, though, as liposomes and amphiphilic polymers can encapsulate 
both hydrophobic, hydrophilic, and amphiphilic cargos [130-132]. Due to their biocompatibility, biodegradability, and relatively low immunogenicity, liposomes have been used to deliver enzymes, genetic material, drugs, and other small molecules [129]. The enhanced mechanical and chemical stability of polymerosomes, compared to liposomes, make them a versatile class of compounds for delivery of, e.g., drugs and genes. Amphiphilic polymers with responsive and/or reactive groups have yielded delivery systems responsible to, and thus releasing their cargo under influence of, external stimuli such as light or changes in $\mathrm{pH}$, temperature or redox conditions [130-132]. Polymerosomes have also been used as vesicular nano-reactors loaded with either enzymes, catalyzing reactions involving extravesicular compounds $[130,132]$, or prodrugs, which are selectively converted to the active compound only under specific chemical or biological conditions [130].

\subsection{Synthesis of Amphiphilic FMGs}

\subsubsection{Early Synthetic Work}

Due to their biocompatibility and inherent biological activity, FMGs were early on deemed as suitable material to be converted into amphiphiles for applications as, e.g., drug delivery agents. The first strategy to convert FMGs into amphiphiles was to partially methacrylate the sulfate esters and/or residual hydroxyl groups on the pendant $\alpha$-L-fucosides. The alkenes on the methacrylate functionality would then be readily available for thiol-ene reactions from thiol-containing drugs and/or thiocholesterol, with primarily the latter giving the glycopolymers amphiphilic properties. To study the self-assembly of these amphiphilic glycopolymers, a methacrylated glycopolymer functionalized with only thiocholesterol was chosen as the first target polymer.

At the start of these efforts, glycopolymers 16 and 18 had just been synthesized. These were deemed suitable for the application in mind due to their relatively long chain lengths and low $Ð$. In the first attempts to synthesize amphiphilic glycopolymers, $O$-sulfated glycopolymer 18 was to be methacrylated (see Scheme 5.1). A reaction in water under basic conditions using glycidyl methacrylate (GM), as the methacrylate source, and tetrabutylammonium bromide (TBAB), as phase-transfer catalyst, had previously been successful in the methacrylation of polysaccharides [133-135]. However, when methacrylating glycopolymer 18 these conditions left impurities of TBAB and caused degradation of the pendant sulfated $\alpha$-L-fucosides. Milder conditions, previously used for sulfated polysaccharides [136], were examined using only GM in a neutral phosphate-buffered saline (PBS) buffer ( $\mathrm{pH}$ 7.4). Although this approach left no 
impurities and caused no degradation, the degree of methacrylation was too low to be definitely spotted on ${ }^{1} \mathrm{H}$ NMR.

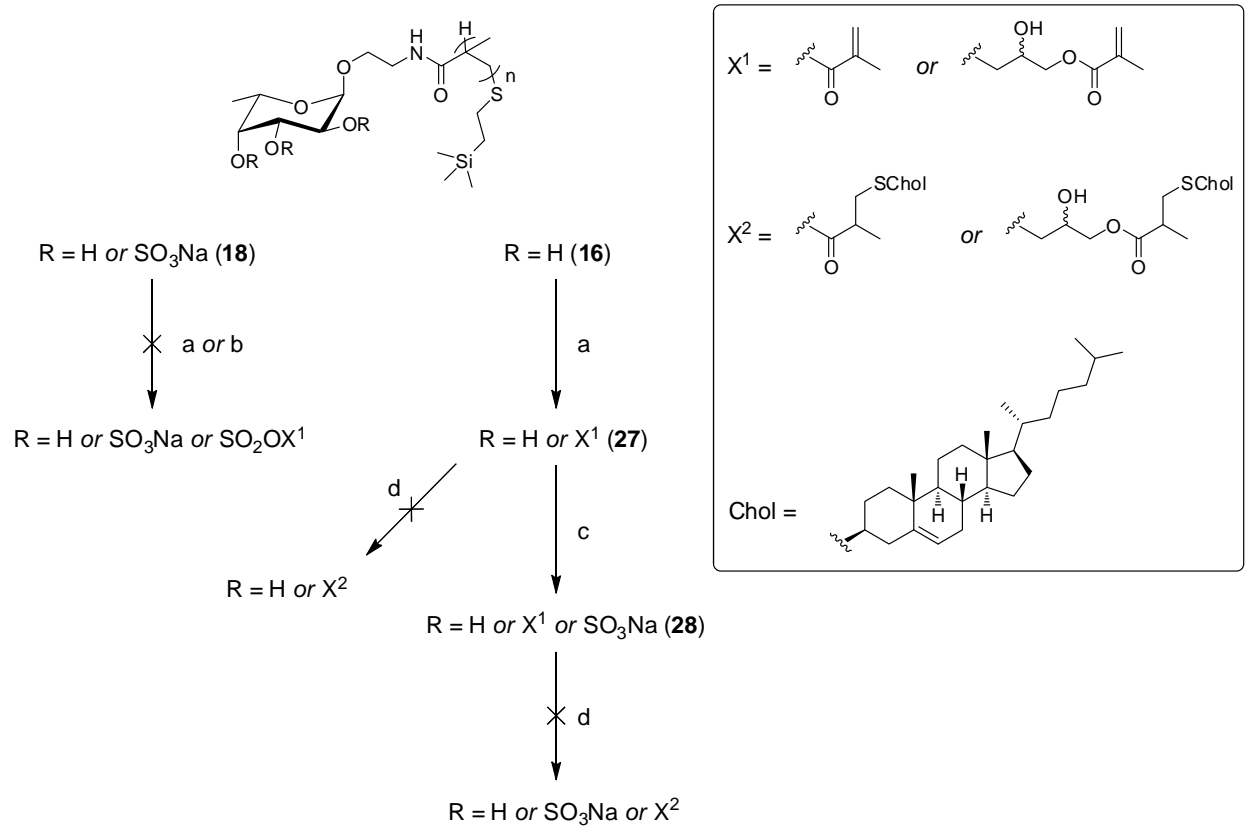

Scheme 5.1. Attempted synthesis of thiocholesterol-coupled glycopolymers. Reagents and conditions: (a) GM, Et $t_{3} \mathrm{~N}, \mathrm{TBAB}, \mathrm{H}_{2} \mathrm{O}$, rt, $24 \mathrm{~h}-6$ days; (b) GM, PBS buffer ( $\mathrm{pH}$ 7.4), rt, 2 days;

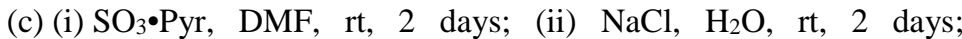
(d) Thiocholesterol, EtOAc, PBS buffer (pH 7.4), rt, $24 \mathrm{~h}-7$ days.

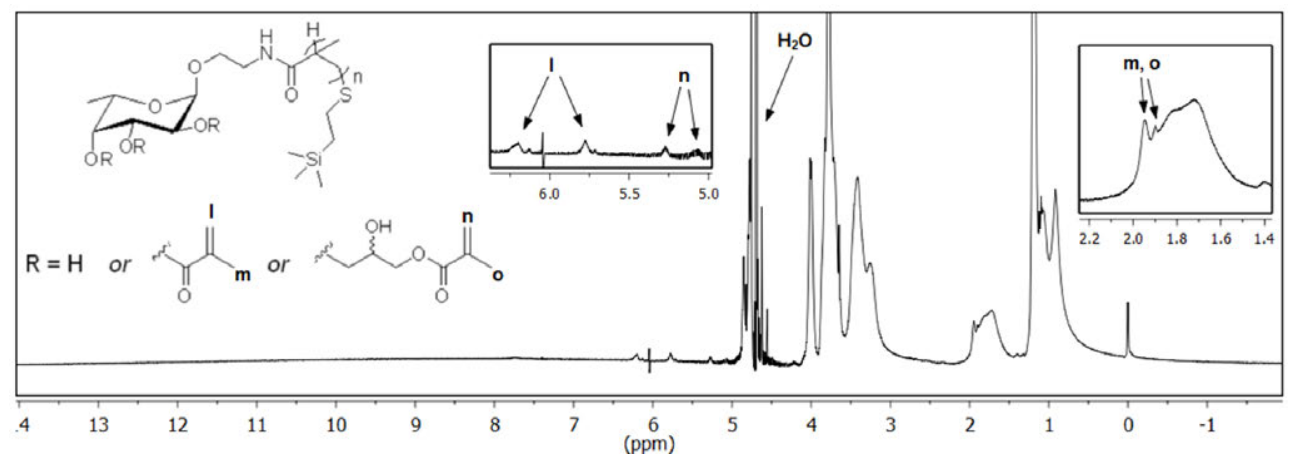

Figure 5.1. ${ }^{1} \mathrm{H}$ NMR spectrum of glycopolymer 27 in $\mathrm{D}_{2} \mathrm{O}, 300 \mathrm{MHz}$, detailing the methacrylate peaks. 
To avoid the issues, caused by the presence of sulfate esters, glycopolymer $\mathbf{1 6}$ was chosen as the new compound to be methacrylated. Using basic conditions with GM and TBAB turned out to be successful this time and yielded methacrylated glycopolymer $\mathbf{2 7}$ (see Scheme 5.1), bearing 5-8 \% degree of methacrylation as determined by peak integration in ${ }^{1} \mathrm{H}$ NMR (see Figure 5.1). Increasing the reaction time from 24 hours up to 6 days did not increase the percentage methacrylated hydroxyl groups and repeated purifications by dialysis turned out to decrease the degree of methacrylation.

The residual hydroxyl groups on the methacrylated glycopolymer 27 were then partially $O$-sulfated by the same procedure that was used to give glycopolymer 18. Ion-exchange by $\mathrm{NaHCO}_{3}$, however, turned out to cause loss of, or decrease in, degree of methacrylation. Eventually, ion-exchange by treatment with excess $\mathrm{NaCl}$ in water turned out to give the desired $O$-sulfated methacrylated glycopolymer 28. As this ion-exchange method actually gave less impurities, than the one previously used, it became the method of choice from this point on. Full experimental details for compounds 27 and 28 can be found in Section 8.3. To furnish the thiocholesterolcoupled FMG, glycopolymer 28 was dissolved in PBS buffer (pH 7.4) and thiocholesterol in ethyl acetate was added. This yielded no reaction, even after 7 days. Hypothesizing that the sulfate esters caused steric and electrostatic repulsion of the thiocholesterol, attempts were made to couple glycopolymer 27 with thiocholesterol instead under the same conditions. Unfortunately, no reaction was observed in this reaction either. Ultimately, the attempts to synthesize amphiphilic FMGs by thiol-ene chemistry with methacrylated glycopolymers had to be abandoned.

The next attempted strategy for synthesizing amphiphilic FMGs was to produce block copolymers, as a result of the successful development of FMGs via RAFT polymerization (see Section 3.5.3). Like other RDRP techniques, RAFT polymerization is well-suited for synthesizing block copolymers and several block copolymers containing blocks with pendant saccharides and blocks with pendant hydrophobic groups have been reported [71].

The choice of macro-RAFT agent fell upon the first intermediate product from the synthesis of glycopolymer 19, the peracetylated $\alpha$-L-fucoside pendant polymer with the benzodithioate end group intact ( $\mathrm{p}(\mathrm{AcFucMAM})$ ) (see Scheme 5.2). As seen in the RAFT mechanism, the benzodithioate group is vital for successful formation of block copolymers (see Section 3.5.3). N-n-octyl methacrylamide (OctMAM) was synthesized, according to a previously described procedure [137], and polymerized with $\mathrm{p}(\mathrm{AcFucMAM})$ as macro-RAFT agent under the same conditions as for the formation 
of $\mathrm{p}$ (AcFucMAM). The resulting product was then modified using the same sequent steps as for the formation of the previously described RAFT-derived glycopolymers. Peaks corresponding to the pendant n-octyl groups on the $\mathrm{p}($ OctMAM) block were, however, difficult to spot on ${ }^{1} \mathrm{H}$ NMR after either of the reaction steps. The [OctMAM] was therefore doubled from 2 per monomeric unit of $\mathrm{p}$ (AcFucMAM) to 4 . The reaction temperature was lowered from 90 to $70^{\circ} \mathrm{C}$ and the reaction time was doubled from 24 to 48 hours. Peaks from the n-octyl groups were still difficult to observe on ${ }^{1} \mathrm{H}$ NMR, though, after purification by suspension in diethyl ether. Analysis of the diethyl ether phase, however, showed strong peaks corresponding to the n-octyl groups, but no peaks corresponding to the pendant $\alpha$-L-fucosides $\mathrm{p}(\mathrm{AcFucMAM})$ block. The resulting end products were therefore likely not $\mathrm{p}$ (FucMAM)- $b$-p(OctMAM) block copolymers, but separate polymers containing only one type of monomeric units.

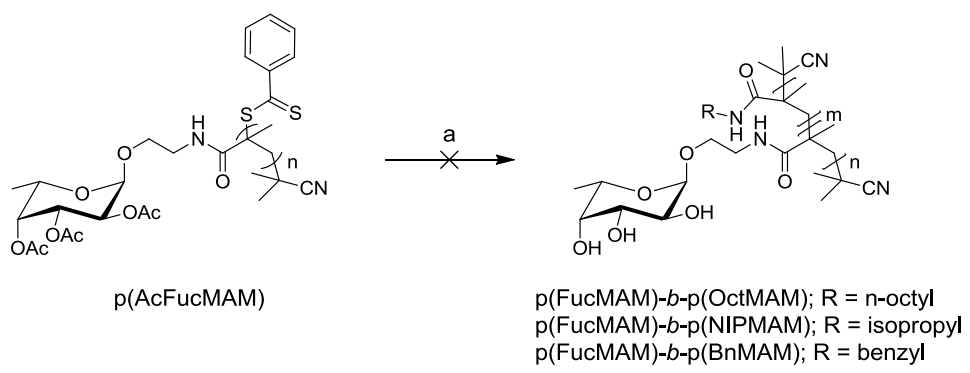

Scheme 5.2. Attempted synthesis of block copolymers via RAFT polymerization. Reagents and conditions: (a) (i) N-n-octyl methacrylamide or $N$-isopropyl methacrylamide or $N$-benzyl methacrylamide, AIBN, 1,4-dioxane, 70 or $90^{\circ} \mathrm{C}, 24$ or $48 \mathrm{~h}$; (ii) AIBN, 1,4-dioxane, $90^{\circ} \mathrm{C}, 24 \mathrm{~h}$; (iii) $\mathrm{NaOMe}, \mathrm{MeOH}, \mathrm{rt}, 24 \mathrm{~h}$.

$\mathrm{N}$-benzyl methacrylamide (BnMAM) and $\mathrm{N}$-isopropyl methacrylamide (NIPMAM) were also used in attempted copolymerizations, with $\mathrm{p}$ (AcFucMAM) as the macro-RAFT agent, under the same conditions. [BnMAM] or [NIPMAM] ratios of 2 or 4 per monomeric unit of $\mathrm{p}(\mathrm{AcFucMAM})$ were used, accompanied by reduced reaction temperature and prolonged reaction time. All these attempted block copolymers were modified under the same conditions as the previously synthesized glycopolymers by the RAFT technique. Both attempted $\mathrm{p}$ (FucMAM)- $b$-p(BnMAM) copolymers showed distinct peaks in ${ }^{1} \mathrm{H}$ NMR corresponding to the pendant benzyl groups on the $\mathrm{p}$ (BnMAM) block. However, after the basic ester hydrolysis step a white solid was formed, which was insoluble in water. Filtration of the solid showed that a polymer containing only the $\mathrm{p}$ (FucMAM) block had been dissolved in water, whereas the solid consisted of $\mathrm{p}(\mathrm{BnMAM})$ only. Again, separate polymers containing only one type of monomer had been formed rather than the desired $\mathrm{p}$ (FucMAM)- $b$-p(BnMAM) 
copolymer. The attempted formation of $\mathrm{p}$ (FucMAM)- $b$-p(NIPMAM) block copolymers gave products entirely soluble in water. This was expected as p(NIPMAM) is soluble in water at room temperature compared to $\mathrm{p}($ OctMAM) and $\mathrm{p}(\mathrm{BnMAM})$. Peaks in the ${ }^{1} \mathrm{H}$ NMR spectrum corresponding to both blocks were clearly visible after all synthetic steps. Analysis by GPC, however, showed no significant change in $M_{\mathrm{n}}$ after either step compared to $\mathrm{p}$ (AcFucMAM), only $Ð$ increased slightly. As successful formation of block copolymers would increase the $M_{\mathrm{n}}$, it is likely separate polymers were once again formed.

The unsuccessful attempts to synthesize amphiphilic block copolymers likely stems from degradation of the benzodithioate end group during the synthesis of the $\mathrm{p}$ (AcFucMAM) macro-RAFT agent. Aromatic peaks corresponding to the benzodithioate group were visible in the ${ }^{1} \mathrm{H}$ NMR spectrum of $\mathrm{p}$ (AcFucMAM). However, these were less intense than expected, compared to the other peaks, given the length of the polymer. RAFT groups, such as benzodithioate, can be degraded by light, heat or solvents containing oxidizing species, e.g. 1,4-dioxane [95]. This would make the combination of relatively long reaction time, relatively high temperature and choice of 1,4-dioxane as solvent responsible for the degradation of the benzodithioate end groups, during the synthesis of the $\mathrm{p}$ (AcFucMAM) macro-RAFT agent.

As the strategy of synthesizing amphiphilic FMGs by formation of block copolymers turned out to be unsuccessful as well, a third approach was evaluated. RAFT remained the polymerization technique of choice and was used also in this third attempt to synthesize amphiphilic FMGs. Rather than forming amphiphilic block copolymers though, this new strategy relied on using RAFT agents bearing hydrophobic groups to form FMGs with amphiphilic properties.

\subsubsection{Synthesis of Hydrophobic RAFT Agents (Paper IV)}

Although the formation of block copolymers is the most common approach when synthesizing amphiphiles via RAFT polymerization, there have been reports on polymers with amphiphilic properties despite only one type of monomers being used $[99,103,132,138,139]$. These polymers are typically synthesized by using RAFT agents, bearing either hydrophobic or hydrophilic groups, when polymerizing monomers with water solubility properties opposite to those of the RAFT agent. Du et al reported the self-assembly of polymers containing only hydrophilic monomers and small hydrophobic end groups, the latter stemming from the RAFT agent [139]. Xu et al revealed that hydrophobic end groups will not only cause self-assembly of otherwise 
hydrophilic polymers, but can also control the architecture despite constituting only $6 \%$ of the total polymer weight [99]. This approach (described in Paper IV) therefore seemed worth exploring in the pursuit to synthesize amphiphilic FMGs.

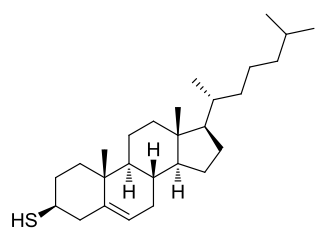

Thiocholesterol

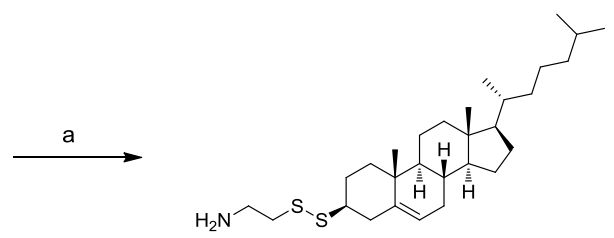

29
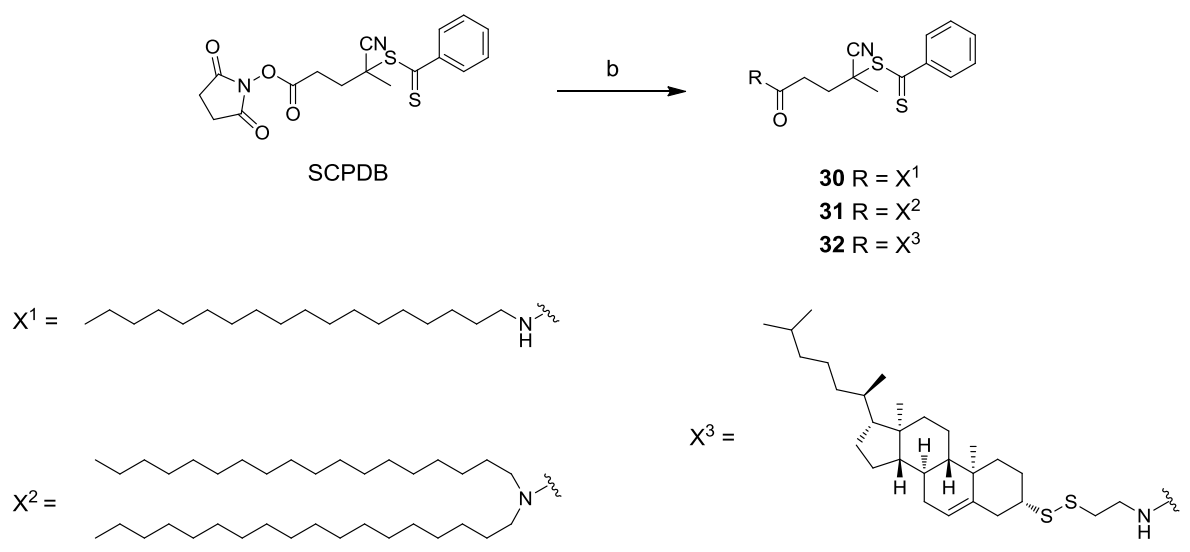

Scheme 5.3. Synthesis of hydrophobic RAFT agents. Reagents and conditions: (a) cystamine dihydrochloride, $\mathrm{Et}_{3} \mathrm{~N}, \mathrm{DCM}, \mathrm{MeOH}, \mathrm{rt}$, $21 \mathrm{~h}, 69 \%$; (b) octadecylamine or dioctadecylamine or 29, DCM, rt, $24 \mathrm{~h}, 84 \%\left(\mathrm{R}=\mathrm{X}^{1}\right), 83 \%\left(\mathrm{R}=\mathrm{X}^{2}\right), 74 \%\left(\mathrm{R}=\mathrm{X}^{3}\right)$.

As the polymer chains in the FMGs are hydrophilic, tailored RAFT agents bearing hydrophobic groups were needed to give the FMGs amphiphilic properties. The previously successful RAFT polymerizations employed RAFT agents bearing benzodithioate as the Z-group and cyanopropyl derivatives as the R-groups (see Section 3.5.3). As starting material in the synthesis of hydrophobic RAFT agents a similar compound, SCPDB (see Scheme 5.3), was therefore chosen. Due to its activated succinimide ester, SCPDB is readily available for reactions with hydrophobic amines or alcohols via acyl substitution. Amines became the compounds of choice as esters, formed when reacting SCPDB with alcohols, would potentially undergo hydrolysis in the basic ester hydrolysis step during the post-polymerization modifications of the RAFT glycopolymers. The amides formed via reaction of SCPDB with amines would 
not pose such a problem. SCPDB was therefore coupled with octadecylamine and dioctadecylamine which yielded RAFT agents 30 and 31, respectively. The octadecylamine group was deemed sufficiently big to give polymers amphiphilic properties. The dioctadecylamine group, however, also had potential to mimic natural double tailed lipids, which might be interesting in certain biomedical applications. Another hydrophobic group of natural origin considered interesting to incorporate into FMGs was cholesterol. The hydroxyl group on cholesterol had previously been converted to amine in multiple steps by Fyrner et al [140]. Aiming for a more rapid synthetic approach, thiocholesterol (rather than cholesterol) was reacted with cystamine by thiol-disulfide exchange to give cholesteryl derivative $\mathbf{2 9}$ bearing a primary amine. Coupling of 29 with SCPDB then gave RAFT agent 32. The hydrophobic RAFT agents 30, 31, and $\mathbf{3 2}$ were then used as CTAs in the third approach to synthesize amphiphilic FMGs.

\subsubsection{Polymerizations Using Hydrophobic RAFT Agents (Paper IV)}

In Paper IV monomer 9 was polymerized, using the hydrophobic RAFT agents, and modified post-polymerization under the same conditions as for glycopolymer 19 (see Section 3.5.3). This gave glycopolymers 33, 34, and $\mathbf{3 5}$ using RAFT agents 30, 31, and 32, respectively (see Scheme 5.4).

Table 5.1. Characterization of the major products of glycopolymers 33-38.

\begin{tabular}{ccccccc}
\hline Polymer & CTA & {$[\mathrm{M}]:[\mathrm{CTA}]:[\mathbf{I}]^{\mathbf{a}}$} & $\begin{array}{c}\text { Yield }^{\mathbf{b}} \\
(\boldsymbol{\%})\end{array}$ & $\begin{array}{c}\boldsymbol{M}_{\boldsymbol{n}, \text { theo }^{\mathbf{c}}} \\
(\mathbf{g} / \mathbf{m o l})\end{array}$ & $\begin{array}{c}\boldsymbol{M}_{\boldsymbol{n}, \mathbf{G P C}^{\mathbf{d}}} \\
(\mathbf{g} / \mathbf{m o l})\end{array}$ & $\boldsymbol{D}^{\mathbf{d}}$ \\
\hline $\mathbf{3 3}$ & $\mathbf{3 0}$ & $50: 1: 0.2$ & 41 & 6090 & 4410 & 1.19 \\
$\mathbf{3 4}$ & $\mathbf{3 1}$ & $50: 1: 0.1$ & 15 & 2760 & 4650 & 1.16 \\
$\mathbf{3 5}$ & $\mathbf{3 2}$ & $50: 1: 0.2$ & 8 & 1760 & 3080 & 1.20 \\
$\mathbf{3 6}$ & $\mathbf{3 0}$ & $25: 1: 0.2$ & 33 & 2680 & 1970 & 1.15 \\
$\mathbf{3 7}$ & $\mathbf{3 1}$ & $25: 1: 0.1$ & 44 & 3690 & 2560 & 1.13 \\
$\mathbf{3 8}$ & $\mathbf{3 2}$ & $28: 1: 0.1$ & 29 & 2610 & 2140 & 1.33 \\
\hline
\end{tabular}

${ }^{\mathrm{a}} \mathrm{M}=\mathbf{9}$ and $\mathrm{I}=\mathrm{AIBN} .{ }^{\mathrm{b}}$ Over multiple steps. ${ }^{\mathrm{c}} \mathbf{M}_{n}$, theo $=([\mathrm{M}] /[\mathrm{CTA}]) *$

$\mathrm{M}_{\text {monomer }} \mathbf{9}$ * Yield $+\mathrm{M}_{\text {chain ends }} ;$ where $\mathbf{M}_{\text {monomer }} \mathbf{9}=275.30 \mathrm{~g} / \mathrm{mol}, \mathrm{M}_{\text {chain }}$ ends $=445.72 \mathrm{~g} / \mathrm{mol}$ for polymer $\mathbf{3 3}, 698.20 \mathrm{~g} / \mathrm{mol}$ for polymer $\mathbf{3 4}$, $654.07 \mathrm{~g} / \mathrm{mol}$ for polymer $\mathbf{3 5}, 410.70 \mathrm{~g} / \mathrm{mol}$ for polymer 37, $663.18 \mathrm{~g} / \mathrm{mol}$ for polymer 37 and $619.04 \mathrm{~g} / \mathrm{mol}$ for polymer 38 .

${ }^{\mathrm{d}}$ Determined by GPC. 
The yield for glycopolymer $\mathbf{3 3}$ was comparable to the previously obtained RAFT glycopolymers (see Table 5.1), whereas the yields for glycopolymers 34 and 35 were significantly lower with only 15 and $8 \%$, respectively. The dioctadecyl and cholesteryl groups of glycopolymers 34 and $\mathbf{3 5}$, respectively, at the initiating chain ends might be large enough to cause dissolution of the peracetylated intermediate glycopolymers in diethyl ether, something that was not seen with the previously synthesized glycopolymers via RAFT polymerization or with glycopolymer 33. As diethyl ether was used during the work-up following both the polymerization- and benzodithioate end group removal-steps, this was probably the reason for the loss of material.

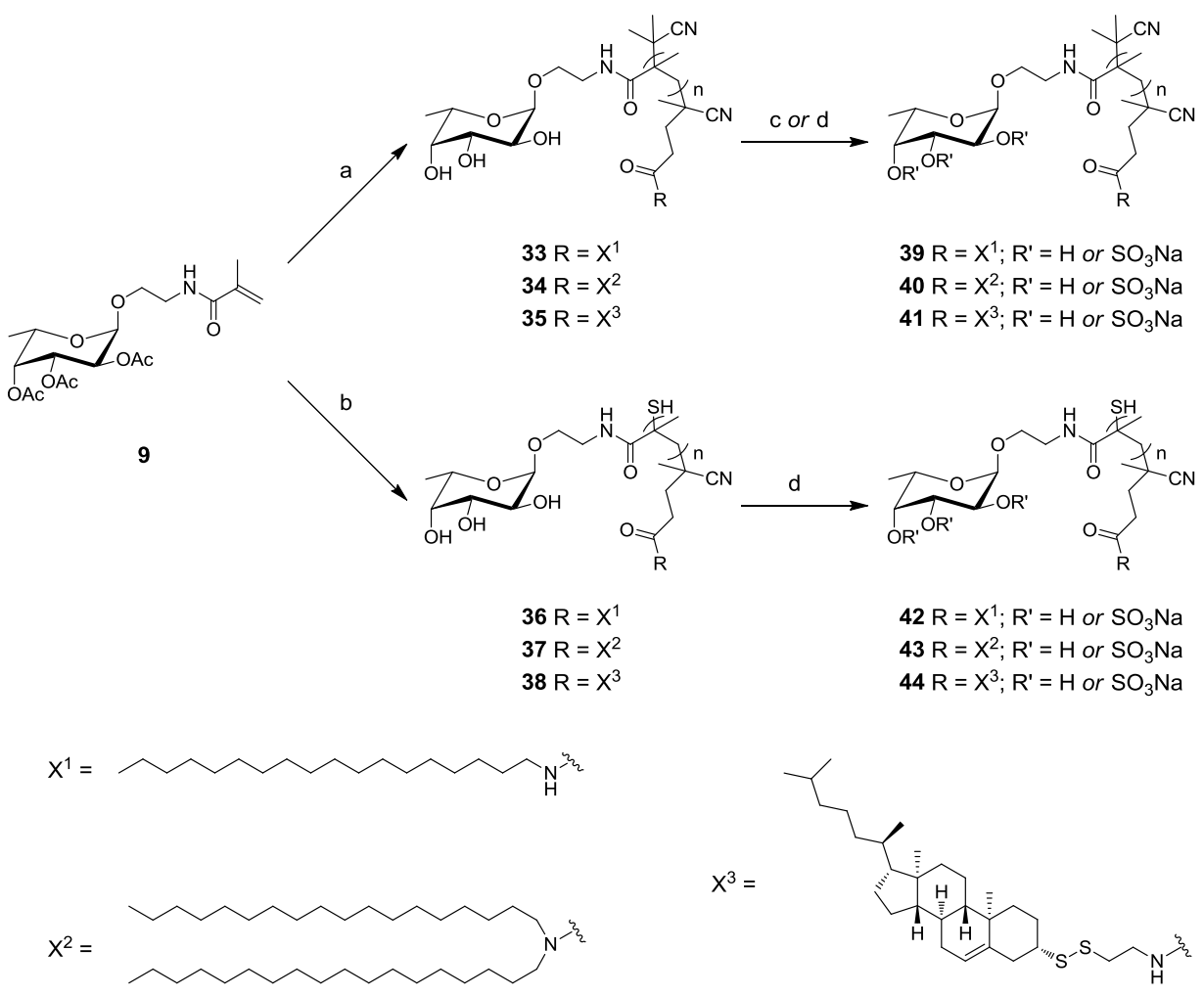

Scheme 5.4. Synthesis of amphiphilic glycopolymers 33-44 through RAFT polymerization. Reagents and conditions: (a) (i) $\mathbf{3 0}$ or $\mathbf{3 1}$ or $\mathbf{3 2}$, AIBN, 1,4-dioxane, $90^{\circ} \mathrm{C}, 24 \mathrm{~h}$; (ii) AIBN, 1,4-dioxane, $90^{\circ} \mathrm{C}, 20 \mathrm{~h}$; (iii) $\mathrm{NaOMe}, \mathrm{MeOH}, \mathrm{rt}, 18 \mathrm{~h}$; (b) (i) $\mathbf{3 0}$ or 31 or 32, AIBN, 1,4-dioxane, $90^{\circ} \mathrm{C}, 24 \mathrm{~h}$; (ii) $\mathrm{NaOMe}, \mathrm{MeOH}, \mathrm{rt}, 22 \mathrm{~h}$; (c) (i) $\mathrm{SO}_{3} \bullet \mathrm{Pyr}, \mathrm{DMF}, \mathrm{rt}, 25 \mathrm{~h}$; (ii) $\mathrm{NaCl}, \mathrm{H}_{2} \mathrm{O}$, rt, $22 \mathrm{~h}$; (d) (i) $\mathrm{SO}_{3} \cdot \mathrm{Pyr}, \mathrm{DMF}, \mathrm{rt}, 23 \mathrm{~h}$; (ii) $\mathrm{NaHCO}_{3}$, $\mathrm{H}_{2} \mathrm{O}$, rt, 3 h; (iii) $\mathrm{NaCl}, \mathrm{H}_{2} \mathrm{O}$, rt, 20 h. 


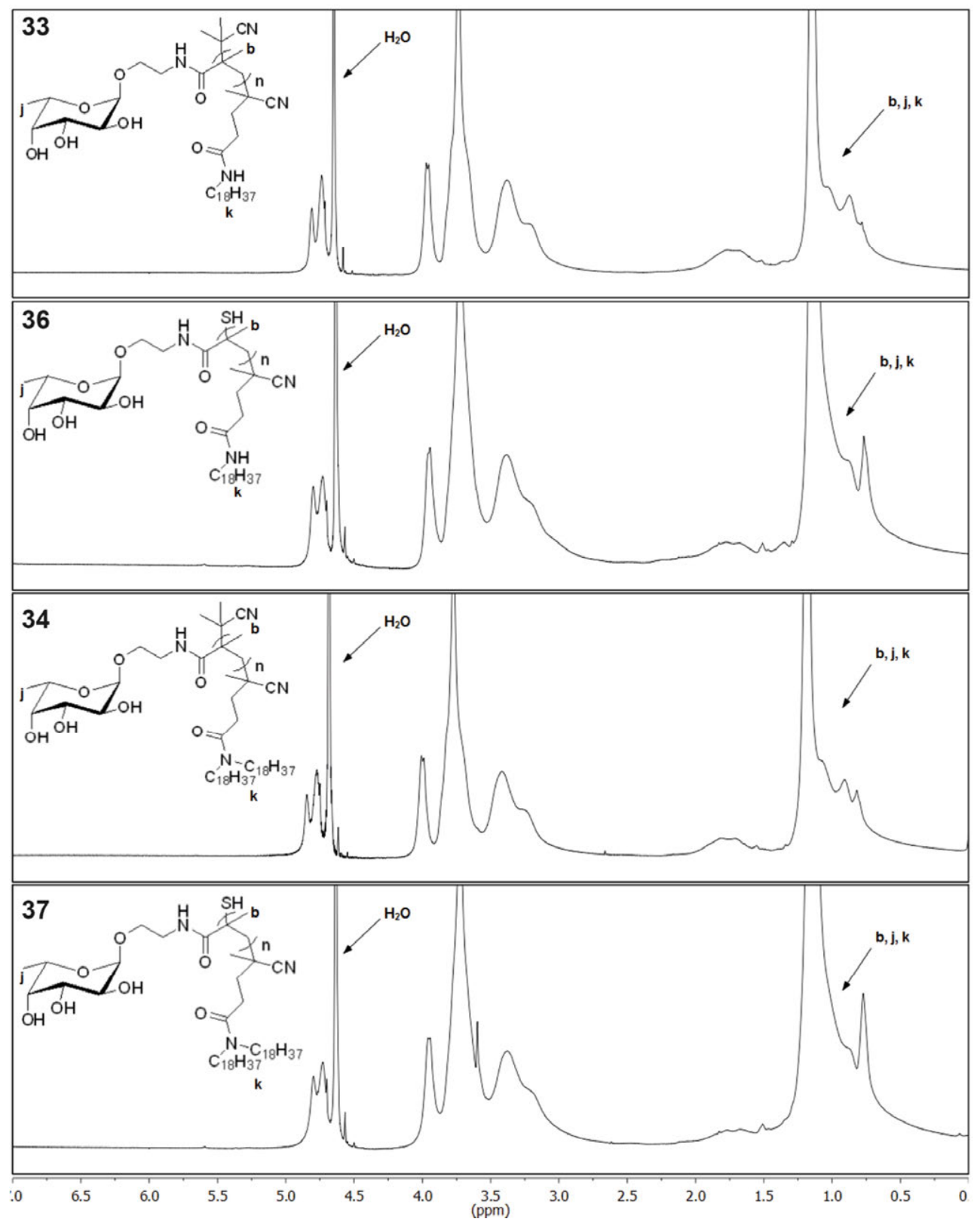

Figure 5.2. ${ }^{1} \mathrm{H}$ NMR spectra for (from top to bottom) glycopolymers 33, 36, 34, and 37 in $\mathrm{D}_{2} \mathrm{O}, 300 \mathrm{MHz}$.

To guarantee the amphiphilic properties, even shorter glycopolymers were synthesized, using the hydrophobic RAFT agents, by lowering the [M]:[CTA] ratio to around 25:1. The peracetylated glycopolymer thus obtained using RAFT agent $\mathbf{3 0}$ dissolved almost 
completely in diethyl ether, hence confirming the theory regarding the low yields for glycopolymers 34 and $\mathbf{3 5}$. The peracetylated glycopolymers were therefore, without purification, directly subjected to basic ester hydrolysis after the polymerization step. This yielded glycopolymers 36, 37, and 38 using RAFT agents 30, 31, and 32, respectively (see Scheme 5.4). These glycopolymers were obtained in more evenly distributed yields (see Table 5.1), compared to their longer counterparts, and bore thiols instead of cyanopropyl groups at the terminating chain end.

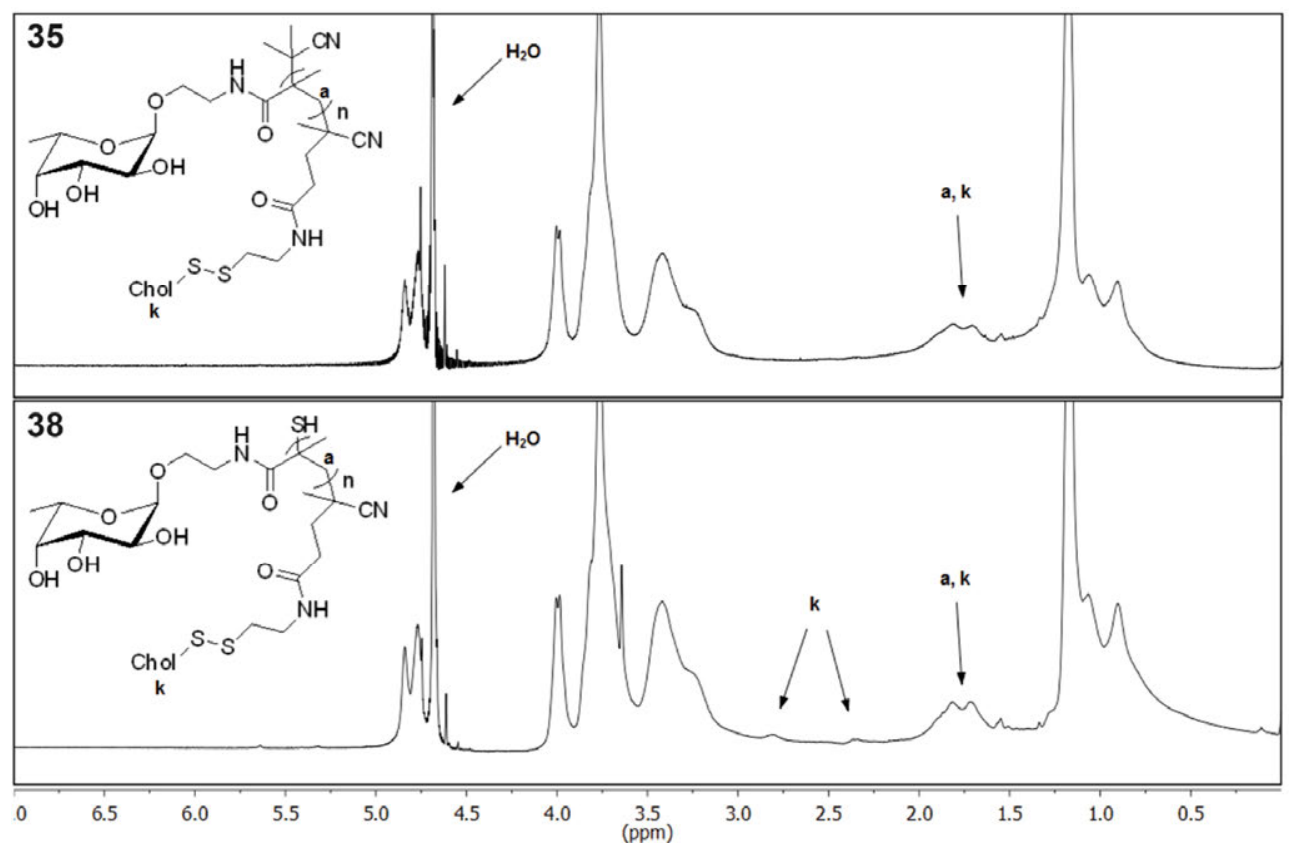

Figure 5.3. ${ }^{1} \mathrm{H}$ NMR spectra for glycopolymers 35 (top) and 38 (bottom) in $\mathrm{D}_{2} \mathrm{O}, 300 \mathrm{MHz}$.

${ }^{1} \mathrm{H}$ NMR spectra for glycopolymers 33-38 (see Figure 5.2 and Figure 5.3) corresponded well to the spectra for the previously synthesized FMGs 19 (see Figure 3.9 (top)), 16 (see Figure 3.7 (top)) and $\mathbf{1 3}$ (see Figure 3.5 (bottom)). Peaks corresponding to the octadecyl or dioctadecyl end groups of glycopolymers $33, \mathbf{3 4}, \mathbf{3 6}$, and $\mathbf{3 7}$ were clearly visible, although merged with the peaks corresponding to the methyl groups on the polymer backbone and the pendant fucosides (see Figure 5.2). Integration of these combined peaks showed larger proton content compared to the previously synthesized FMGs, thus confirming successful incorporation of the hydrophobic end groups. The increased proton content and intensity of these peaks for glycopolymers 36 and 37, compared to glycopolymers $\mathbf{3 3}$ and $\mathbf{3 4}$, also indicated the latter had shorter chain lengths than the former, as expected. In contrast, the peaks corresponding to the cholesteryl end 
groups in the spectra for glycopolymers $\mathbf{3 5}$ and $\mathbf{3 8}$ were more difficult to spot (see Figure 5.3). Again though, these peaks were more visible for glycopolymer 38, than glycopolymer 35, indicating the latter had shorter chain length compared to the former.

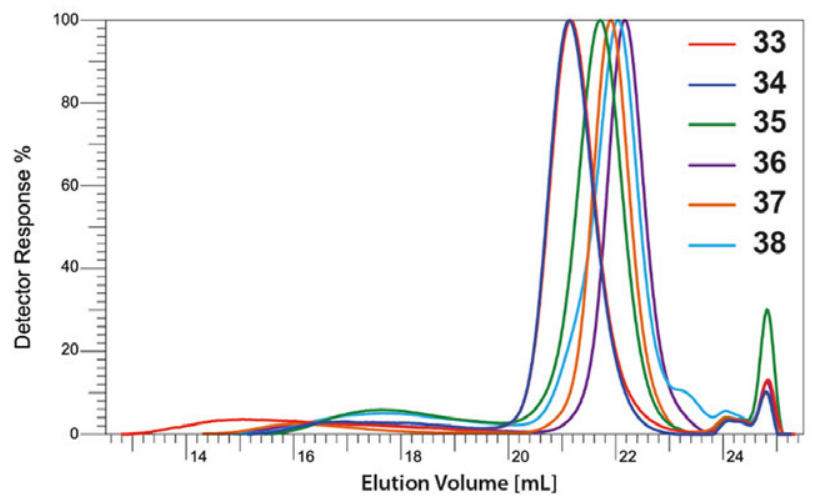

Figure 5.4. GPC traces for glycopolymers 33 (red), 34 (dark blue), 35 (green), 36 (purple), 37 (orange), and $\mathbf{3 8}$ (light blue) with DMSO as eluent and dextran/pullulan standards.

GPC traces for glycopolymers 33-38 (see Figure 5.4) showed bimodal distributions, similar to the previously synthesized glycopolymers by the RAFT polymerization technique (see Figure 3.9 (bottom)), with a large major peak containing low molecular weight polymers and a small minor peak containing high molecular weight polymers. The polymers in the minor peaks showed the following $M_{n}, Ð$ and weight percentage of the total polymer compositions: glycopolymers $39\left(M_{n},=107000 \mathrm{~g} / \mathrm{mol}, \oslash=2.76\right.$, $12 \mathrm{wt} \%), 40\left(M_{n},=56100 \mathrm{~g} / \mathrm{mol}, \oslash=1.55,8 \mathrm{wt} \%\right), 41\left(M_{n},=44100 \mathrm{~g} / \mathrm{mol}, \oslash=1.51\right.$, $13 \mathrm{wt} \%), 42\left(M_{n},=52100 \mathrm{~g} / \mathrm{mol}, \oslash=2.07,9 \mathrm{wt} \%\right), 43\left(M_{n},=84900 \mathrm{~g} / \mathrm{mol}, \oslash=1.87\right.$, $6 \mathrm{wt} \%)$, and $44\left(M_{n},=42000 \mathrm{~g} / \mathrm{mol}, \oslash=1.76,13 \mathrm{wt} \%\right)$. The $M_{n}$ for the polymers in the major peak again corresponded fairly well to the theoretical $M_{n}$ (see Table 5.1). As expected, and partially confirmed by ${ }^{1} \mathrm{H}$ NMR, glycopolymers $\mathbf{3 6}, \mathbf{3 7}$, and 38 showed lower $M_{n}$ than glycopolymers $\mathbf{3 3}, \mathbf{3 4}$, and $\mathbf{3 5}$. All glycopolymers showed fairly narrow dispersities $(\nexists=1.13-1.33)$. As mentioned in Section 3.5.3, free thiols on the terminating polymer chain end might cause coupling of polymer chains through the formation of disulfides. These would manifest as small shoulders on the high molecular weight side of the peaks in the GPC traces, as seen when excess termination occur via radical-radical coupling of polymer chains [141]. The lack of such shoulders on the major peaks for glycopolymers 36-38 indicates that disulfide formation occurred to a negligible degree. 
Table 5.2. Characterization of glycopolymers 39-44.

\begin{tabular}{ccccc}
\hline Polymer & Carbon $^{\mathbf{a}}(\mathbf{w t} \%)$ & Sulfur $^{\mathbf{a}}(\mathbf{w t} \boldsymbol{\%})$ & $\mathbf{D S}^{\mathbf{b}}(\boldsymbol{\%})$ & CAC $^{\mathbf{c}}(\mathbf{m g} / \mathbf{L})$ \\
\hline $\mathbf{3 9}$ & 23.0 & 14.0 & 91 & 85.8 \\
$\mathbf{4 0}$ & 25.4 & 14.0 & 83 & 51.5 \\
$\mathbf{4 1}$ & 23.1 & 13.5 & 88 & 52.0 \\
$\mathbf{4 2}$ & 25.8 & 12.8 & 74 & 38.3 \\
$\mathbf{4 3}$ & 22.8 & 13.4 & 88 & 40.5 \\
$\mathbf{4 4}$ & 23.8 & 13.4 & 84 & 18.4 \\
\hline
\end{tabular}

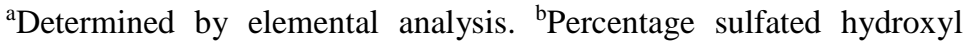
groups per available hydroxyl group. ${ }^{\mathrm{c}}$ Determined by DLS.

Glycopolymers 33-38 were then partially $O$-sulfated to furnish the amphiphilic FMGs. Glycopolymers $\mathbf{3 3}$ and $\mathbf{3 4}$ were $O$-sulfated via the same procedure as for the previously synthesized glycopolymers via RAFT polymerization (see Section 3.5.3) yielding glycopolymers 39 and 40, respectively. During this procedure the crude product precipitated, was isolated and then furnished via ion-exchange in $\mathrm{NaCl}$ (aq.). The precipitates of the shorter amphiphilic glycopolymers were, however, difficult to isolate without loss of material. $\mathrm{NaHCO}_{3}$ (aq.) was therefore added directly to the reaction mixture, without isolation of the precipitated intermediate polymers, followed by addition of $\mathrm{NaCl}$. This procedure gave partially $O$-sulfated glycopolymers $\mathbf{4 2}, \mathbf{4 3}$, and 44 from glycopolymers 36, 37, and 38, respectively. Due to the low amount of available material, glycopolymer 35 was $O$-sulfated following the same procedure which produced glycopolymer 41. The FMGs synthesized via thiol-mediated chain transfer and RAFT polymerizations showed surprisingly uniform DS (see Section 3.5.2 and Table 3.4). However, elemental analysis showed a rather broad distribution of DS between the amphiphilic $O$-sulfated glycopolymers (see Table 5.2), compared to the aforementioned glycopolymers. Altered solubility of the glycopolymers, caused by the hydrophobic end groups, is a possible explanation to these results. This might result in earlier or later precipitation from DMF, as seen with the biotinylated glycopolymer 22 (see Section 3.5.3). The presence of the hydrophobic end groups also makes the DS more difficult to calculate as, per the RAFT mechanism, all glycopolymers will not contain these groups at the initiating chain end. E.g., the polymers in the minor peaks in the GPC traces most likely do not contain any hydrophobic end groups at all. 
A

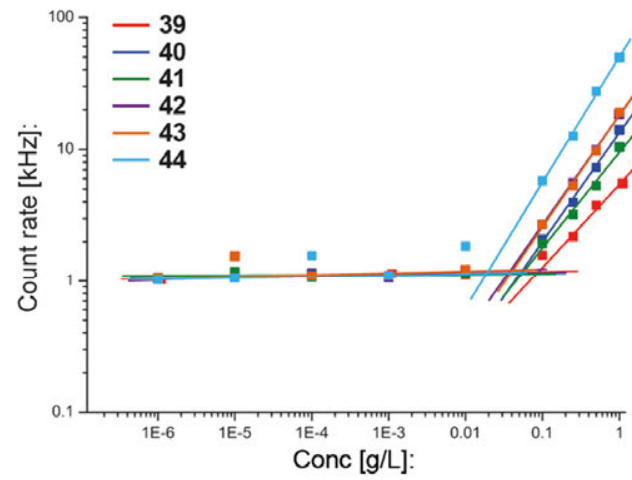

C

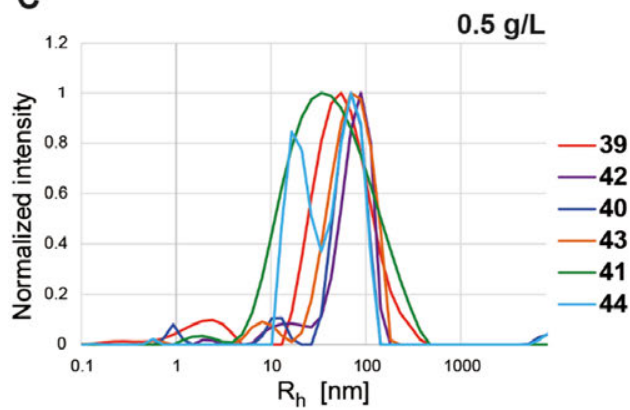

B

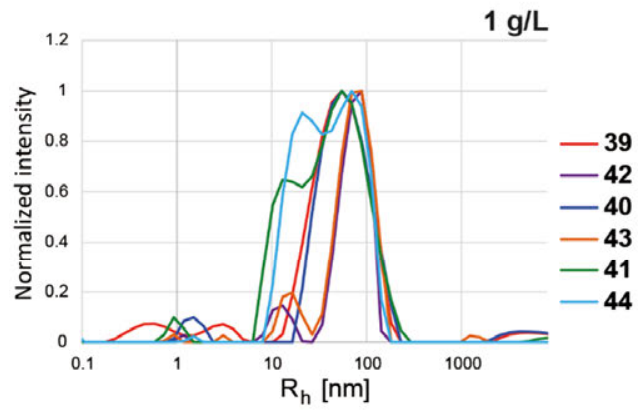

D

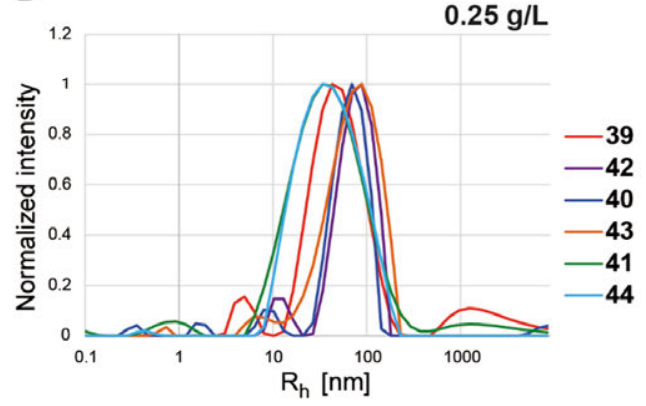

Figure 5.5. Characterization of aggregates of glycopolymers 39-44 in water by DLS: Overlay determination of CACs (A). Unweighted hydrodynamic radius distributions at; $1 \mathrm{~g} / \mathrm{L}(\mathrm{B}), 0.5 \mathrm{~g} / \mathrm{L}(\mathrm{C})$ and $0.25 \mathrm{~g} / \mathrm{L}(\mathrm{D})$.

To determine their amphiphilic nature and ability to self-assemble and form aggregates, sulfated glycopolymers 39-44 were dissolved in water at different concentrations and the solutions analyzed by dynamic light scattering (DLS). The DLS correlation curves showed a distinct presence of aggregates for all glycopolymers at higher concentrations, whereas the solutions containing lower concentrations of glycopolymers showed no presence of aggregates. The scattered intensities from the detector were plotted against the concentrations for each glycopolymer (see Figure 5.5 A). The two linear concentration-dependent and concentration-independent sections were extrapolated for each glycopolymer and the intersection points determined their respective CAC (see Table 5.2). As expected, the glycopolymers with longer polymer chains $(\mathbf{3 9}, \mathbf{4 0}$, and 41) displayed higher CACs than their counterparts bearing shorter polymer chains but the same hydrophobic end groups $(\mathbf{4 2}, \mathbf{4 3}$, and $\mathbf{4 4}$, respectively). Overall, the CACs were fairly uniform (38.3-52.0 $\mathrm{mg} / \mathrm{L}$ for glycopolymers 40-43) except for glycopolymers 39 and $\mathbf{4 4}$. Glycopolymer 39 bears the smallest hydrophobic end group 
compared to the length of its polymer chain and was therefore expected to display the highest CAC, which was also the case $(85.8 \mathrm{mg} / \mathrm{L})$. Glycopolymers 43 and $\mathbf{4 4}$ have similarly sized hydrophobic end groups with regards to their respective chain length. However, the CAC for glycopolymer 43 was $40.5 \mathrm{mg} / \mathrm{L}$ whereas glycopolymer 44 showed a CAC of only $18.4 \mathrm{mg} / \mathrm{L}$. This could be explained by the dioctadecyl end group on glycopolymer $\mathbf{4 3}$ being far more flexible than the cholesteryl end group on glycopolymer $\mathbf{4 4}$ and therefore less able to induce aggregation. The hydrodynamic radius $\left(\mathrm{R}_{\mathrm{h}}\right)$ distributions were also determined for the aggregates of all $O$-sulfated amphiphilic glycopolymers at 1 (see Figure 5.5 B), 0.5 (see Figure 5.5.C) and $0.25 \mathrm{~g} / \mathrm{L}$ (see Figure $5.5 \mathrm{D}$ ), by fitting the correlation curves. All glycopolymers displayed aggregates with average sizes of 30-60 nm and the distributions did not seem to change significantly at different concentrations.

With the successful synthesis of amphiphilic FMGs able to self-assemble in water, the next step was to consider suitable applications. Due to their presumed inherent antiviral properties, the amphiphilic glycopolymers were considered appropriate agents for delivery of antiviral drugs such as acyclovir. Aggregates of amphiphilic FMGs loaded with antiviral drugs in the hydrophobic core could possibly inhibit viral infections through multiple mechanisms. The first step towards this application was to evaluate the antiviral properties of the amphiphilic glycopolymers and determine any effects the hydrophobic end groups might have on the polymers' ability to inhibit viral infections.

\subsection{Antiviral Properties of Amphiphilic FMGs (Paper IV)}

As mentioned in Section 4.1.2, sulfated polysaccharides exert their antiviral properties by reversibly inhibiting viral entry and infection of cells. They generally lack the ability to irreversibly inactivate the viruses though, i.e. act virucidal. This has been proposed as the main reason for the lack of antiviral effect of sulfated polysaccharides in human clinical trials. However, Ekblad et al showed that sulfated tetrasaccharides with cholestanyl end groups interfered with the viral entry of cells and irreversibly inactivated the infectivity of HSV-1 and Herpes Simplex Virus-2 (HSV-2), i.e. they acted both as typical sulfated polysaccharides and virucidal [142]. This compound acted virucidally by disrupting the lipid envelope of the viral particles when the activity against infection of HSV-2 was studied [143]. The virucidal activity shown against HSV-1 is likely asserted through a similar mechanism of action. The same group showed, in an earlier report, that oligosaccharides as small as tetrasaccharides were sufficient to inhibit HSV-1 infection [144]. These results suggested that FMGs bearing hydrophobic end 
groups might show superior antiviral properties compared to the previously tested FMGs, despite shorter average chain lengths.

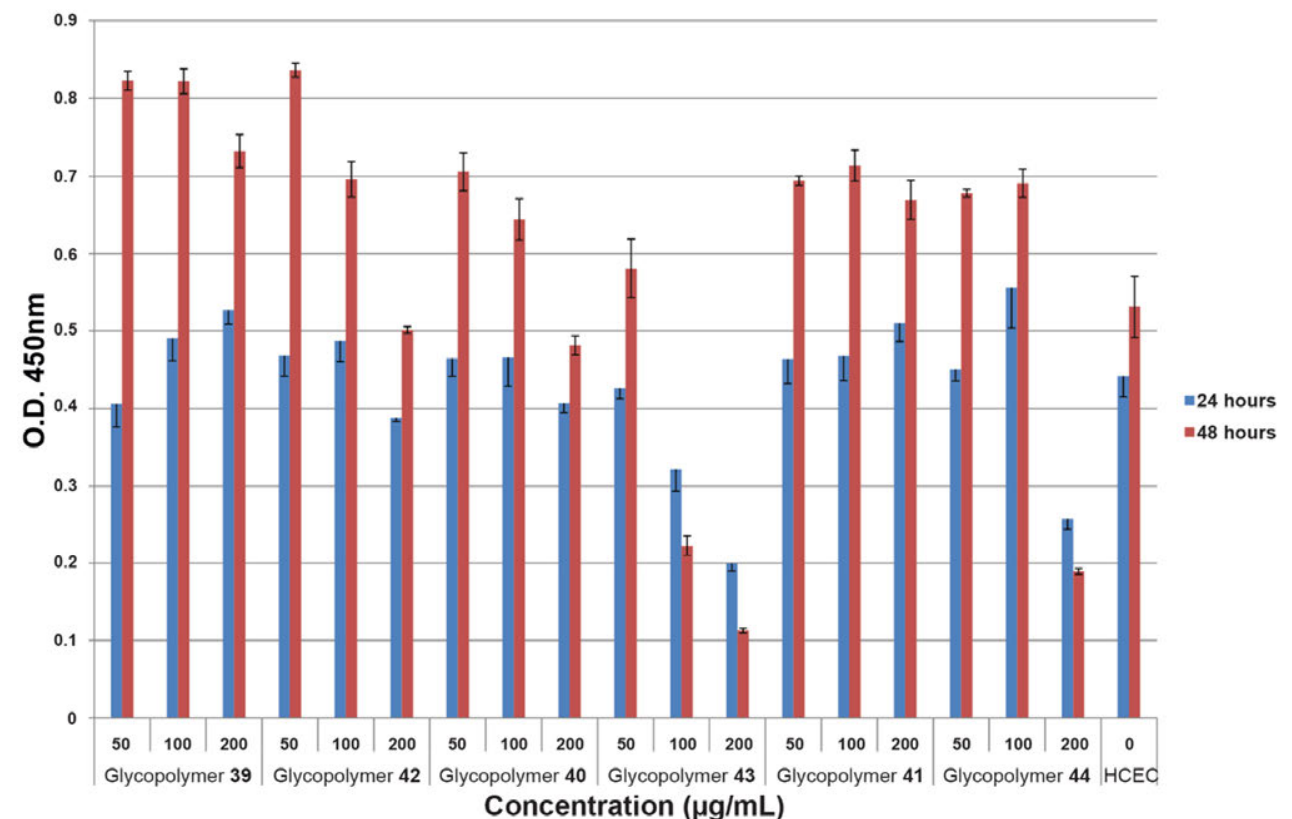

Figure 5.6. Cell viability by WST-1 assay of HCECs treated with glycopolymers 39-44.

In Paper IV the cytotoxicity of the amphiphilic FMGs to HCECs was first examined, in different doses, by WST-1 assay after 24 and 48 hours (see Figure 5.6). Amphiphilic glycopolymers 39-42 showed results similar to the previously synthesized glycopolymers, i.e. no decrease in cell viability. Somewhat surprising, treating the HCECs with glycopolymers $\mathbf{4 3}$ and $\mathbf{4 4}$ turned out to decrease the cell viability in doses of 100 and $200 \mu \mathrm{g} / \mathrm{mL}$ (for glycopolymer 43) and $200 \mu \mathrm{g} / \mathrm{mL}$ (for glycopolymer 44), thus making them cytotoxic. As a comparison, the virucidal sulfated tetrasaccharide reported by Ekblad et al also showed cytotoxic properties. Albeit at higher doses compared to the doses where virucidal properties were shown.

To investigate the antiviral properties of the amphiphilic FMGs, their inhibitory effects on viral spreading were tested under the same conditions as for the previously tested FMGs (see Figure 4.5). Glycopolymers 39-44 were added to HCECs infected with HSV-1 in doses of $100 \mu \mathrm{g} / \mathrm{mL}$, except for glycopolymer $\mathbf{4 3}$ which was added in doses of $50 \mu \mathrm{g} / \mathrm{mL}$ due to the cytotoxicity shown at $100 \mu \mathrm{g} / \mathrm{mL}$ doses. As seen with the previously tested glycopolymers, all amphiphilic glycopolymers significantly decreased 
the viral spreading, compared to non-treated HCECs, after 24, 48, and 72 hours (see Figure 5.7). Glycopolymers $\mathbf{4 2}$ and $\mathbf{4 3}$ actually reduced the number of infected cells between 24 and 48 hours, whereas it increased for the other tested glycopolymers. Glycopolymer 43 even inhibited the infection completely, a result never seen before with antiviral FMGs. This showed that incorporation of hydrophobic end groups to the polymer chains can result in superior antiviral properties compared to FMGs lacking hydrophobic end groups.

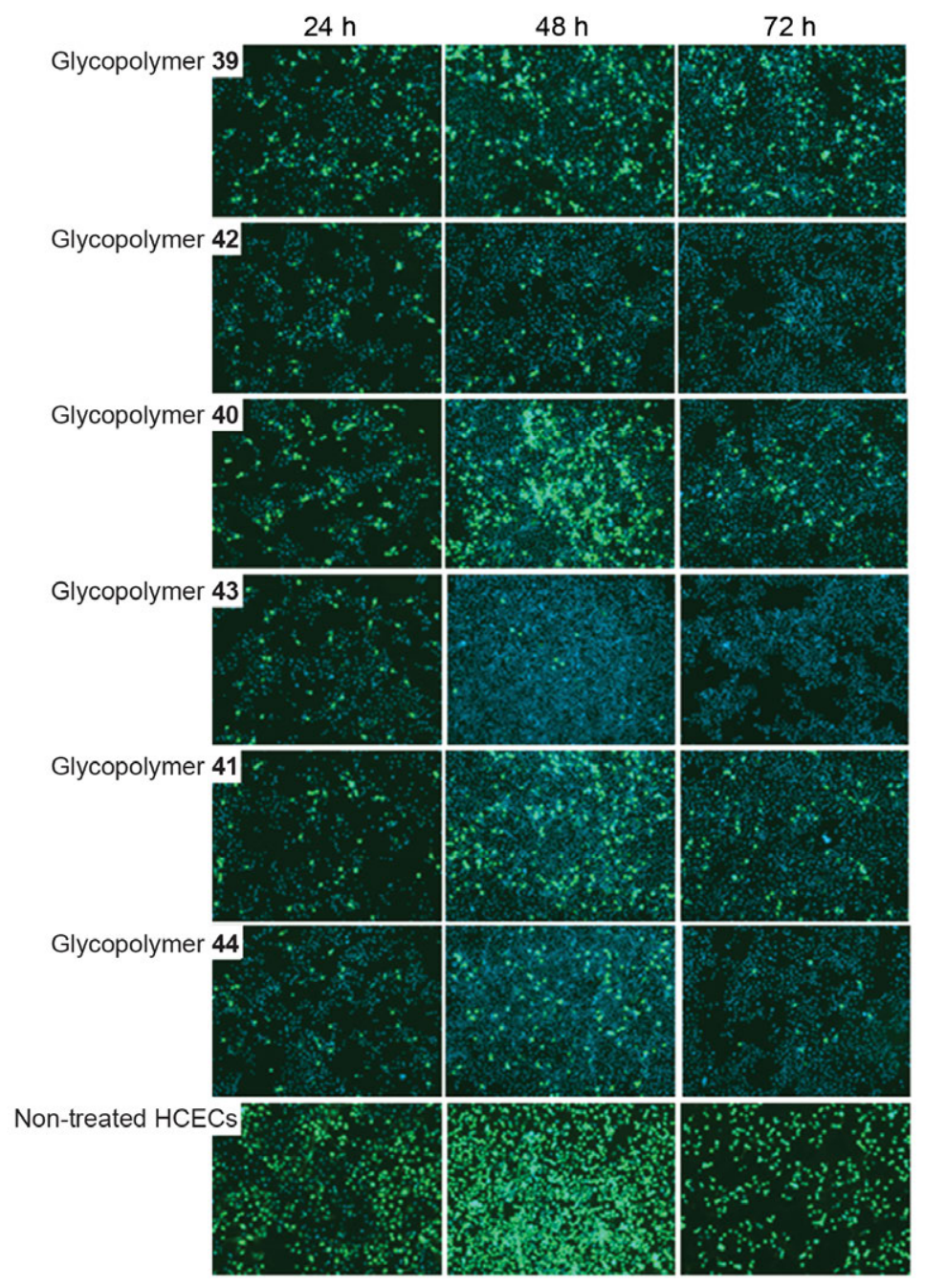

Figure 5.7. Inhibitory effect of glycopolymers 39-44 on HSV-1 spreading at 24, 48, and 72 hours when compounds were added 1 hour after infection of HCECs. Infected cells stained with HSV-1/2 antibody (green) and HCEC nuclei stained with DAPI (blue). 


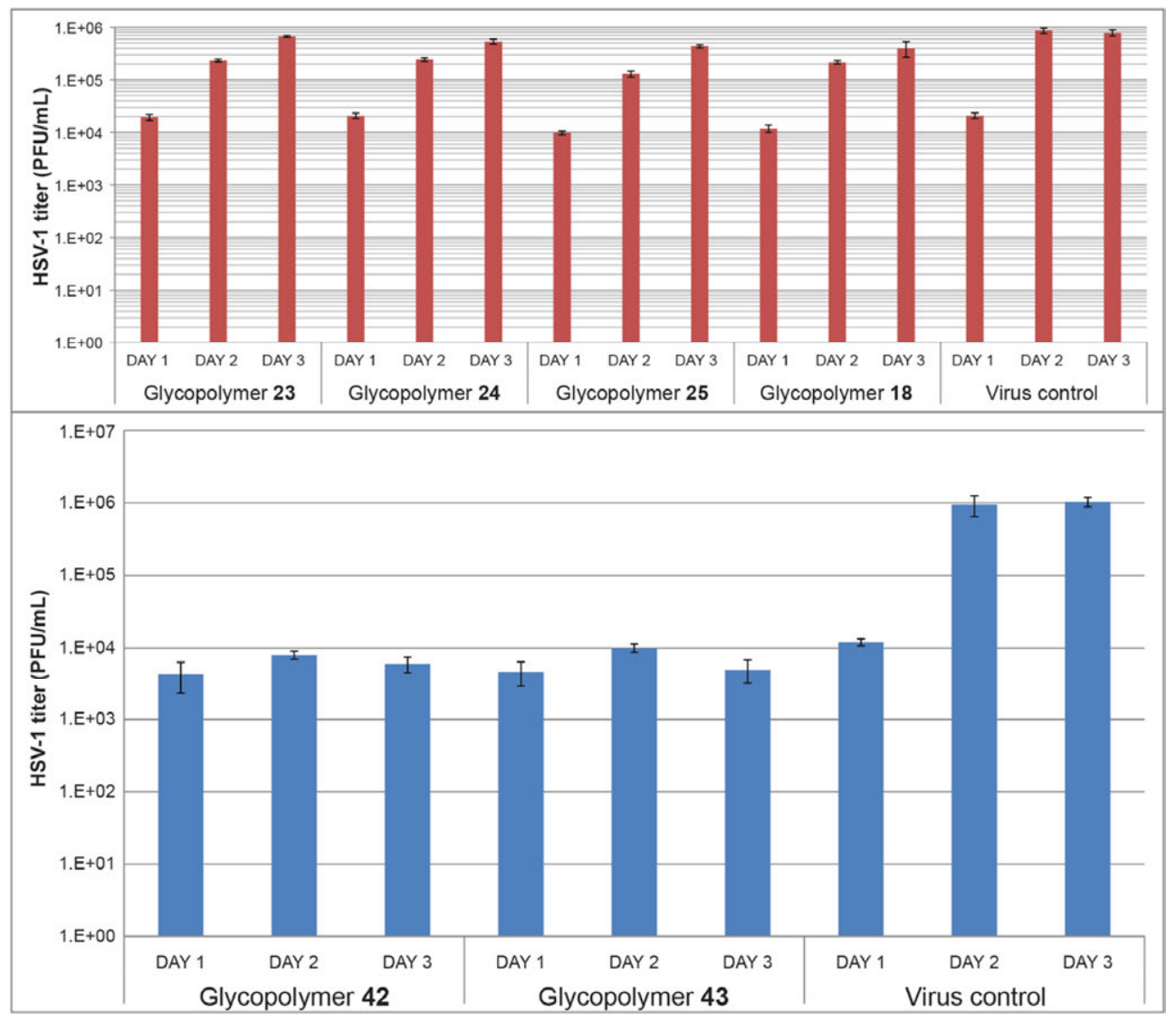

Figure 5.8. Viral titers from cell culture media of HSV-1-infected HCECs treated with glycopolymers $18, \mathbf{2 3 - 2 5}$, and $\mathbf{4 2 - 4 3}$, or fucoidan. The amounts of active viruses were quantified through viral plaque assay.

To confirm the inhibitory effects of glycopolymers 42 and 43 , and determine their potential virucidal properties, cell culture media from HCECs from the viral spreading assay were analyzed by a plaque formation assay (see Figure 5.8). Glycopolymers 18 and 23-25 (for a summary of structures and characterization see Section 8.4) had been analyzed earlier, with the same protocol, and now served as references. In these assays, cell culture media from infected HCECs were collected and diluted to concentrations where the glycopolymers or fucoidan showed no inhibitory effects. The dilutions were then incubated with Vero cells allowing active viruses from the cell culture media to infect and spread. The numbers of viral plaques formed were then quantified to indirectly measure the amount of active viruses in the HCEC cell culture media. The results showed that glycopolymers 18 and 23-25 slowed down the viral spreading, but was unable to inhibit it completely. This suggested these glycopolymers reversibly 
blocks viral entry and infection of cells, which was in agreement with the antiviral mechanism of action found for other FMGs not bearing hydrophobic end groups (see Section 4.1.3). In contrast, the amphiphilic glycopolymers $\mathbf{4 2}$ and $\mathbf{4 3}$ completely blocked the spreading of the viral infection as the viral titer from HCECs treated with these glycopolymers remained constant after 48 and 72 hours. This confirmed the results obtained from the viral infection spreading assay and the role of the hydrophobic end groups on the antiviral properties of FMGs. However, these results also indicated that glycopolymers $\mathbf{4 2}$ and $\mathbf{4 3}$ do not irreversibly inactivate the viruses, i.e. does not exhibit virucidal properties, as there was no significant reduction of formed plaques after 72 hours.

The investigation of the antiviral activity of the amphiphilic FMGs showed that the hydrophobic end groups had a profound effect on improving the inhibition of HSV-1 infections. It also showed that the glycopolymers bearing the shorter polymer chains were more potent than their counterparts with longer chains, thus opening for optimization of the chain length to further increase the antiviral potency. Even though the amphiphilic glycopolymers did not display virucidal properties, the results obtained still serve as a promising step towards the goal of synthesizing virucidal glycopolymers for applications as therapeutics and/or drug delivery agents. 



\section{FMG-Coated Gold Nanoparticles (Paper II)}

\subsection{Gold Nanoparticles}

Like other nanoparticles, gold nanoparticles (AuNPs) exhibit sizes ranging from 1 to $100 \mathrm{~nm}$ and have large surface area-to-volume ratios [145,146]. They are easily synthesized in various shapes and sizes in aqueous media [146,147] and are of great interest for various biomedical applications, due to their biocompatibility and high chemical and thermal stability [145-148]. Their electronic structure make them useful as tools in surface plasmon resonance imaging and as signal amplifiers. Their unique optical properties, due to strong light absorption and scattering, enable sensitive single live cell and in vivo imaging [148]. AuNPs have also been used as radio sensitizers in radiotherapy [145,147]. Furthermore, AuNPs act as photothermal transducers by absorbing energy and releasing heat via non-radiative methods, which primarily destroy abnormal cells and tissues such as tumor cells. As they are easily functionalized and modified, AuNPs are ideal carriers for drug and gene delivery [145-148] and have shown to alter the pharmacokinetics and pharmacodynamics of the loaded drugs. This combination of therapeutics and imaging is known as theranostics [148]. 


\subsubsection{AuNPs in Cancer Therapy}

Conventional drugs frequently encounter difficulties when used in cancer therapy due to multidrug resistance and poor penetration of the tumor cells. Numerous approaches have been studied to circumvent these issues and improve the efficacy, while simultaneously reducing the toxicity towards normal cells [146]. Their unique chemical, physical and optical properties, along with their biocompatibility, make AuNPs well suited for such approaches. Apart from their use as imaging agents and biosensors in cancer diagnostics [147], AuNPs have been extensively studied as delivery agents of anticancer drugs such as doxorubicin, paclitaxel, and cisplatin [145]. Perhaps most importantly, though, AuNPs have shown to accumulate in tumor environments $[145,146]$. They are accumulated either passively, by entering cancer tissue through leaky tumor vasculature, or actively, through functionalization of the AuNPs with ligands displaying high affinity for receptors overexpressed in tumor cells. Such ligands are commonly antibodies, peptides, carbohydrates, or small organic molecules [147].

\subsubsection{Carbohydrate-Coated AuNPs}

One factor that limits the use of AuNPs in clinical applications is their tendency to aggregate. One method to overcome this flaw is to coat the AuNPs with polymers or other macromolecules showing poor self-interaction [147], e.g. carbohydrates. Numerous carbohydrate-coated AuNPs have been reported with either poly- or oligosaccharides, carbohydrate-functionalized self-assembled monolayers, or glycopolymers as the carbohydrate source [149]. Carbohydrate-coated AuNPs can be synthesized either by using the carbohydrate source as a capping agent in the synthesis of the AuNPs, or by grafting the carbohydrate source onto the surface of the AuNPs $[147,150]$. As carbohydrate-coated AuNPs have shown to mimic the carbohydrate presentation at cell surfaces, they have mostly been applied in binding studies to lectins or in other recognition studies $[149,150]$. In these studies, the AuNPs' primary function was to spatially arrange the carbohydrates. In some studies, the carbohydrates have been used as bioadhesive coatings or as carriers in drug-delivery systems. Carbohydrate-coated AuNPs have shown to increase the drug loading, prolong the residence time, and further enhance the biocompatibility compared to other AuNPs [151]. In these studies, the properties of the carbohydrates were primarily used to enhance the properties of the AuNPs. On some occasions, though, the combined properties of both the carbohydrates and the AuNPs were more thoroughly used for theranostics or diagnostic applications [151]. However, the combined use of the unique properties of AuNPs and inherent anticancer carbohydrates such as fucoidan or 
fucoidan-mimetics are far less common, although some work exist [13]. It therefore seemed worthwhile to explore the therapeutic potential of AuNPs coated with FMGs.

\subsection{Anticancer Fucoidan}

Of all the biological properties exhibited by fucoidan, anticancer is perhaps the most studied one. Fucoidan has shown activity in vitro and in vivo against various types of cancers acting through different mechanisms, such as suppressing tumor growth, decreasing metastasis, inhibiting angiogenesis, activating the immune system, and inducing cell cycle arrest and apoptosis through both intrinsic (mitochondrial-mediated) and extrinsic (death receptor-mediated) pathways [152,153]. One such cancer type is colon cancer, the third most common cancer type in the world with a $40 \%$ mortality rate primarily due to metastasis to the liver [153]. Fucoidan from various brown seaweeds has shown activity against colon cancer cell lines such as HT-29 [154,155], HCT-15 [156], and HCT116 [155-158], with lower efficacy towards the latter compared to the former two cell lines $[155,156]$. The exact mechanisms of the activity towards various types of tumor cells are debated. Fucoidan has shown to both inhibit cell growth of, and induce apoptosis in, cancer cells [155-157]. The apoptosis occurs either through mitochondrial-mediated [155,156] or death receptor-mediated [155] pathways (both of which involves increased caspase activities) or by modulating the endoplasmic reticulum stress cascades [157].

\subsection{Synthesis of FMG-Coated AuNPs (Paper II)}

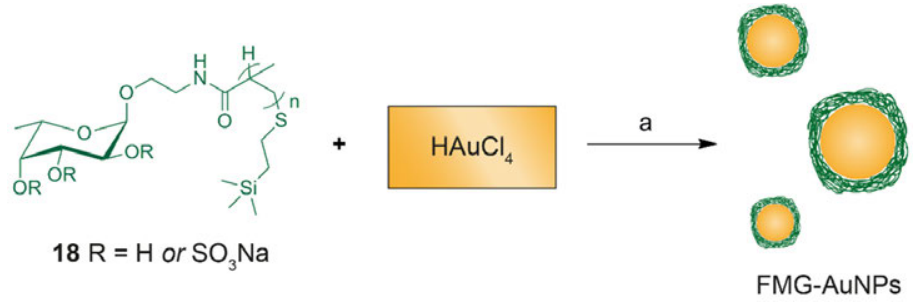

Scheme 6.1. Synthesis of FMG-coated AuNPs. Reagents and conditions: $\mathrm{NaBH}_{4}, \mathrm{H}_{2} \mathrm{O}, 60^{\circ} \mathrm{C}$.

In Paper II FMG-coated AuNPs (FMG-AuNPs) were successfully synthesized by reduction of $\mathrm{HAuCl}_{4}$ using $\mathrm{NaBH}_{4}$, as the reducing agent, and FMG 18, as the capping agent (see Scheme 6.1). Amongst the various FMGs available, 18 was chosen due to its long chain length and low $Ð$. The narrow $Ð$ of FMG 18 was assumed to be beneficial in keeping the $\oslash$ of the resulting FMG-AuNPs low, whereas the large $M_{n}$ was deemed to 
yield a more stable FMG-coating, through entanglement of the polymer chains, compared to the available FMGs with shorter chain length. As a control, chondroitin sulfate AuNPs (CS-AuNPs) were synthesized under similar conditions.
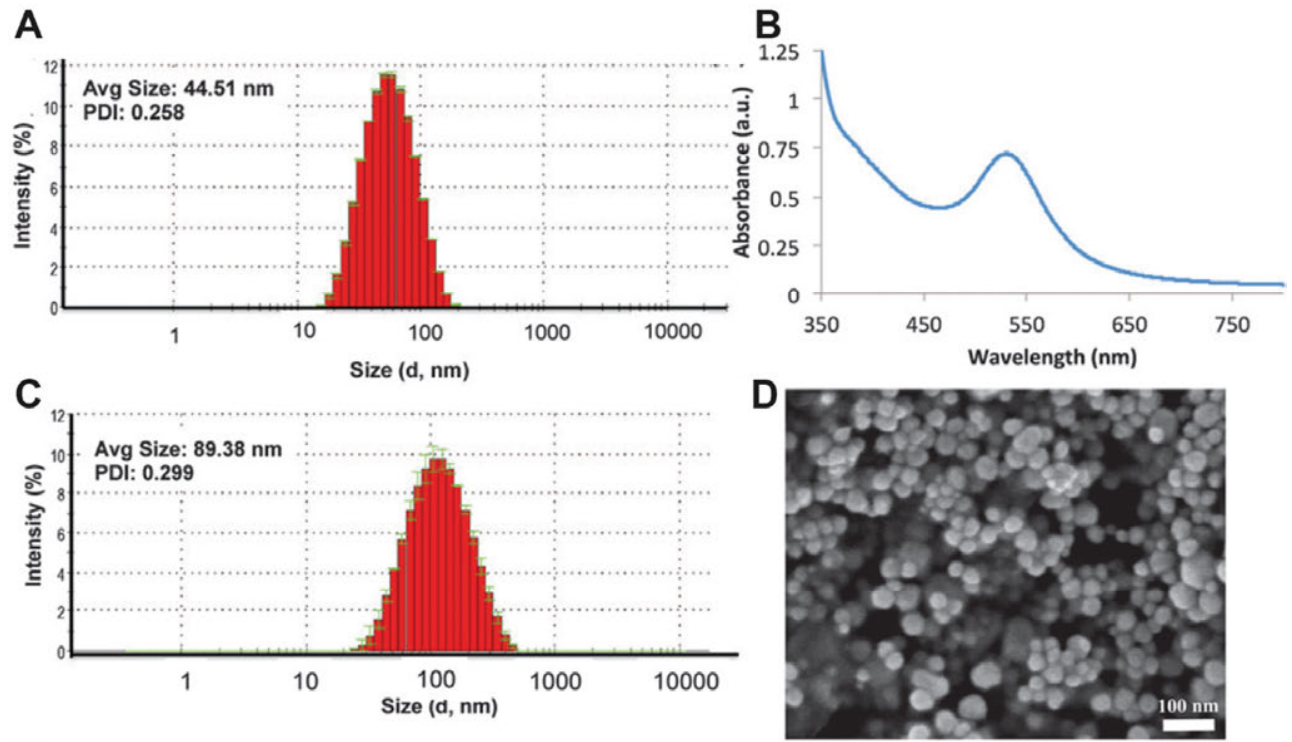

E
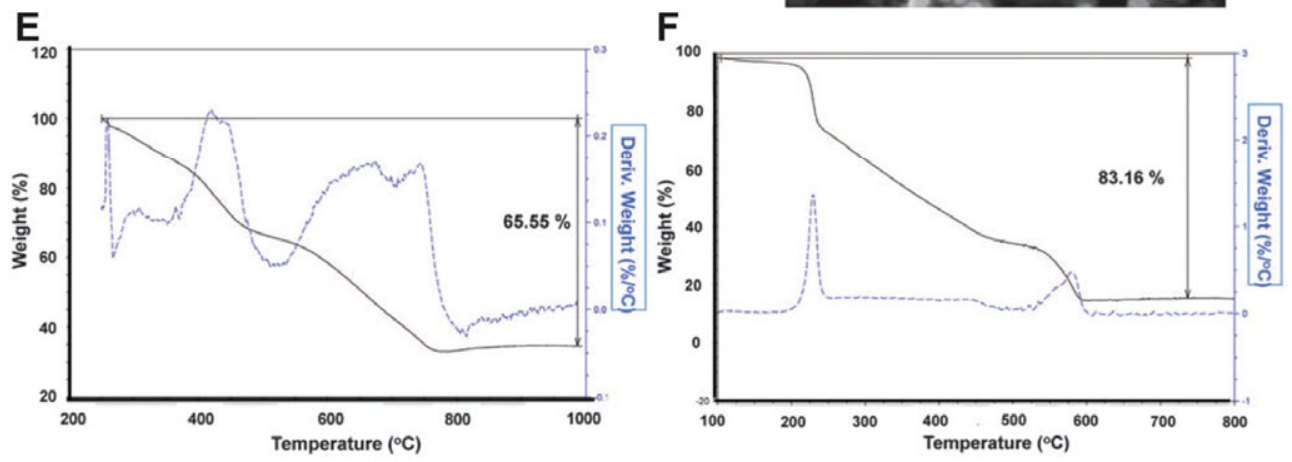

Figure 6.1. Characterization of FMG-AuNPs: DLS profile before lyophilization (A), UV-Vis spectra (B), DLS profile after lyophilization (C), SEM picture (D), and thermogravimetric analysis profile (E). Thermogravimetric analysis profile for CS-AuNPs is also included (F). Reproduced from [93] with permission from the Royal Society of Chemistry.

Characterization of the FMG-AuNPs by DLS showed a monomodal distribution with an average size of $44.51 \mathrm{~nm}$ (see Figure 6.1 A). To test their colloidal stability, i.e. their tendency to aggregate, the FMG-AuNPs where lyophilized, re-dissolved, and characterized by DLS once more. After this procedure, the FMG-AuNPs still showed a 
monomodal distribution with a slight increase in average size to $89.38 \mathrm{~nm}$ (see Figure $6.1 \mathrm{C}$ ). This indicated the FMG-AuNPs possess good colloidal stability, which is believed to be due to electrostatic repulsion between the FMG chains. SEM analysis showed particle sizes ranging from 20 to $55 \mathrm{~nm}$ (see Figure $6.1 \mathrm{D}$ ). This difference in size compared to the DLS measurements can be attributed to the hygroscopic properties of the FMG coatings, which increase their size in the DLS profiles due to hydration. This does not affect the SEM analysis, though, which was done in the dry state. DLS profile of the CS-AuNPs also showed monomodal distribution, with a similar $Ð$ and an average size of $99.34 \mathrm{~nm}$. Analysis of the FMG-AuNPs by UV-Vis showed $\lambda_{\max }$ at $530 \mathrm{~nm}$ (see Figure $6.1 \mathrm{~B}$ ) indicating spherical particles, which was confirmed by single surface plasmon resonance and the SEM image. To determine the Au-core/coating ratio, the FMG-AuNPs and CS-AuNPs were subjected to thermogravimetric analysis. This displayed that 65.55 and $83.16 \mathrm{wt} \%$, respectively, of the total nanoparticle composition is FMG 18-/CS-coating (see Figure 6.1 E and F).

\subsubsection{Anticancer Properties}

The cytotoxicity, i.e. anticancer properties, of the FMG-AuNPs against human colon cancer cell line HCT116 was examined in Paper II using FMG 18 and the CS-AuNPs as references. As a control, the cytotoxicity against non-tumor mouse fibroblast cell line NIH3T3 was also tested. FMG 18 showed no cytotoxicity against neither HCT116 (see Figure 6.2 A) nor NIH3T3 (see Figure 6.2 B) cells. The latter indicated biocompatibility, whereas the former indicated lack of anticancer properties at the doses tested. However, fucoidan has shown to induce significant apoptosis in HCT116 cells only at doses as high as $800-1000 \mu \mathrm{g} / \mathrm{mL}[156,158]$. This means the results obtained for FMG 18 were actually comparable to the results obtained for native fucoidan. On the other hand, the FMG-AuNPs showed significant dose-dependent cytotoxicity against HCT116 cells with $50 \%$ cell death occurring at $457.08 \mu \mathrm{g} / \mathrm{mL}$. They were, however, non-toxic to the NIH3T3 fibroblast cells, which indicated a selective cytotoxicity towards the colon cancer cells and hence anticancer properties. The reason the FMG-AuNPs display superior anticancer properties over FMG 18 remains unclear. Increased multivalency due to concentration of FMG chains or accumulation of the AuNPs, and hence the FMG chains, around the cancer cells are, however, possible explanations. The reference CS-AuNPs, though, actually showed less cytotoxicity towards the HCT116 cancer cells than the NIH3T3 fibroblast cells. This further serves the conclusion that the FMG-coating gives the AuNPs both anticancer properties and enhances their biocompatibility. 
A

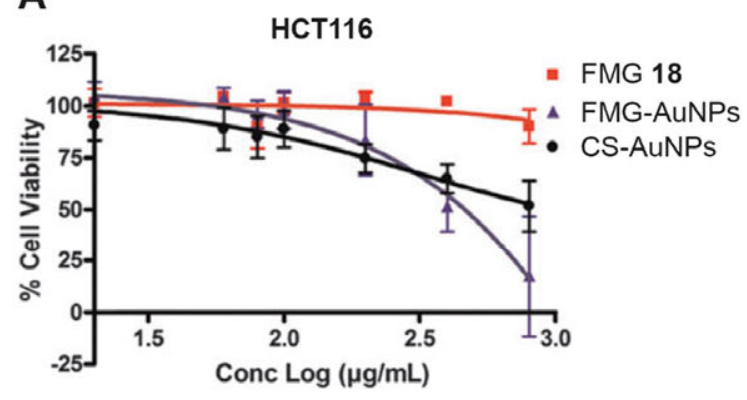

B

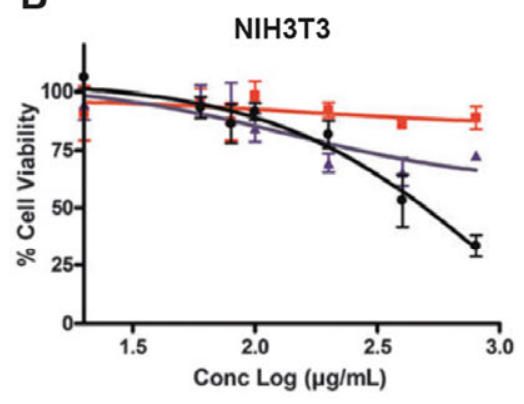

D

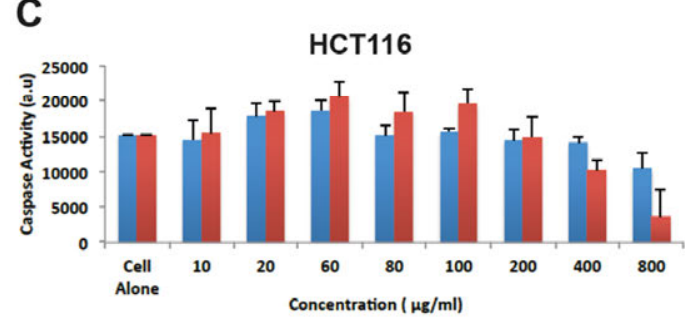

FMG 18

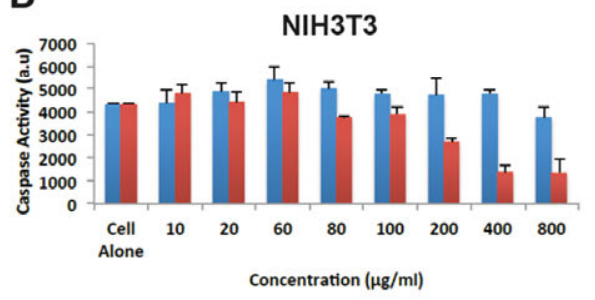

FMG-AuNPS

Figure 6.2. Anticancer properties of FMG 18 and FMG-AuNPs: Dose-dependent cytotoxicity of FMG 18, FMG-AuNPs, and CS-AuNPs towards HCT116 (A) and NIH3T3 (B) cell lines. Caspase 3/7 activities of HCT116 (C) and NIH3T3 (D) cell lines treated with FMG 18 or FMG-AuNPs. Reproduced from [93] with permission from the Royal Society of Chemistry.

To briefly examine the mechanism behind these anticancer properties, caspase 3/7 activities were tested. Caspase activities increase during both mitochondrial-mediated and death receptor-mediated apoptosis $[155,158]$, such an assay would, therefore, serve as a strong indicator of either or both of these mechanisms. No significant caspase 3/7 activity was, however, observed in neither HCT116 cancer cells (see Figure 6.2 C) nor NIH3T3 fibroblast cells (see Figure 6.2 D) upon treatment with FMG 18 or the FMG-AuNPs. It was therefore concluded that the anticancer activity is asserted through another mechanism, which remains to be investigated.

The selective cytotoxicity shown by the FMG-AuNPs towards HCT116 cancer cells proves the concept of enhancing the anticancer properties of fucoidan by combining AuNPs and fucoidan-mimetics. This strategy is worth exploring further in the pursuit of novel therapies against different types of cancer. 


\section{Conclusions and Future Prospects}

The research presented in this thesis shows that polymethacrylamides bearing pendant partially $O$-sulfated $\alpha$-L-fucosides mimic the antiviral and platelet activating properties of fucoidan. These fucoidan-mimetic glycopolymers were synthesized from tailored fucoside monomers, which were polymerized via radical polymerization and the resulting polymers modified post-polymerization. By exploring three different radical polymerization techniques, the chain length of the glycopolymers was varied, and partially controlled, often with low dispersity.

The FMGs showed antiviral properties equivalent to, and acting by the same mechanism as, sulfated polysaccharides of natural origin. The inhibitory effect on HSV-1 infection was, however, significantly improved by tailoring the initiating chain end of the glycopolymers with hydrophobic groups.

The FMGs also proved to induce platelet aggregation in dose-responses identical to those of fucoidan. Investigations on the platelet activating properties showed these were exerted through intracellular signaling and induced platelet surface changes also identical to those of fucoidan. The possibility of platelet aggregation through agglutination was also excluded. 
The FMGs were also used as capping agents in the synthesis of AuNPs, yielding FMG-coated AuNPs. These showed improved colloidal stability, even after lyophilization, and selective cytotoxicity towards a human colon cancer cell line.

Even though this thesis has demonstrated possible applications of FMGs as tools for studying cellular responses in platelets, as possible antiviral therapeutics for treating HSV-1 infections and as components in nanoparticle systems for anticancer therapy, there is still plenty to explore. The results presented herein have given only some information on the significance of the polymer chain length on the biological properties. The importance of factors such as the DS, the density of pendant fucosides on the polymer chain and the distance between the polymer backbone and the fucosides, are still left to fully investigate. All these factors need to be systematically varied to elucidate the SAR of the FMGs. The detailed mechanisms of action of the platelet activating and improved antiviral properties are also subjects to investigation. There are also plenty of other biological properties attributed to fucoidan which remains to be studied using FMGs.

This thesis has only scratched the surface of the potential biomedical applications of FMGs. Using previously unexplored RDRP techniques, or fine-tuning the currently used ones, could yield new functional FMGs. These could be tailored for application as building blocks in drug or gene delivery systems, as ligands for molecular recognition in diagnostics and bioengineering, or as bioactive components in biomaterials, e.g., for tissue engineering. Researchers of all biomedically related disciplines have a new class of compounds to explore, fucoidan-mimetic glycopolymers. 


\section{Appendix}

\subsection{General Synthetic Procedures}

All chemicals used were purchased from Sigma-Aldrich. ${ }^{1} \mathrm{H}$ and ${ }^{13} \mathrm{C}$ NMR spectra (300 and 75.4 MHz, respectively) were recorded using a Varian spectrometer in $\mathrm{D}_{2} \mathrm{O}$ at $25^{\circ} \mathrm{C}$. The resonance of $\mathrm{D}_{2} \mathrm{O}$ at $\delta=4.79$ was used as reference for ${ }^{1} \mathrm{H}$ NMR [159]. All NMR spectra were processed in MestReNova v8.1.2-11889. Spectra/Por Dialysis Membranes $6(\mathrm{MWCO}=1000)$ or $3(\mathrm{MWCO}=3500)$ were used for dialysis. Prior to dialysis, filtering was performed using Acrodisc LC PVDF $0.45 \mu \mathrm{m}$ filters.

\subsection{Experimentals for Compounds Described in Section 3.2}

\section{Synthesis of 2-Aminoethyl 2,3,4-Tri- $O$-Sulfo- $\alpha$-L-Fucopyranoside Trisodium Salt} (4). Fucoside 3 [66] (0.205 g, $0.879 \mathrm{mmol})$ and $\mathrm{SO}_{3} \cdot \operatorname{Pyr}(2.11 \mathrm{~g}, 13.25 \mathrm{mmol})$ were dissolved in DMF $(5.0 \mathrm{~mL})$ and stirred at room temperature for 20 hours. $\mathrm{NaHCO}_{3}$ $(2.89 \mathrm{~g}, 35.48 \mathrm{mmol})$ was added and the suspension was stirred for 1 hour at room temperature. The suspension was filtered and the solid re-suspended twice in $\mathrm{MeOH}$ and filtered. The filtrates were combined and the solvent evaporated. The resulting solid was dissolved in deionized water, washed three times with DCM, and lyophilized. The intermediate tri-sulfated fucoside was dissolved in $\mathrm{MeOH}(10.0 \mathrm{~mL}), 20 \% \mathrm{Pd} / \mathrm{C}$ 
$(0.030 \mathrm{~g})$ was added, and the suspension stirred under $\mathrm{H}_{2}(\mathrm{~g})$ atmosphere at room temperature for 19 hours. Filtering on Celite and evaporation of the solvent afforded tri-sulfated fucoside $4(0.174 \mathrm{~g}, 0.339 \mathrm{mmol}, 39 \%)$ as a bright white amorphous solid. ${ }^{1} \mathrm{H}$ NMR (300 MHz, D $\left.2 \mathrm{O}\right): \delta 5.23(\mathrm{~d}, 1 \mathrm{H}, J=3.8 \mathrm{~Hz}), 4.92(\mathrm{~d}, 1 \mathrm{H}, J=3.2 \mathrm{~Hz}), 4.72(\mathrm{dt}$, $1 \mathrm{H}, J=3.2,10.5 \mathrm{~Hz}), 4.54(\mathrm{dt}, 1 \mathrm{H}, J=3.8,10.5 \mathrm{~Hz}), 4.26(\mathrm{q}, 1 \mathrm{H}, J=6.5 \mathrm{~Hz}), 3.83-3.90$ $(\mathrm{m}, 1 \mathrm{H}), 3.56-3.76(\mathrm{~m}, 1 \mathrm{H}), 2.94-3.10(\mathrm{~m}, 2 \mathrm{H}), 1.29(\mathrm{~d}, 3 \mathrm{H}, J=6.5 \mathrm{~Hz}) .{ }^{13} \mathrm{C}$ NMR $(75.4$ $\left.\mathrm{MHz}, \mathrm{D}_{2} \mathrm{O}\right): \delta 96.6,79.0,72.5,72.4,66.2,49.0,39.7,15.8$.

Synthesis of Glycopolymer 6. Polyacrylic acid $5\left(M_{\mathrm{n}}=1800\right)(1.03 \mathrm{~g})$ was suspended in $\mathrm{SOCl}_{2}(5.0 \mathrm{~mL})$, refluxed at $80^{\circ} \mathrm{C}$ under stirring for 21 hours, and excess $\mathrm{SOCl}_{2}$ evaporated. The resulting intermediate polyacryloyl chloride $(0.031 \mathrm{~g})$ and $\mathrm{Et}_{3} \mathrm{~N}$ $(0.067 \mathrm{~mL}, 0.483 \mathrm{mmol})$ were dissolved in DMF $(5.0 \mathrm{~mL})$ and added to a solution of compound 4 (0.174 g, $0.339 \mathrm{mmol})$ in DMF $(5.0 \mathrm{~mL})$. The combined solution was stirred for 40 hours at room temperature, deionized water $(5.0 \mathrm{~mL})$ added, and the solution stirred at room temperature for 2 hours. The solvent was evaporated and the crude glycopolymer re-dissolved in deionized water $(10 \mathrm{~mL})$ and purified by dialysis $(\mathrm{MWCO}=1000)$ against deionized water for 72 hours, with frequent changes of deionized water. Lyophilization yielded glycopolymer $6(0.080 \mathrm{~g})$ as a yellow/brown powder.

\subsection{Experimentals for Compounds Described in Section 5.2.1}

Methacrylation of Glycopolymer 16 (27). Glycopolymer 16 (0.300 g) was dissolved in deionized water $(30 \mathrm{~mL})$. Et $3 \mathrm{~N}$ (1.078 mL, $7.78 \mathrm{mmol}), \mathrm{GM}(1.470 \mathrm{~mL}, 11.12 \mathrm{mmol})$, and TBAB (1.180 g, $3.66 \mathrm{mmol})$ were added with vigorous stirring before the addition of the next compound. The solution was stirred at room temperature for 24 hours, purified by dialysis ( $\mathrm{MWCO}=3500$ ) against deionized water for 48 hours, with frequent changes of deionized water, and then lyophilized to afford methacrylated glycopolymer $27(0.262 \mathrm{~g})$ as a white powder.

$\boldsymbol{O}$-sulfation of Methacrylated Glycopolymer 27 (28). Methacrylated glycopolymer 27 $(0.031 \mathrm{~g})$ and $\mathrm{SO}_{3} \bullet \operatorname{Pyr}(0.278 \mathrm{~g}, 1.75 \mathrm{mmol})$ were dissolved in DMF (10 mL) and stirred for 54 hours. A precipitate formed almost instantly, which was scraped off the walls of the flask continuously during the reaction. Storage in freezer for 1 hour allowed for further precipitation and the precipitate was then isolated by decanting the solution. The isolated precipitate was dissolved in $\mathrm{NaCl}$ (aq., 1.0 M) and stirred for 44 hours. Dialysis $(\mathrm{MWCO}=3500)$ against $\mathrm{NaCl}(\mathrm{aq} ., 0.1 \mathrm{M})$ for 72 hours and deionized water for 24 
hours, with frequent changes of deionized water, followed by freeze-drying yielded partially $O$-sulfated methacrylated glycopolymer $28(0.060 \mathrm{~g})$ as a white powder. 


\subsection{Summary of All Synthetic Glycopolymers}

Table 8.1. Characterization of all synthetic glycopolymers.

\begin{tabular}{|c|c|c|c|c|c|c|}
\hline \multicolumn{2}{|c|}{ Polymers $^{\mathrm{a}}$} & \multirow[t]{2}{*}{ Structure $^{b}$} & \multirow[t]{2}{*}{$\mathbf{R}^{\mathbf{b}}$} & \multirow{2}{*}{$\begin{array}{c}M_{\mathrm{n}}^{\mathrm{c}}(\mathrm{g} / \mathrm{mol}) \\
\text { (non-Sulf.) }\end{array}$} & \multirow{2}{*}{$\begin{array}{c}\bigoplus^{\mathbf{c}} \\
\text { (non-sulf.) }\end{array}$} & \multirow{2}{*}{$\begin{array}{c}\operatorname{DS}^{d}(\%) \\
\text { (sulf.) }\end{array}$} \\
\hline Non-sulf. & Sulf. & & & & & \\
\hline 12 & 14 & A & $\mathrm{H}$ & 26800 & 2.83 & 62 \\
\hline 13 & 15 & A & $\mathrm{Me}$ & 30200 & 2.15 & 66 \\
\hline 16 & 18 & B & - & 90600 & 1.32 & 87 \\
\hline 17 & - & B & - & 109000 & 1.33 & - \\
\hline 19 & 23 & $\mathrm{C}$ & $\mathrm{Me}$ & $3690^{\mathrm{e}}$ & $1.23^{\mathrm{e}}$ & 89 \\
\hline 20 & 24 & $\mathrm{C}$ & $\mathrm{Me}$ & $7400^{\mathrm{e}}$ & $1.42^{\mathrm{e}}$ & 86 \\
\hline 21 & 25 & $\mathrm{C}$ & $\mathrm{Me}$ & $9440^{\mathrm{e}}$ & $1.79^{\mathrm{e}}$ & 87 \\
\hline 22 & 26 & $\mathrm{C}$ & $\mathrm{X}^{1}$ & $8060^{\mathrm{e}}$ & $1.41^{\mathrm{e}}$ & 81 \\
\hline 33 & 39 & $\mathrm{C}$ & $X^{2}$ & $4410^{\mathrm{e}}$ & $1.19^{\mathrm{e}}$ & 91 \\
\hline 34 & 40 & $\mathrm{C}$ & $\mathrm{X}^{3}$ & $4650^{\mathrm{e}}$ & $1.16^{\mathrm{e}}$ & 83 \\
\hline 35 & 41 & $\mathrm{C}$ & $X^{4}$ & $3080^{\mathrm{e}}$ & $1.20^{\mathrm{e}}$ & 88 \\
\hline 36 & 42 & $\mathrm{D}$ & $X^{2}$ & $1970^{\mathrm{e}}$ & $1.15^{\mathrm{e}}$ & 74 \\
\hline 37 & 43 & $\mathrm{D}$ & $X^{3}$ & $2560^{\mathrm{e}}$ & $1.13^{\mathrm{e}}$ & 88 \\
\hline 38 & 44 & D & $X^{4}$ & $2140^{\mathrm{e}}$ & $1.33^{\mathrm{e}}$ & 84 \\
\hline
\end{tabular}

${ }^{\text {a }}$ The polymers on the left are non-sulfated glycopolymers; the polymers on the right are their sulfated derivatives. ${ }^{b}$ See Figure 8.1. ${ }^{c}$ Determined by GPC; applies to the non-sulfated glycopolymers only. ${ }^{\mathrm{d} D e t e r m i n e d}$ by elemental analysis; applies to the sulfated glycopolymers only. ${ }^{\mathrm{e}}$ The data presented for the non-sulfated RAFT-derived glycopolymers refers to the major product of each glycopolymer. 


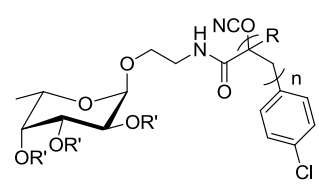

A

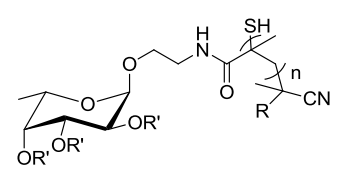

D<smiles>[Y]CCCC(=O)NCCOCCOCCNC(=O)CCCC[C@H]1SC[C@H]2NC(=O)N[C@@H]21</smiles>

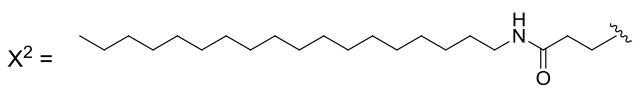

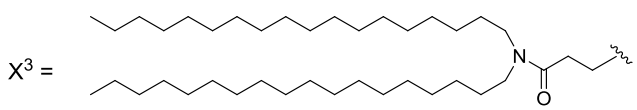

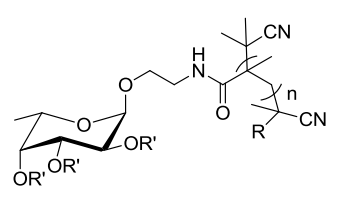

C

$$
\begin{aligned}
& R=H, M e, X^{1}, X^{2}, X^{3} \text { or } X^{4} \\
& R^{\prime}=H ; \text { for non-sulfated glycopolymers } \\
& R^{\prime}=\mathrm{H} \text { or } \mathrm{SO}_{3} \mathrm{Na} \text {; for sulfated glycopolymers }
\end{aligned}
$$

Figure 8.1. Structures of all synthetic glycopolymers described in Table 8.1 . 



\section{References}

[1] Li, B.; Lu, F.; Wei, X.; Zhao, R. Fucoidan: Structure and Bioactivity. Molecules, 2008, 13, 1671-1695.

[2] Fitton, J.H.; Stringer, D.N.; Karpiniec, S.S. Therapies from Fucoidan: An Update. Mar. Drugs, 2015, 13, 5920-5946.

[3] Berteau, O.; Mulloy, B. Sulfated Fucans, Fresh Perspectives: Structures, Functions, and Biological Properties of Sulfated Fucans and an Overview of Enzymes Active Toward this Class of Polysaccharide. Glycobiology, 2003, 13, 29R-40R.

[4] Wijesinghe, W.A.J.P.; Jeon, Y. Biological Activities and Potential Industrial Applications of Fucose Rich Sulfated Polysaccharides and Fucoidans Isolated from Brown Seaweeds: A Review. Carbohydr. Polym., 2012, 88, 13-20.

[5] Lakshmana Senthil, S.; Vinoth Kumar, T.; Geetharamani, D.; Suja, G.; Yesudas, R.; Chacko, A. Fucoidan - an a-Amylase Inhibitor from Sargassum Wightii with Relevance to NIDDM. Int. J. Biol. Macromol., 2015, 81, 644-647.

[6] Fitton, J.H. Therapies from Fucoidan; Multifunctional Marine Polymers. Mar. Drugs, 2011, 9, 1731-1760.

[7] Venkatesan, J.; Lowe, B.; Anil, S.; Manivasagan, P.; Kheraif, A.A.A.; Kang, K.; Kim, S. Seaweed Polysaccharides and their Potential Biomedical Applications.

Starch/Staerke, 2015, 67, 381-390.

[8] Cunha, L.; Grenha, A. Sulfated Seaweed Polysaccharides as Multifunctional Materials in Drug Delivery Applications. Mar. Drugs, 2016, 14, 42.

[9] Venkatesan, J.; Anil, S.; Kim, S.; Shim, M.S. Seaweed Polysaccharide-Based Nanoparticles: Preparation and Applications for Drug Delivery. Polymers, 2016, 8, 30.

[10] Lee, K.W.; Jeong, D.; Na, K. Doxorubicin Loading Fucoidan Acetate Nanoparticles for Immune and Chemotherapy in Cancer Treatment. Carbohydr. Polym., 2013, 94, 850-856. 
[11] Yu, S.; Wu, S.; Wu, J.; Wen, D.; Mi, F. Preparation of Fucoidan-Shelled and GenipinCrosslinked Chitosan Beads for Antibacterial Application. Carbohydr. Polym., 2015, 126, 97-107.

[12] Huang, Y.; Li, R.; Chen, J.; Chen, J. Biphasic Release of Gentamicin from Chitosan/Fucoidan Nanoparticles for Pulmonary Delivery. Carbohydr. Polym., 2016, 138, 114-122.

[13] Manivasagan, P.; Bharathiraja, S.; Bui, N.Q.; Jang, B.; Oh, Y.; Lim, I.G.; Oh, J. Doxorubicin-Loaded Fucoidan Capped Gold Nanoparticles for Drug Delivery and Photoacoustic Imaging. Int. J. Biol. Macromol., 2016, 91, 578-588.

[14] Sezer, A.D.; Cevher, E.; Hatipoğlu, F.; Oğurtan, Z.; Baş, A.L.; Akbuğa, J. Preparation of Fucoidan-Chitosan Hydrogel and its Application as Burn Healing Accelerator on Rabbits. Biol. Pharm. Bull., 2008, 31, 2326-2333.

[15] Jeong, H.; Venkatesan, J.; Kim, S. Hydroxyapatite-Fucoidan Nanocomposites for Bone Tissue Engineering. Int. J. Biol. Macromol., 2013, 57, 138-141.

[16] Igondjo Tchen Changotade, S.; Korb, G.; Bassil, J.; Barroukh, B.; Willig, C.; ColliecJouault, S.; Durand, P.; Godeau, G.; Senni, K. Potential Effects of a Low-MolecularWeight Fucoidan Extracted from Brown Algae on Bone Biomaterial Osteoconductive Properties. J. Biomed. Mater. Res. Part A, 2008, 87, 666-675.

[17] Jin, G.; Kim, G.H. Rapid-Prototyped PCL/Fucoidan Composite Scaffolds for Bone Tissue Regeneration: Design, Fabrication, and Physical/Biological Properties. J. Mater. Chem., 2011, 21, 17710-17718.

[18] Puvaneswary, S.; Talebian, S.; Raghavendran, H.B.; Murali, M.R.; Mehrali, M.; Afifi, A.M.; Kasim, N.H.B.A.; Kamarul, T. Fabrication and in Vitro Biological Activity of BTCP-Chitosan-Fucoidan Composite for Bone Tissue Engineering. Carbohydr. Polym., 2015, 134, 799-807.

[19] Lee, H.M.; Kim, J.; Cho, T. Applications of Ophthalmic Biomaterials Embedded with Fucoidan. J. Ind. Eng. Chem., 2012, 18, 1197-1201.

[20] Reys, L.L.; Silva, S.S.; da Costa.D.S.; Oliveira, N.M.; Mano, J.F.; Reis, R.L.; Silva, T.H. Fucoidan Hydrogels Photo-Cross-Linked with Visible Radiation as Matrices for Cell Culture. ACS Biomater. Sci. Eng., 2016, 2, 1151-1161.

[21] Holtkamp, A.D.; Kelly, S.; Ulber, R.; Lang, S. Fucoidans and Fucoidanases - Focus on Techniques for Molecular Structure Elucidation and Modification of Marine Polysaccharides. Appl. Microbiol. Biotechnol., 2009, 82, 1-11.

[22] Ale, M.T.; Mikkelsen, J.D.; Meyer, A.S. Important Determinants for Fucoidan Bioactivity: A Critical Review of Structure-Function Relations and Extraction Methods for Fucose-Containing Sulfated Polysaccharides from Brown Seaweeds. Marine Drugs, 2011, 9, 2106-2130.

[23] Ustyuzhanina, N.E.; Bilan, M.I.; Ushakova, N.A.; Usov, A.I.; Kiselevskiy, M.V.; Nifantiev, N.E. Fucoidans: Pro- Or Antiangiogenic Agents? Glycobiology, 2014, 24 , 1265-1274.

[24] Rioux, L.; Turgeon, S.L.; Beaulieu, M. Effect of Season on the Composition of Bioactive Polysaccharides from the Brown Seaweed Saccharina Longicruris.

Phytochemistry, 2009, 70, 1069-1075.

[25] Cumashi, A.; Ushakova, N.A.; Preobrazhenskaya, M.E.; D'Incecco, A.; Piccoli, A.; Totani, L.; Tinari, N.; Morozevich, G.E.; Berman, A.E.; Bilan, M.I. et al. A Comparative Study of the Anti-Inflammatory, Anticoagulant, Antiangiogenic, and Antiadhesive Activities of Nine Different Fucoidans from Brown Seaweeds. Glycobiology, 2007, 17, 541-552.

[26] Morya, V.K.; Kim, J.; Kim, E. Algal Fucoidan: Structural and Size-Dependent Bioactivities and their Perspectives. Appl. Microbiol. Biotechnol., 2012, 93, 71-82. 
[27] Yang, C.; Chung, D.; Shin, I.; Lee, H.; Kim, J.; Lee, Y.; You, S. Effects of Molecular Weight and Hydrolysis Conditions on Anticancer Activity of Fucoidans from Sporophyll of Undaria Pinnatifida. Int. J. Biol. Macromol., 2008, 43, 433-437.

[28] Hu, Y.; Li, S.; Li, J.; Ye, X.; Ding, T.; Liu, D.; Chen, J.; Ge, Z.; Chen, S. Identification of a Highly Sulfated Fucoidan from Sea Cucumber Pearsonothuria Graeffei with WellRepeated Tetrasaccharides Units. Carbohydr. Polym., 2015, 134, 808-816.

[29] Jain, R.K.; Matta, K.L. Methyl 3,4-0-Isopropylidene-2-O-(4-Methoxybenzyl)-1-ThioB-L-Fucopyranoside - a Novel, Efficient Glycosylating Reagent for the Synthesis of Linear and Other a-L-Fucosyl Oligosaccharides. Tetrahedron Lett., 1990, 31, 43254328.

[30] Jain, R.K.; Matta, K.L. Synthesis of Methyl 2-O-(Sodium a-L-Fucopyranosyl 3- and 4-Sulfate)-a-L-Fucopyranoside. Carbohydr. Res., 1990, 208, 280-286.

[31] Hua, Y.; Gu, G.; Du, Y. Synthesis and Biological Activities of Octyl 2,3,4-Tri-OSulfo-a-L- Fucopyranosyl-(1 $\rightarrow$ 3)-2,4-Di-O-Sulfo-a-L-Fucopyranosyl-(1 $\rightarrow$ 3)-2,4Di-O-Sulfo-a-L-Fucopyranosyl-(1 $\rightarrow$ 3)-2,4-Di-O-Sulfo-B-L- Fucopyranoside. Carbohydr. Res., 2004, 339, 867-872.

[32] Hua, Y.; Du, Y.; Yu, G.; Chu, S. Synthesis and Biological Activities of Octyl 2,3-DiO-Sulfo-a-L- Fucopyranosyl-(1 $\rightarrow$ 3)-2-O-Sulfo-a-L-Fucopyranosyl-(1 $\rightarrow$ 4)-2,3-Di-

O-Sulfo-a-L-Fucopyranosyl-(1 $\rightarrow$ 3)-2-O-Sulfo-a-L- Fucopyranosyl-(1 $\rightarrow$ 4)-2,3-DiO-Sulfo-B-L-Fucopyranoside. Carbohydr. Res., 2004, 339, 2083-2090.

[33] Arafuka, S.; Koshiba, N.; Takahashi, D.; Toshima, K. Systematic Synthesis of Sulfated Oligofucosides and their Effect on Breast Cancer MCF-7 Cells. Chem. Commun., 2014, 50, 9831-9834.

[34] Kasai, A.; Arafuka, S.; Koshiba, N.; Takahashi, D.; Toshima, K. Systematic Synthesis of Low-Molecular Weight Fucoidan Derivatives and their Effect on Cancer Cells. Org. Biomol. Chem., 2015, 13, 10556-10568.

[35] Khatuntseva, E.A.; Ustuzhanina, N.E.; Zatonskii, G.V.; Shashkov, A.S.; Usov, A.I.; Nifantiev, N.E. Synthesis, NMR and Conformational Studies of Fucoidan Fragments 1: ${ }^{1}$ Desulfated 2,3-and 3,4-Branched Trisaccharide Fragments and Constituting Disaccharides. J. Carbohydr. Chem., 2000, 19, 1151-1173.

[36] Gerbst, A.G.; Ustuzhanina, N.E.; Grachev, A.A.; Khatuntseva, E.A.; Tsvetkov, D.E.; Whitfield, D.M.; Berces, A.; Nifantiev, N.E. Synthesis, NMR, and Conformational Studies of Fucoidan Fragments. III. Effect of Benzoyl Group at O-3 on Stereoselectivity of Glycosylation by 3-0- and 3,4-Di-0-Benzoylated 2-0Benzylfucosyl Bromides. J. Carbohydr. Chem., 2001, 20, 821-831.

[37] Gerbst, A.G.; Ustuzhanina, N.E.; Grachev, A.A.; Zlotina, N.S.; Khatuntseva, E.A.; Tsvetkov, D.E.; Shashkov, A.S.; Usov, A.I.; Nifantiev, N.E. Synthesis, NMR, and Conformational Studies of Fucoidan Fragments. IV. ${ }^{1}$ 4-Mono- and 4,4'-Disulfated $(1 \rightarrow 3)$-a-L-Fucobioside and 4-Sulfated Fucoside Fragments. J. Carbohydr. Chem., 2002, 21, 313-324.

[38] Gerbst, A.G.; Ustuzhanina, N.E.; Grachev, A.A.; Khatuntseva, E.A.; Tsvetkov, D.E.; Shashkov, A.S.; Usov, A.I.; Preobrazhenskaya, M.E.; Ushakova, N.A.; Nifantiev, N.E. Synthesis, NMR, and Conformational Studies of Fucoidan Fragments. V. ${ }^{1}$ Linear 4,4',4"-Tri-O-Sulfated and Parent Non-Sulfated $(1 \rightarrow 3)$-Fucotrioside Fragments. $J$. Carbohydr. Chem., 2003, 22, 109-122.

[39] Gerbst, A.G.; Grachev, A.A.; Ustyuzhanina, N.E.; Khatuntseva, E.A.; Tsvetkov, D.E.; Usov, A.I.; Shashkov, A.S.; Preobrazhenskaya, M.E.; Ushakova, N.A.; Nifantiev, N.E. The Synthesis and NMR and Conformational Studies of Fucoidan Fragments: VI. Fragments with an a-(1 $\rightarrow$ 2)-Linked Fucobioside Unit. Russ. J. Bioorg. Chem., 2004, 30, 137-147. 
[40] Grachev, A.A.; Gerbst, A.G.; Ustuzhanina, N.E.; Khatuntseva, E.A.; Shashkov, A.S.; Usov, A.I.; Nifantiev, N.E. Synthesis, NMR, and Conformational Studies of Fucoidan Fragments. VII. ${ }^{(1)}$ Influence of Length and 2,3-Branching on the Conformational Behavior of Linear $(1 \rightarrow 3)$-Linked Oligofucoside Chains. J. Carbohydr. Chem., 2005, 24, 85-100.

[41] Ustyuzhanina, N.; Krylov, V.; Grachev, A.; Gerbst, A.; Nifantiev, N. Synthesis, NMR and Conformational Studies of Fucoidan Fragments, 8: ${ }^{1}$ Convergent Synthesis of Branched and Linear Oligosaccharides. Synthesis, 2006, 4017-4031.

[42] Krylov, V.B.; Kaskova, Z.M.; Vinnitskiy, D.Z.; Ustyuzhanina, N.E.; Grachev, A.A.; Chizhov, A.O.; Nifantiev, N.E. Acid-Promoted Synthesis of Per-O-Sulfated Fucooligosaccharides Related to Fucoidan Fragments. Carbohydr. Res., 2011, 346, 540-550.

[43] Vinnitskiy, D.Z.; Krylov, V.B.; Ustyuzhanina, N.E.; Dmitrenok, A.S.; Nifantiev, N.E. The Synthesis of Heterosaccharides Related to the Fucoidan from Chordaria Flagelliformis Bearing a-L-Fucofuranosyl Unit. Org. Biomol. Chem., 2016, 14, 598611.

[44] Anisimova, N.Y.; Ustyuzhanina, N.E.; Donenko, F.V.; Bilan, M.I.; Ushakova, N.A.; Usov, A.I.; Nifantiev, N.E.; Kiselevskiy, M.V. Influence of Fucoidans and their Derivatives on Antitumor and Phagocytic Activity of Human Blood Leucocytes. Biochemistry (Moscow), 2015, 80, 925-933.

[45] Becer, C.R.; Hartmann, L. Glycopolymer Code, 1st ed.; The Royal Society of Chemistry, 2015.

[46] Narain, R. Glycopolymers: Synthesis and Applications, 1st ed.; Smithers Rapra Technology, 2014.

[47] Vázquez-Dorbatt, V.; Lee, J.; Lin, E.; Maynard, H.D. Synthesis of Glycopolymers by Controlled Radical Polymerization Techniques and their Applications. ChemBioChem, 2012, 13, 2478-2487.

[48] Narla, S.N.; Nie, H.; Li, Y.; Sun, X. Recent Advances in the Synthesis and Biomedical Applications of Chain-End Functionalized Glycopolymers. J. Carbohydr. Chem., 2012, 31, 67-92.

[49] Miura, Y. Design and Synthesis of Well-Defined Glycopolymers for the Control of Biological Functionalities. Kobunshi, 2013, 62, 33-34.

[50] Miura, Y.; Hoshino, Y.; Seto, H. Glycopolymer Nanobiotechnology. Chem. Rev., 2015, 116, 1673-1692.

[51] Spain, S.G.; Gibson, M.I.; Cameron, N.R. Recent Advances in the Synthesis of WellDefined Glycopolymers. J. Polym. Sci. Part A, 2007, 45, 2059-2072.

[52] Schatz, C.; Lecommandoux, S. Polysaccharide-Containing Block Copolymers: Synthesis, Properties and Applications of an Emerging Family of Glycoconjugates. Macromol. Rapid Commun., 2010, 31, 1664-1684.

[53] Jung, H.; Mok, H. Mixed Micelles for Targeted and Efficient Doxorubicin Delivery to Multidrug-Resistant Breast Cancer Cells. Macromol. Biosci., 2016, 16, 748-758.

[54] Lo, Y.; Wang, H.; Liao, Z.; Wang, L. The Synthesis and Comparison of Chondroitin Sulfate-Modified PDMAEMA with Chondroitin Sulfate-Modified PEI as a Potential Gene Delivery Vector. RSC Adv., 2016, 6, 38209-38222.

[55] Ferji, K.; Nouvel, C.; Babin, J.; Albouy, P.; Li, M.; Six, J. Controlled Synthesis of New Amphiphilic Glycopolymers with Liquid Crystal Grafts. J. Polym. Sci. Part A, 2013, 51, 3829-3839.

[56] Dupayage, L.; Nouvel, C.; Six, J. Protected Versus Unprotected Dextran Macroinitiators for ATRP Synthesis of Dex-G-PMMA. J. Polym. Sci. Part A, 2011, 49, 35-46. 
[57] Wu, M.; Forero Ramirez, L.M.; Rodriguez Lozano, A.; Quémener, D.; Babin, J.; Durand, A.; Marie, E.; Six, J.; Nouvel, C. First Multi-Reactive Dextran-Based Inisurf for Atom Transfer Radical Polymerization in Miniemulsion. Carbohydr. Polym., 2015, 130, 141-148.

[58] Kapishon, V.; Whitney, R.A.; Champagne, P.; Cunningham, M.F.; Neufeld, R.J. Polymerization Induced Self-Assembly of Alginate Based Amphiphilic Graft Copolymers Synthesized by Single Electron Transfer Living Radical Polymerization. Biomacromolecules, 2015, 16, 2040-2048.

[59] Das, D.; Mukherjee, S.; Pal, A.; Das, R.; Sahu, S.G.; Pal, S. Synthesis and Characterization of Biodegradable Copolymer Derived from Dextrin and Poly(Vinyl Acetate) Via Atom Transfer Radical Polymerization. RSC Adv., 2016, 6, 9352-9359.

[60] Kwan, S.; Marić, M. Thermoresponsive Polymers with Tunable Cloud Point Temperatures Grafted from Chitosan Via Nitroxide Mediated Polymerization. Polymer, 2016, 86, 69-82.

[61] Hatton, F.L.; Ruda, M.; Lansalot, M.; D'Agosto, F.; Malmström, E.; Carlmark, A. Xyloglucan-Functional Latex Particles Via RAFT-Mediated Emulsion Polymerization for the Biomimetic Modification of Cellulose. Biomacromolecules, 2016, 17, 14141424.

[62] Becer, C.R. The Glycopolymer Code: Synthesis of Glycopolymers and Multivalent Carbohydrate-Lectin Interactions. Macromol. Rapid Commun., 2012, 33, 742-752.

[63] Voit, B.; Appelhans, D. Glycopolymers of various Architectures - More than Mimicking Nature. Macromol. Chem. Phys., 2010, 211, 727-735.

[64] Cecioni, S.; Imberty, A.; Vidal, S. Glycomimetics Versus Multivalent Glycoconjugates for the Design of High Affinity Lectin Ligands. Chem. Rev., 2015, 115, 525-561.

[65] Jenkins, A.D.; Kratochvíl, P.; Stepto, R.F.T.; Suter, U.W. Glossary of Basic Terms in Polymer Science (IUPAC Recommendations 1996). Pure Appl. Chem., 2009, 68, 2287.

[66] Ni, J.; Singh, S.; Wang, L. Synthesis of Maleimide-Activated Carbohydrates as Chemoselective Tags for Site-Specific Glycosylation of Peptides and Proteins. Bioconjug. Chem., 2003, 14, 232-238.

[67] Vermeer, H.J.; Van Dijk, C.M.; Kamerling, J.P.; Vliegenthart, J.F.G. Fucosylation of Linear Alcohols: A Study of Parameters Influencing the Stereochemistry of Glycosylation. Eur. J. Org. Chem., 2001, 193-203.

[68] Wang, S.; Galanos, N.; Rousset, A.; Buffet, K.; Cecioni, S.; Lafont, D.; Vincent, S.P.; Vidal, S. Fucosylation of Triethyleneglycol-Based Acceptors into 'Clickable' aFucosides. Carbohydr. Res., 2014, 395, 15-18.

[69] Harris, D.C.; Lucy, C.A. Quantitative Chemical Analysis, 9th ed. ed.; W. H. Freeman and Company, 2016.

[70] Agrawal, Y.K.; Rao, K.V. Polyhydroxamic Acids: Synthesis, Ion Exchange Separation and Atomic Absorption Spectrophotometric Determination of Divalent Metal Ions. React. Polym., 1995, 25, 79-87.

[71] Ghadban, A.; Albertin, L. Synthesis of Glycopolymer Architectures by ReversibleDeactivation Radical Polymerization. Polym., 2013, 5, 431-526.

[72] Carraher, E.; Seymour, R.B. Seymour/Carraher's Polymer Chemistry, 7th ed. ed.; CRC Press, cop., 2008.

[73] Lange, M.; Pettersen, A.L.; Undheim, K. Synthesis of Secondary Amines by Reductive Dimerization of Azides. Tetrahedron, 1998, 54, 5745-5752.

[74] An, I.; Seong, H.; Ahn, K.H. Reductive Dimerization of Azides to Secondary Amines Under Hydrogenation Conditions. Bull. Korean Chem. Soc., 2004, 25, 420-422. 
[75] Patel, A.; Lindhorst, T.K. A Modular Approach for the Synthesis of Oligosaccharide Mimetics. J. Org. Chem., 2001, 66, 2674-2680.

[76] Grande, D.; Cuerrero, R.; Gnanou, Y. Cyanoxyl-Mediated Free-Radical Polymerization of Acrylic Acid: Its Scope and Limitations. J. Polym. Sci. Part A, 2005, 43, 519-533.

[77] Grande, D.; Baskaran, S.; Baskaran, C.; Gnanou, Y.; Chaikof, E.L. Glycosaminoglycan-Mimetic Biomaterials. 1. Nonsulfated and Sulfated Glycopolymers by Cyanoxyl-Mediated Free-Radical Polymerization. Macromolecules, 2000, 33, 1123-1125.

[78] Grande, D.; Baskaran, S.; Chaikof, E.L. Glycosaminoglycan Mimetic Biomaterials. 2. Alkene- and Acrylate-Derivatized Glycopolymers Via Cyanoxyl-Mediated FreeRadical Polymerization. Macromolecules, 2001, 34, 1640-1646.

[79] Baskaran, S.; Grande, D.; Sun, X.; Yayon, A.; Chaikof, E.L. GlycosaminoglycanMimetic Biomaterials. 3. Glycopolymers Prepared from Alkene-Derivatized Monoand Disaccharide-Based Glycomonomers. Bioconjug. Chem., 2002, 13, 1309-1313.

[80] Sun, X.; Grande, D.; Baskaran, S.; Hanson, S.R.; Chaikof, E.L. Glycosaminoglycan Mimetic Biomaterials. 4. Synthesis of Sulfated Lactose-Based Glycopolymers that Exhibit Anticoagulant Activity. Biomacromolecules, 2002, 3, 1065-1070.

[81] Sun, X.; Faucher, K.M.; Houston, M.; Grande, D.; Chaikof, E.L. Design and Synthesis of Biotin Chain-Terminated Glycopolymers for Surface Glycoengineering. J. Am. Chem. Soc., 2002, 124, 7258-7259.

[82] Hou, S.; Sun, X.; Dong, C.; Chaikof, E.L. Facile Synthesis of Chain-End Functionalized Glycopolymers for Site-Specific Bioconjugation. Bioconjug. Chem., 2004, 15, 954-959.

[83] Tengdelius, M.; Lee, C.; Grenegård, M.; Griffith, M.; Påhlsson, P.; Konradsson, P. Synthesis and Biological Evaluation of Fucoidan-Mimetic Glycopolymers through Cyanoxyl-Mediated Free-Radical Polymerization. Biomacromolecules, 2014, 15, 2359-2368.

[84] Snyder, H.R.; Stewart, J.M.; Allen, R.E.; Dearborn, R.J. The Mechanism of Modifier Action in the GR-S Polymerization. I. J. Am. Chem. Soc., 1946, 68, 1422-1428.

[85] Henríquez, C.; Bueno, C.; Lissi, E.A.; Encinas, M.V. Thiols as Chain Transfer Agents in Free Radical Polymerization in Aqueous Solution. Polymer, 2003, 44, 5559-5561.

[86] Endo, K.; Sawada, T. Control of Polymer Structure by a Chain-Transfer Reaction in the Radical Polymerization of Acrylamide by B-Mercaptopropionic Acid and 1,2,6Hexanetriol Trithioglycolate. Colloid Polym. Sci., 2001, 279, 1058-1063.

[87] Gugliotta, L.M.; Salazar, A.; Vega, J.R.; Meira, G.R. Emulsion Polymerization of Styrene. use of N-Nonyl Mercaptan for Molecular Weight Control. Polymer, 2001, 42, 2719-2726.

[88] Reinelt, S.; Steinke, D.; Ritter, H. End-Group-Functionalized Poly(N,NDiethylacrylamide) Via Free-Radical Chain Transfer Polymerization: Influence of Sulfur Oxidation and Cyclodextrin on Self-Organization and Cloud Points in Water. Beilstein J. Org. Chem., 2014, 10, 680-691.

[89] Maatz, G.; Maciollek, A.; Ritter, H. Cyclodextrin-Induced Host-Guest Effects of Classically Prepared Poly(NIPAM) Bearing Azo-Dye End Groups. Beilstein J. Org. Chem., 2012, 8, 1929-1935.

[90] Yamada, A.; Hiruta, Y.; Wang, J.; Ayano, E.; Kanazawa, H. Design of Environmentally Responsive Fluorescent Polymer Probes for Cellular Imaging. Biomacromolecules, 2015, 16, 2356-2362.

[91] Paasonen, L.; Romberg, B.; Storm, G.; Yliperttula, M.; Urtti, A.; Hennink, W.E. Temperature-Sensitive Poly(N-(2-Hydroxypropyl)Methacrylamide Mono/Dilactate)- 
Coated Liposomes for Triggered Contents Release. Bioconjugate Chem., 2007, 18, 2131-2136.

[92] Van Elk, M.; Deckers, R.; Oerlemans, C.; Shi, Y.; Storm, G.; Vermonden, T.; Hennink, W.E. Triggered Release of Doxorubicin from Temperature-Sensitive Poly(N-(2-Hydroxypropyl)-Methacrylamide Mono/Dilactate) Grafted Liposomes. Biomacromolecules, 2014, 15, 1002-1009.

[93] Tengdelius, M.; Gurav, D.; Konradsson, P.; Påhlsson, P.; Griffith, M.; Oommen, O.P. Synthesis and Anticancer Properties of Fucoidan-Mimetic Glycopolymer Coated Gold Nanoparticles. Chem. Commun., 2015, 51, 8532-8535.

[94] Gregory, A.; Stenzel, M.H. The use of Reversible Addition Fragmentation Chain Transfer Polymerization for Drug Delivery Systems. Expert Opin. Drug Delivery, 2011, 8, 237-269.

[95] Stenzel, M.H. RAFT Polymerization: An Avenue to Functional Polymeric Micelles for Drug Delivery. Chem. Commun., 2008, 3486-3503.

[96] Barner-Kowollik, C.; Buback, M.; Charleux, B.; Coote, M.L.; Drache, M.; Fukuda, T.; Goto, A.; Klumperman, B.; Lowe, A.B.; McLeary, J.B. et al. Mechanism and Kinetics of Dithiobenzoate-Mediated RAFT Polymerization. I. the Current Situation. J. Polym. Sci. Part A, 2006, 44, 5809-5831.

[97] Buback, M.; Vana, P. Mechanism of Dithiobenzoate-Mediated RAFT Polymerization: A Missing Reaction Step. Macromol. Rapid Commun., 2006, 27, 1299-1305.

[98] Moad, G. Mechanism and Kinetics of Dithiobenzoate-Mediated Raft Polymerization Status of the Dilemma. Macromol. Chem. Phys., 2014, 215, 9-26.

[99] Xu, J.; Tao, L.; Boyer, C.; Lowe, A.B.; Davis, T.P. Facile Access to Polymeric Vesicular Nanostructures: Remarkable $\Omega$-End Group Effects in Cholesterol and Pyrene Functional (Co)Polymers. Macromolecules, 2011, 44, 299-312.

[100] Perrier, S.; Takolpuckdee, P.; Mars, C.A. Reversible Addition-Fragmentation Chain Transfer Polymerization: End Group Modification for Functionalized Polymers and Chain Transfer Agent Recovery. Macromolecules, 2005, 38, 2033-2036.

[101] Tengdelius, M.; Kardeby, C.; Fälker, K.; Griffith, M.; Påhlsson, P.; Konradsson, P.; Grenegård, M. Fucoidan-Mimetic Glycopolymers as Tools for Studying Molecular and Cellular Responses in Human Blood Platelets. Macromol. Biosci., 2016, Accepted manuscript.

[102] Obata, M.; Kobori, T.; Hirohara, S.; Tanihara, M. Aqueous RAFT Synthesis of Block and Statistical Copolymers of 2-(a-D-Mannopyranosyloxy)Ethyl Methacrylate with 2(N,N-Dimethylamino)Ethyl Methacrylate and their Application for Nonviral Gene Delivery. Polym. Chem., 2015, 6, 1793-1804.

[103] Togashi, D.; Otsuka, I.; Borsali, R.; Takeda, K.; Enomoto, K.; Kawaguchi, S.; Narumi, A. Maltopentaose-Conjugated CTA for RAFT Polymerization Generating Nanostructured Bioresource-Block Copolymer. Biomacromolecules, 2014, 15, 45094519.

[104] Wei, Z.; Hao, X.; Gan, Z.; Hughes, T.C. One-Pot Synthesis of Hyperbranched Glycopolymers by RAFT Polymerization. J. Polym. Sci. Part A, 2012, 50, 2378-2388.

[105] Jiang, X.; Housni, A.; Gody, G.; Boullanger, P.; Charreyre, M.; Delair, T.; Narain, R. Synthesis of Biotinylated a-D-Mannoside Or N-Acetyl B-D-Glucosaminoside Decorated Gold Nanoparticles: Study of their Biomolecular Recognition with Con A and WGA Lectins. Bioconjug. Chem., 2010, 21, 521-530.

[106] Baba, M.; Snoeck, R.; Pauwels, R.; de Clercq, E. Sulfated Polysaccharides are Potent and Selective Inhibitors of various Enveloped Viruses, Including Herpes Simplex Virus, Cytomegalovirus, Vesicular Stomatitis Virus, and Human Immunodeficiency Virus. Antimicrob. Agents Chemother., 1988, 32, 1742-1745. 
[107] Lee, J.; Hayashi, K.; Hashimoto, M.; Nakano, T.; Hayashi, T. Novel Antiviral Fucoidan from Sporophyll of Undaria Pinnatifida (Mekabu). Chem. Pharm. Bull., 2004, 52, 1091-1094.

[108] Hayashi, K.; Nakano, T.; Hashimoto, M.; Kanekiyo, K.; Hayashi, T. Defensive Effects of a Fucoidan from Brown Alga Undaria Pinnatifida Against Herpes Simplex Virus Infection. Int. Immunopharmacol., 2008, 8, 109-116.

[109] Szczubialka, K.; Pyrc, K.; Nowakowska, M. In Search for Effective and Definitive Treatment of Herpes Simplex Virus Type 1 (HSV-1) Infections. RSC Adv., 2016, 6, 1058-1075.

[110] Labetoulle, M.; Auquier, P.; Conrad, H.; Crochard, A.; Daniloski, M.; Bouée, S.; El Hasnaoui, A.; Colin, J. Incidence of Herpes Simplex Virus Keratitis in France. Ophthalmology, 2005, 112, 888-895.

[111] Ishiyama, M.; Suiga, M.; Sasamoto, K.; Mizoguchi, M.; He, P. A New Sulfonated Tetrazolium Salt that Produces a Highly Water-Soluble Formazan Dye. Chem. Pharm. Bull., 1993, 41, 1118-1122.

[112] Besednova, N.N.; Makarenkova, I.D.; Zvyagintseva, T.N.; Imbs, T.I.; Somova, L.M.; Zaporozhets, T.S. Antiviral Activity and Pathogenetic Targets for Seaweed Sulfated Polysaccharides in Herpesvirus Infections. Biochem. (Moscow) Suppl. Ser. B Biomed. Chem., 2016, 10, 31-42.

[113] Ghosh, T.; Chattopadhyay, K.; Marschall, M.; Karmakar, P.; Mandal, P.; Ray, B. Focus on Antivirally Active Sulfated Polysaccharides: From Structure-Activity Analysis to Clinical Evaluation. Glycobiology, 2009, 19, 2-15.

[114] Zhu, W.; Chiu, L.C.M.; Ooi, V.E.C.; Chan, P.K.S.; Ang Jr., P.O. Antiviral Property and Mechanisms of a Sulphated Polysaccharide from the Brown Alga Sargassum Patens Against Herpes Simplex Virus Type 1. Phytomedicine, 2006, 13, 695-701.

[115] Dürig, J.; Bruhn, T.; Zurborn, K.; Gutensohn, K.; Bruhn, H.D.; Béress, L. Anticoagulant Fucoidan Fractions from Fucus Vesiculosus Induce Platelet Activation in Vitro. Thromb. Res., 1997, 85, 479-491.

[116] Liu, T.; Scallan, C.D.; Broze Jr., G.J.; Patarroyo-White, S.; Pierce, G.F.; Johnson, K.W. Improved Coagulation in Bleeding Disorders by Non-Anticoagulant Sulfated Polysaccharides (NASP). Thromb. Haemost., 2006, 95, 68-76.

[117] Zhang, Z.; Till, S.; Jiang, C.; Knappe, S.; Reutterer, S.; Scheiflinger, F.; Szabo, C.M.; Dockal, M. Structure-Activity Relationship of the Pro- and Anticoagulant Effects of Fucus Vesiculosus Fucoidan. Thromb. Haemost., 2013, 111, 429-437.

[118] Zhang, Z.; Till, S.; Knappe, S.; Quinn, C.; Catarello, J.; Ray, G.J.; Scheiflinger, F.; Szabo, C.M.; Dockal, M. Screening of Complex Fucoidans from Four Brown Algae Species as Procoagulant Agents. Carbohydr. Polym., 2015, 115, 677-685.

[119] Manne, B.K.; Getz, T.M.; Hughes, C.E.; Alshehri, O.; Dangelmaier, C.; Naik, U.P.; Watson, S.P.; Kunapuli, S.P. Fucoidan is a Novel Platelet Agonist for the C-Type Lectin-Like Receptor 2 (CLEC-2). J. Biol. Chem., 2013, 288, 7717-7726.

[120] Alshehri, O.M.; Montague, S.; Watson, S.; Carter, P.; Sarker, N.; Manne, B.K.; Miller, J.L.C.; Herr, A.B.; Pollitt, A.Y.; O'Callaghan, C.A. et al. Activation of Glycoprotein VI (GPVI) and C-Type Lectin-Like Receptor-2 (CLEC-2) Underlies Platelet Activation by Diesel Exhaust Particles and Other Charged/Hydrophobic Ligands. Biochem. J., 2015, 468, 459-473.

[121] Kim, T.H.; Lee, E.K.; Lee, M.J.; Kim, J.H.; Yang, W.S. Fucoidan Inhibits Activation and Receptor Binding of Transforming Growth Factor-ß1. Biochem. Biophys. Res. Commun., 2013, 432, 163-168.

[122] Bachelet, L.; Bertholon, I.; Lavigne, D.; Vassy, R.; Jandrot-Perrus, M.; Chaubet, F.; Letourneur, D. Affinity of Low Molecular Weight Fucoidan for P-Selectin Triggers its 
Binding to Activated Human Platelets. Biochim. Biophys. Acta Gen. Subj., 2009, 1790, 141-146.

[123] King, S.; Short, M.; Harmon, C. Glycoprotein IIb/IIIa Inhibitors: The Resurgence of Tirofiban. Vasc. Pharmacol., 2016, 78, 10-16.

[124] Shattil, S.J. Signaling through Platelet Integrin aIIbß3: Inside-Out, Outside-in, and Sideways. Thromb. Haemost., 1999, 82, 318-325.

[125] McKenzie, M.E.; Malinin, A.I.; Bell, C.R.; Dzhanashvili, A.; Horowitz, E.D.; Oshrine, B.R.; Atar, D.; Serebruany, V.L. Aspirin Inhibits Surface Glycoprotein IIb/IIIa, PSelectin, CD63, and CD107a Receptor Expression on Human Platelets. Blood Coagul. Fibrinolysis, 2003, 14, 249-253.

[126] Hermans, C.; Wittevrongel, C.; Thys, C.; Smethurst, P.A.; Van Geet, C.; Freson, K. A Compound Heterozygous Mutation in Glycoprotein VI in a Patient with a Bleeding Disorder. J. Thromb. Haemost., 2009, 7, 1356-1363.

[127] Shattil, S.J.; Hoxie, J.A.; Cunningham, M.; Brass, L.F. Changes in the Platelet Membrane Glycoprotein IIb.IIIa Complex during Platelet Activation. J. Biol. Chem., 1985, 260, 11107-11114.

[128] Clark, E.A.; Brugge, J.S. Tyrosine Phosphorylation in Platelets. Potential Roles in Intracellular Signal Transduction. Trends Cardiovasc. Med., 1993, 3, 218-227.

[129] Salim, M.; Minamikawa, H.; Sugimura, A.; Hashim, R. Amphiphilic Designer NanoCarriers for Controlled Release: From Drug Delivery to Diagnostics. MedChemComm, 2014, 5, 1602-1618.

[130] Blanazs, A.; Armes, S.P.; Ryan, A.J. Self-Assembled Block Copolymer Aggregates: From Micelles to Vesicles and their Biological Applications. Macromol. Rapid Commun., 2009, 30, 267-277.

[131] Müller, L.K.; Landfester, K. Natural Liposomes and Synthetic Polymeric Structures for Biomedical Applications. Biochem. Biophys. Res. Commun., 2015, 468, 411-418.

[132] Zhu, Y.; Yang, B.; Chen, S.; Du, J. Polymer Vesicles: Mechanism, Preparation, Application, and Responsive Behavior. Prog. Polym. Sci., 2016.

[133] Leach, J.B.; Bivens, K.A.; Patrick Jr., C.W.; Schmidt, C.E. Photocrosslinked Hyaluronic Acid Hydrogels: Natural, Biodegradable Tissue Engineering Scaffolds. Biotechnol. Bioeng., 2003, 82, 578-589.

[134] Leach, J.B.; Schmidt, C.E. Characterization of Protein Release from Photocrosslinkable Hyaluronic Acid-Polyethylene Glycol Hydrogel Tissue Engineering Scaffolds. Biomaterials, 2005, 26, 125-135.

[135] Ibrahim, S.; Kothapalli, C.R.; Kang, Q.K.; Ramamurthi, A. Characterization of Glycidyl Methacrylate - Crosslinked Hyaluronan Hydrogel Scaffolds Incorporating Elastogenic Hyaluronan Oligomers. Acta Biomater., 2011, 7, 653-665.

[136] Li, Q.; Wang, D.; Elisseeff, J.H. Heterogeneous-Phase Reaction of Glycidyl Methacrylate and Chondroitin Sulfate: Mechanism of Ring-OpeningTransesterification Competition. Macromolecules, 2003, 36, 2556-2562.

[137] Ritter, H.; Schwarz-Barac, S.; Stein, P. Cyclodextrins in Polymer Synthesis: Two-Step Reaction to Aliphatic Poly(Methacrylimide) Foams by Thermal Treatment of Copolymers obtained from Cyclodextrin Complexes of Tert-Butyl Methacrylate and various N-Alkyl Methacrylamides. Macromolecules, 2003, 36, 318-322.

[138] Yu, M.; Tan, J.; Yang, J.; Zeng, Z. Z-Type and R-Type Macro-RAFT Agents in RAFT Dispersion Polymerization-another Mechanism Perspective on PISA. Polym. Chem., 2016, 7, 3756-3765.

[139] Du, J.; Willcock, H.; Patterson, J.P.; Portman, I.; O'Reilly, R.K. Self-Assembly of Hydrophilic Homopolymers: A Matter of RAFT End Groups. Small, 2011, 7, 20702080. 
[140] Fyrner, T.; Magnusson, K.; Nilsson, K.P.R.; Hammarström, P.; Aili, D.; Konradsson, P. Derivatization of a Bioorthogonal Protected Trisaccharide Linker - Toward Multimodal Tools for Chemical Biology. Bioconjugate Chem., 2012, 23, 1333-1340.

[141] Pei, Y.; Jarrett, K.; Garces, L.G.; Saunders, M.; Croue, J.; Roth, P.J.; Buckley, C.E.; Lowe, A.B. Synthesis and Characterisation of Non-Ionic AB-Diblock Nanoparticles Prepared by RAFT Dispersion Polymerization with Polymerization-Induced SelfAssembly. RSC Adv., 2016, 6, 28130-28139.

[142] Ekblad, M.; Adamiak, B.; Bergstrom, T.; Johnstone, K.D.; Karoli, T.; Liu, L.; Ferro, V.; Trybala, E. A Highly Lipophilic Sulfated Tetrasaccharide Glycoside Related to Muparfostat (PI-88) Exhibits Virucidal Activity Against Herpes Simplex Virus. Antiviral Res., 2010, 86, 196-203.

[143] Said, J.S.; Trybala, E.; Görander, S.; Ekblad, M.; Liljeqvist, J.; Jennische, E.; Lange, S.; Bergström, T. The Cholestanol-Conjugated Sulfated Oligosaccharide PG545 Disrupts the Lipid Envelope of Herpes Simplex Virus Particles. Antimicrob. Agents Chemother., 2016, 60, 1049-1057.

[144] Nyberg, K.; Ekblad, M.; Bergström, T.; Freeman, C.; Parish, C.R.; Ferro, V.; Trybala, E. The Low Molecular Weight Heparan Sulfate-Mimetic, PI-88, Inhibits Cell-to-Cell Spread of Herpes Simplex Virus. Antiviral Res., 2004, 63, 15-24.

[145] Liang, H.; Tian, H.; Deng, M.; Chen, X. Gold Nanoparticles for Cancer Theranostics. Chin. J. Chem., 2015, 33, 1001-1010.

[146] Pedrosa, P.; Vinhas, R.; Fernandes, A.; Baptista, P.V. Gold Nanotheranostics: Proofof-Concept Or Clinical Tool? Nanomaterials, 2015, 5, 1853-1879.

[147] Muddineti, O.S.; Ghosh, B.; Biswas, S. Current Trends in using Polymer Coated Gold Nanoparticles for Cancer Therapy. Int. J. Pharm., 2015, 484, 252-267.

[148] Kim, E.Y.; Kumar, D.; Khang, G.; Lim, D. Recent Advances in Gold NanoparticleBased Bioengineering Applications. J. Mater. Chem. B, 2015, 3, 8433-8444.

[149] Adak, A.K.; Li, B.; Lin, C. Advances in Multifunctional Glycosylated Nanomaterials: Preparation and Applications in Glycoscience. Carbohydr. Res., 2015, 405, 2-12.

[150] Marradi, M.; Chiodo, F.; García, I.; Penadés, S. Glyconanoparticles as Multifunctional and Multimodal Carbohydrate Systems. Chem. Soc. Rev., 2013, 42, 4728-4745.

[151] Sunasee, R.; Adokoh, C.K.; Darkwa, J.; Narain, R. Therapeutic Potential of Carbohydrate-Based Polymeric and Nanoparticle Systems. Expert Opin. Drug Deliv., 2014, 11, 867-884.

[152] Atashrazm, F.; Lowenthal, R.M.; Woods, G.M.; Holloway, A.F.; Dickinson, J.L. Fucoidan and Cancer: A Multifunctional Molecule with Anti-Tumor Potential. Mar. Drugs, 2015, 13, 2327-2346.

[153] Moussavou, G.; Kwak, D.H.; Obiang-Obonou, B.W.; Maranguy, C.A.O.; DinzounaBoutamba, S.; Lee, D.H.; Pissibanganga, O.G.M.; Ko, K.; Seo, J.I.; Choo, Y.K. Anticancer Effects of Different Seaweeds on Human Colon and Breast Cancers. Mar. Drugs, 2014, 12, 4898-4911.

[154] Wang, C.; Wu, T.; Hsieh, S.; Tsai, Y.; Yeh, C.; Huang, C. Antioxidant Activity and Growth Inhibition of Human Colon Cancer Cells by Crude and Purified Fucoidan Preparations Extracted from Sargassum Cristaefolium. J. Food Drug Anal., 2015, 23, 766-777.

[155] Kim, E.J.; Park, S.Y.; Lee, J.; Park, J.H.Y. Fucoidan Present in Brown Algae Induces Apoptosis of Human Colon Cancer Cells. BMC Gastroenterol., 2010, 10.

[156] Foley, S.A.; Mulloy, B.; Tuohy, M.G. An Unfractionated Fucoidan from Ascophyllum Nodosum: Extraction, Characterization, and Apoptotic Effects in Vitro. J. Nat. Prod., 2011, 74, 1851-1861. 
[157] Chen, S.; Zhao, Y.; Zhang, Y.; Zhang, D. Fucoidan Induces Cancer Cell Apoptosis by Modulating the Endoplasmic Reticulum Stress Cascades. PLoS ONE, 2014, 9.

[158] Vishchuk, O.S.; Ermakova, S.P.; Zvyagintseva, T.N. The Effect of Sulfated $(1 \rightarrow 3)$-aL-Fucan from the Brown Alga Saccharina Cichorioides Miyabe on ResveratrolInduced Apoptosis in Colon Carcinoma Cells. Mar. Drugs, 2013, 11, 194-212.

[159] Fulmer, G.R.; Miller, A.J.M.; Sherden, N.H.; Gottlieb, H.E.; Nudelman, A.; Stoltz, B.M.; Bercaw, J.E.; Goldberg, K.I. NMR Chemical Shifts of Trace Impurities: Common Laboratory Solvents, Organics, and Gases in Deuterated Solvents Relevant to the Organometallic Chemist. Organometallics, 2010, 29, 2176-2179. 



\section{Papers}

The articles associated with this thesis have been removed for copyright reasons. For more details about these see:

http://urn.kb.se/resolve?urn=urn:nbn:se:liu:diva-131093 